Final Technical Report

\title{
Continuous Severe Plastic Deformation Processing of Aluminum Alloys
}

DOE Award Number: DE-FC36-01ID14022

Raghavan Srinivasan (PI)

Prabir K. Chaudhury

Balakrishna Cherukuri

Qingyou Han

David Swenson

Percy Gros

Project Period:

February 21, 2001 - March 31, 2006

Report Date:

June 30, 2006

Award Recipient:

Wright State University

3640 Colonel Glenn Highway

Dayton, Ohio 45435

Subcontractors:

Intercontinental Manufacturing Co., Garland TX General Dynamics/OTS, Garland TX

Edison Materials Technology Center, Kettering, $\mathrm{OH}$

Queen City Forging Co., Cincinnati, $\mathrm{OH}$

National Lab Partner:

Oak Ridge National Laboratory, Oak Ridge TN

Contacts:

Raghavan Srinivasan (Wright State University)

(937) 775-5093, raghavan.srinivasan@wright.edu

Qingyou Han (Oak Ridge National Laboratory)

(865) 574-4352 hanq@ornl.gov

David Swenson and Percy Gros

(Edison Materials Technology Center)

(937) 259-1365

dswenson@emtec.org, pgros@emtec.org

Rob Mayer, Queen City Forging Co.

(513) 321-7200, rob@qcforge.com

Prabir K. Chaudhury (Consultant, Phoenix, AZ)

(469) 682-2258 pchaudhury@cox.net 


\section{Acknowledgement}

This report is based upon work supported by the U. S. Department of Energy under Award No. DE-FC36-01ID14022

Disclaimer: "Any findings, opinions, and conclusions or recommendations expressed in this report are those of the author(s) and do not necessarily reflect the views of the Department of Energy"

This report does not contain any proprietary data, classified information, or information subject to export control classification. 


\section{Table of Contents}

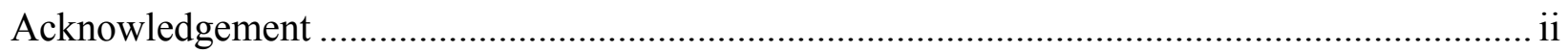

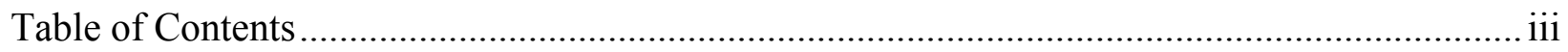

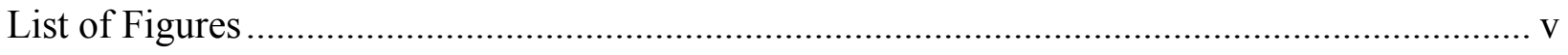

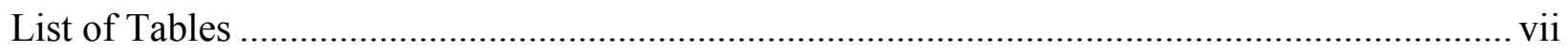

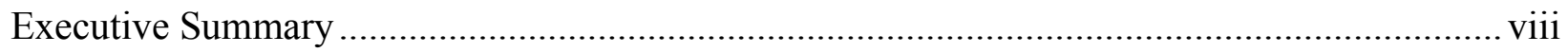

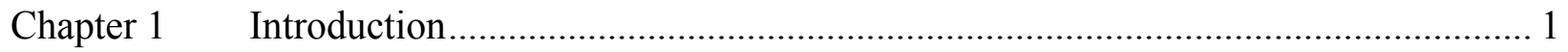

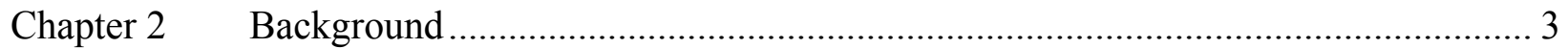

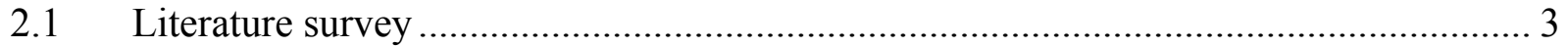

2.1.1 Equal Channel Angular Extrusion or Pressing (ECAE/P) ..................................... 3

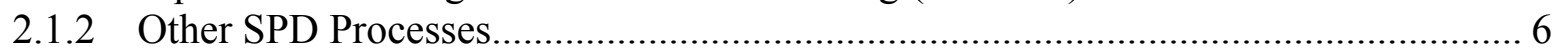

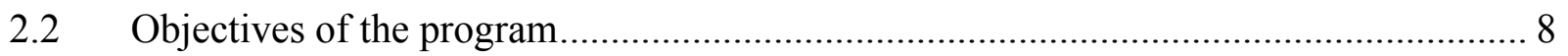

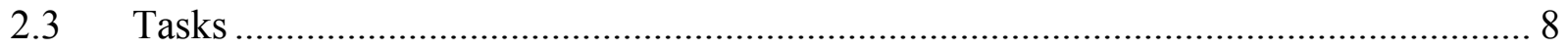

2.4 The R\&D Team and Investigator Qualifications .......................................................... 9

Chapter 3 A Continuous Severe Plastic Deformation (CSPD) Process .................................. 12

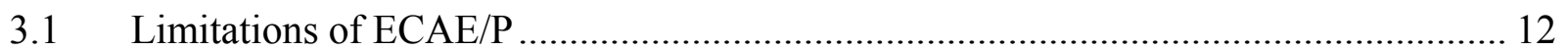

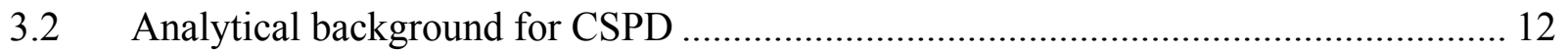

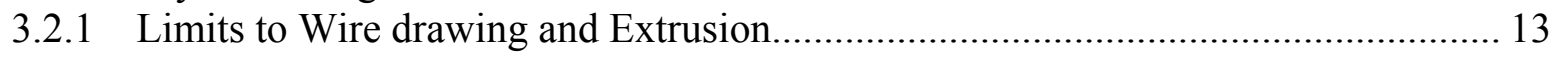

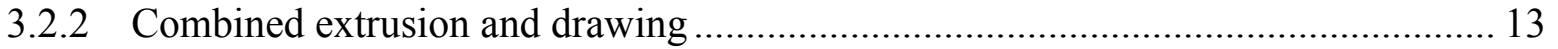

3.2.3 Continuous Severe Plastic Deformation (CSPD) Process ………………............... 16

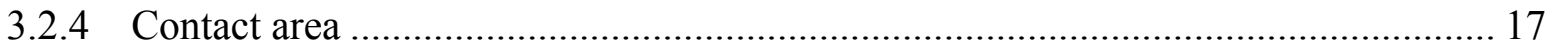

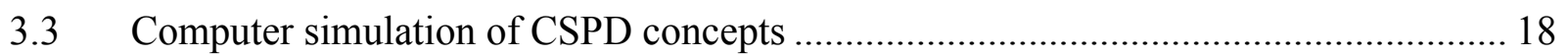

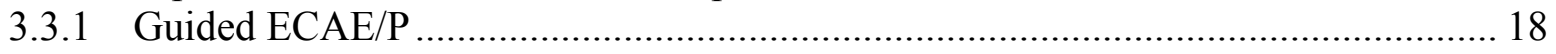

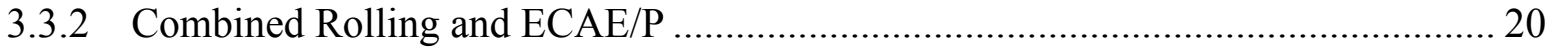

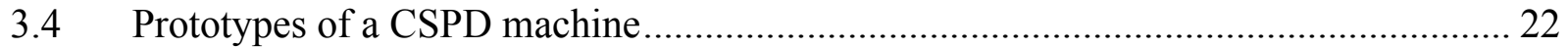

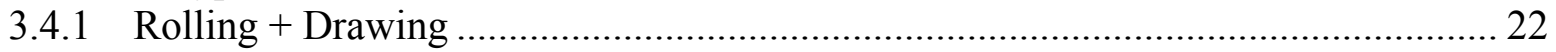

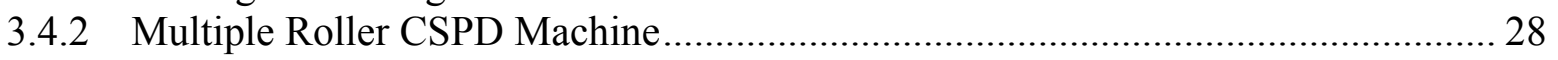

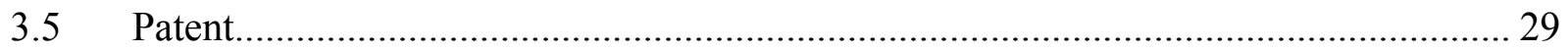

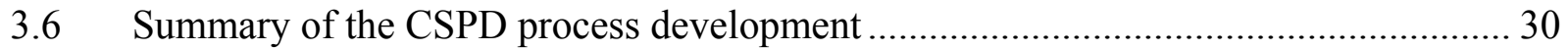

Chapter $4 \quad$ Scaling up of ECAE/P and Forging of SPD Aluminum ....................................... 31

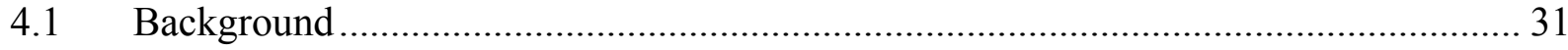

4.2 Scale Up of the Equal Channel Angular Extrusion/Pressing (ECAE/P) Process ......... 32

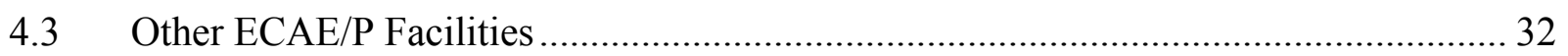

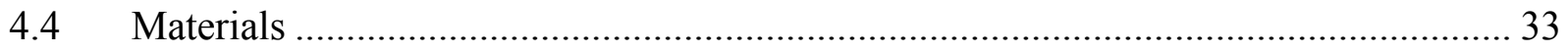

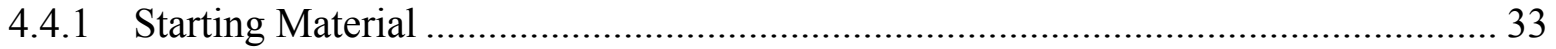


4.4.2 Evolution of microstructure during ECAE/P ............................................... 33

4.4.3 Mechanical Property Changes due to SPD ......................................................... 36

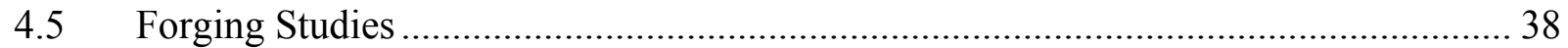

4.5.1 Forging Studies at IMCO ......................................................................... 38

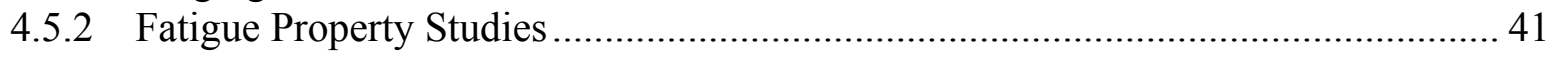

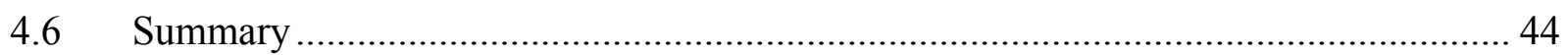

Chapter $5 \quad$ Energy Savings from the use of SPD stock ................................................... 47

5.1 Energy Savings in Billet Heating Furnaces ........................................................... 47

5.2 Energy Savings due to Decreased Material Usage ................................................ 48

5.3 Other Factors Affecting Cost and Energy Consumption ......................................... 50

Chapter $6 \quad$ Technology Transfer ............................................................................. 51

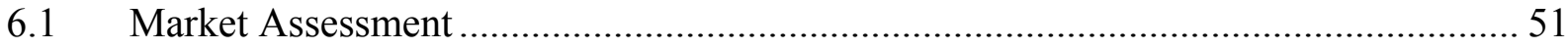

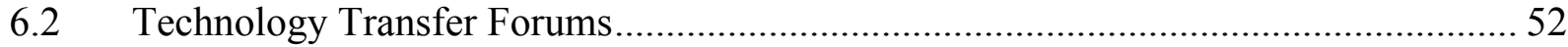

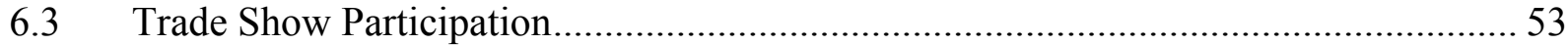

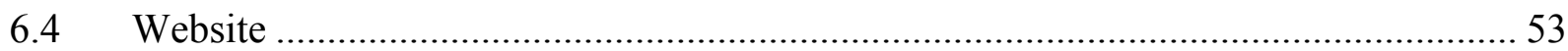

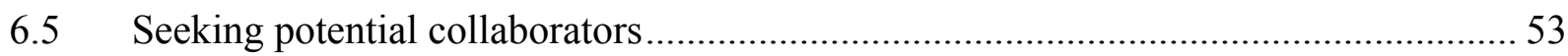

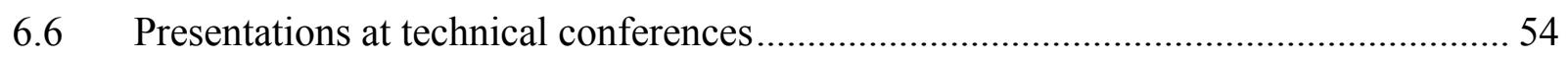

6.7 Publications in peer reviewed journals ........................................................... 55

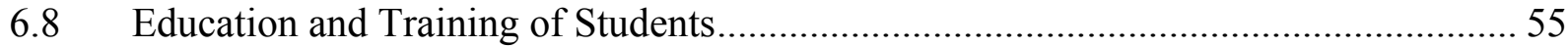

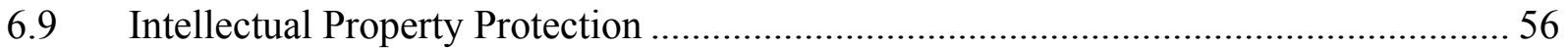




\section{List of Figures}

Figure

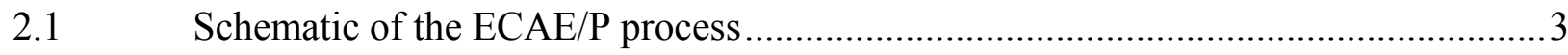

2.2 Physical and computer model of the ECAE/P process ........................................ 4

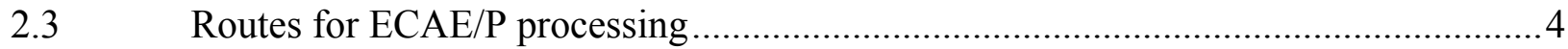

2.4 Finite element simulation of the equal channel angular drawing process ..................5

2.5 Schematic of the High Pressure Torsion (HPT) process .....................................6

2.6 Schematic of the Multiaxial Compression/Forging (MAC/F) process .....................6

2.7 Schematic of the Accumulative Roll Bonding (ARB) process.................................

2.8 Schematic of the Repetitive Corrugation and Straightening (RCS) process ...............8

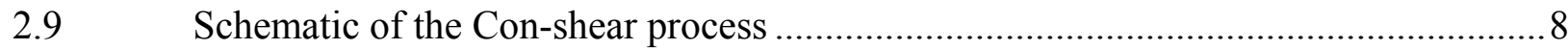

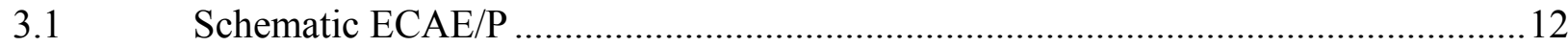

Schematic drawings of wire drawing and extrusion ......................................... 13

3.3 Schematic drawing and computer simulation of drawing...................................... 14

3.4 Schematic drawing and computer simulation of chamber-less extrusion................. 15

S.5 Schematic "Push-Pull" arrangement for CSPD .................................................. 16

"Push-Pull" arrangement using belts and rollers ................................................. 17

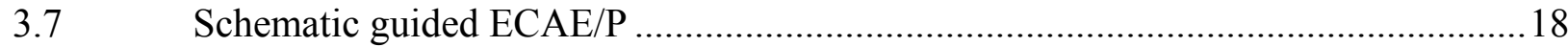

S.8 Simulation of the guided ECAE/P for a die angle of $135^{\circ}$.................................... 19

3.9 Simulation of unsupported ECAE/P for a die angle of $135^{\circ}$................................. 19

3.10 Simulation of guided ECAE/P for a die angle of $90^{\circ}$..........................................20

3.11 Simulation of guided ECAE/P for a die angle of $90^{\circ}$ with "pulling" ......................20

3.12 Simulation of rolling + ECAE/P as a model for a CSPD process ..........................21

3.13 An 80 horsepower United mill used to push a metal bar during CSPD ..................22

3.14 The draw bench used to pull the extruded bar during CSPD...............................22

3.15 The set up of the United mill, draw bench, and ECAE/P die for CSPD..................23

3.16 A long AA6061 specimen being pushed and pulled during CSPD .......................24

3.17 Microstructure of AA6061 after 0 to 3 passes of CSPD......................................25

3.18 Die surface damage, material build up, and blemished specimen surface................27

3.19 The knurled roll assemblies designed to push material during CSPD .....................28

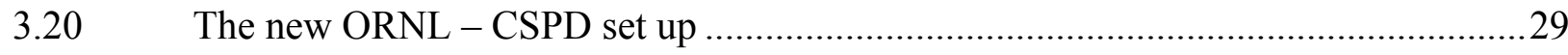


Figure

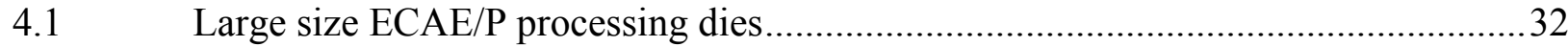

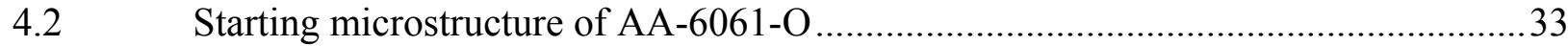

4.3 Relative sizes of the $12.5-\mathrm{mm}, 50-\mathrm{mm}$, and $100-\mathrm{mm}$ cross section

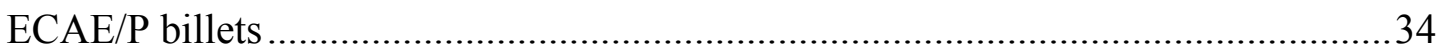

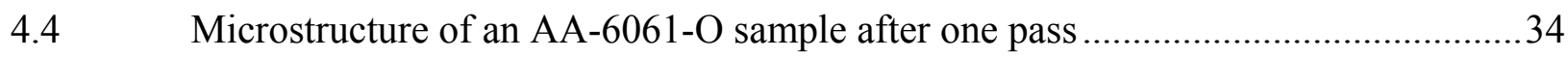

4.5 Microstructure of an AA-6061-O sample after two passes ...................................35

4.6 TEM of 12.5-mm, 50-mm, and 100-mm cross section ECAE/P billets ...................35

4.7 Hardness increase as a function of accumulated strain ......................................36

4.8 Evolution of micro-hardness as a function of accumulated strain ...........................36

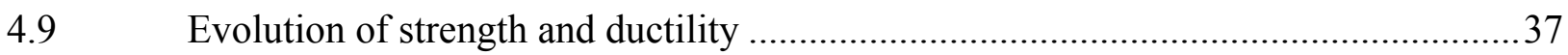

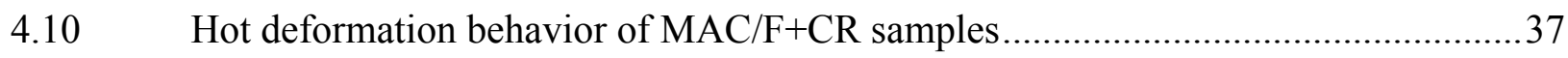

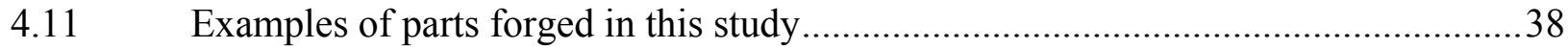

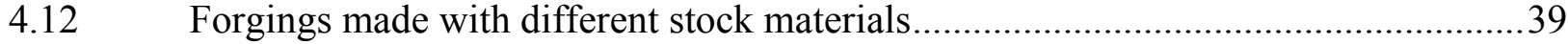

4.13 Forgings made with ECAE/P and extruded stock materials ................................40

4.14 Forging with 100-mm ECAE/P stock and conventional extruded stock ..................41

4.15 Change in hardness (Rockwell E scale) as a function of aging time .......................42

4.16 Dimensions of Krouse fatigue test sample....................................................... 42

4.17 Drawing of a part used to make fatigue samples ..............................................43

4.18 Solid model and a trimmed forging of the part used for making fatigue samples......43

4.19 Fatigue performance specifications for AA 6061-T6 ........................................44

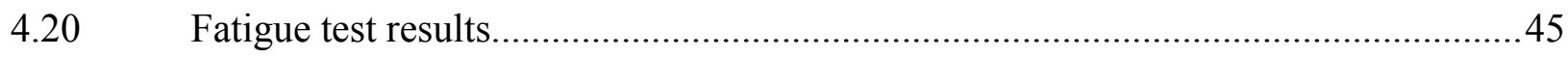

5.1 Variation of temperature with time during heat up of forging stock ......................47

G.2 Gas consumption as a function heat up time .....................................................48

Estimated savings in furnace gas consumption ..................................................49 


\section{List of Tables}

Table

Theoretical strains during ECAE/P............................................................... 16

3.2 Measured pushing forces for the United mill .................................................23

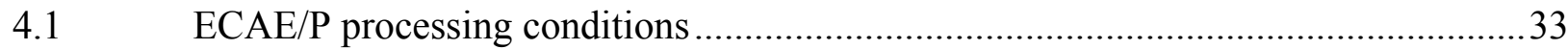

P.2 Properties after forging and heat treatment.................................................... 41

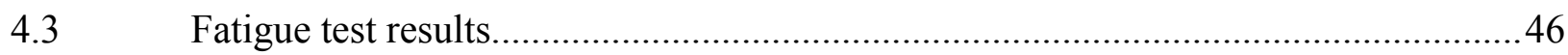

5.1 Projected national annual energy savings through the use of SPD stock .................50

6.1 Trade show listing where CSPD technology was presented...................................53 


\section{Executive Summary}

Metals with grain sizes smaller than $1-\mu \mathrm{m}$ have received much attention in the past decade. These materials have been classified as ultra fine grain (UFG) materials (grain sizes in the range of 100 to $1000-\mathrm{nm}$ ) and nano-materials (grain size $<100-\mathrm{nm}$ ) depending on the grain size. This report addresses the production of bulk UFG metals through the use of severe plastic deformation processing, and their subsequent use as stock material for further thermomechanical processing, such as forging.

A number of severe plastic deformation (SPD) methods for producing bulk UFG metals have been developed since the early 1990s. The most promising of these processes for producing large size stock that is suitable for forging is the equal channel angular extrusion or pressing $(\mathrm{ECAE} / \mathrm{P})$ process. This process involves introducing large shear strain in the workpiece by pushing it through a die that consists of two channels with the same cross-sectional shape that meet at an angle to each other. Since the cross-sections of the two channels are the same, the extruded product can be re-inserted into the entrance channel and pushed again through the die. Repeated extrusion through the ECAE/P die accumulates sufficient strain to breakdown the microstructure and produce ultra fine grain size.

It is well known that metals with very fine grain sizes $(<10-\mu \mathrm{m})$ have higher strain rate sensitivity and greater elongation to failure at elevated temperature, exhibiting superplastic behavior. However, this superplastic behavior is usually manifest at high temperature ( $>$ half the melting temperature on the absolute scale) and very low strain rates $\left(<10^{-4} \mathrm{~s}^{-1}\right)$. UFG metals have been shown to exhibit superplastic characteristics at lower temperature and higher strain rates, making this phenomenon more practical for manufacturing. This enables part unitization and forging more complex and net shape parts. Laboratory studies have shown that this is particularly true for UFG metals produced by SPD techniques. This combination of properties makes UFG metals produced by SPD very attractive as machining, forging or extrusion stock, both from the point of view of formability as well as energy and cost saving. However, prior to this work there had been no attempt to transfer these potential benefits observed in the laboratory scale to industrial shop floor. The primary reason for this was that the laboratory scale studies had been conducted to develop a scientific understanding of the processes that result in grain refinement during SPD. Samples that had been prepared in the laboratory scale were typically only about 10-mm diameter and 50-mm long (about 0.5 -inch diameter and 2-inches long).

The thrust of this project was three-fold: (i) to show that the ECAE/P process can be scaled up to produce long samples, i.e., a continuous severe plastic deformation (CSPD) process, (ii) show the process can be scaled up to produce large cross section samples that could be used as forging stock, and (iii) use the large cross-section samples to produce industrial size forgings and demonstrate the potential energy and cost savings that can be realized if SPD processed stock is adopted by the forging industry.

Aluminum alloy AA-6061 was chosen to demonstrate the feasibility of the approach used. The CSPD process developed using the principles of chamber-less extrusion and drawing, and was demonstrated using rolling and wire drawing equipment that was available at Oak Ridge 
National Laboratory. In a parallel effort, ECAE/P dies were developed for producing 100-mm square cross section SPD billets for subsequent forging. This work was carried out at Intercontinental Manufacturing Co. (IMCO), Garland TX. Forging studies conducted with the ECAE/P billets showed that many of the potential benefits of using UFG material can be realized. In particular, the material yield can be increased, and the amount of material that is lost as scrap can be reduced by as much as $50 \%$. Forging temperatures can also be reduced by over $150^{\circ} \mathrm{C}$, resulting in energy savings in the operation of billet heating furnaces. Looking at only the energy required to make forgings from stock materials, estimated energy savings associated with reduced scrap and lower furnace operating temperatures were greater than $40 \%$ if ECAE/P stock material was used instead of conventionally extruded stock.

Subsequent heat treatment of the forged materials to the T6 condition showed that the mechanical properties of parts made from the ECAE/P stock material were the same as of those made from conventional extruded stock material. Therefore, the energy and cost savings benefits can be realized by the use SPD processed material as forging stock without sacrificing properties in the final part. 


\section{Chapter 1 Introduction}

Ultra fine grain (UFG) materials refer to a class of materials with grain sizes in the range of 100 to $1000-\mathrm{nm}$, i.e., $<1-\mu \mathrm{m}$ [1]. These materials have grain sizes larger than nano-materials which have now come to be accepted as those with grain sizes less than 100-nm. The interest in bulk UFG materials has grown tremendously in the past two decades, and over the same time period, a number of techniques for producing UFG have also been developed.

Methods to produce UFG materials can be grouped into two categories [2]: (a) Bottom-up approach, and (b) Top-down approach. Bottom-up approach involves consolidating nano- or ultra-fine grained materials from the atomic scale. Examples of such processes include inert gas condensation (IGC), and chemical vapor deposition (CVD). Top-down approaches involve the refinement of coarse grains to ultra-fine grains by severe plastic deformation (SPD) techniques that subject the work-piece to high-accumulated strains.

A number of severe plastic deformation (SPD) methods for producing bulk UFG metals have been developed since the early 1990s. The significant feature of these processes is that the external dimensions of the work-piece do not change significantly during the processing. Examples of these methods include equal channel angular extrusion or pressing (ECAE or ECAP) [3], high pressure torsion (HPT) [4], twist extrusion (TE) [5], friction stir processing (FSP) [6], and multi directional forging (MDF), also known as multiaxial compression/forging $(\mathrm{MAC} / \mathrm{F})$ [7]. In addition, there are several methods of producing UFG sheet metals, such as accumulative roll bonding (ARB) [8] and repeated corrugation and straightening (RCS) [9]. Please note that the references listed are only representative of a large body of work in this area. The reader is directed to the proceedings of several topical conferences $[10,11,12,13,14,15,16,17$,$] and to the NanoSPD consortium of academic, industrial and$ governmental entities [18] that work in this area.

Severe plastic deformation processes listed above typically achieve grain refinement in the metal through the introduction of large strain. The accumulated energy of deformation aids in the formation of ultra fine grains in a continuous recrystallization process, rather than a nucleation and growth process that is observed in traditional thermomechanical processing operations. Another feature of several of these SPD processes is that the external dimensions of the work piece remain unchanged. This allows for the repeated application of the process to accumulate larger strains.

Ultra fine grained materials have a number of attractive properties, the most significant from the structural and manufacturing point of view are that they have high strength at low temperatures (Hall-Petch effect) [19,20], while exhibiting improved formability at elevated temperatures. This combination of properties makes UFG metals produced by SPD very attractive as machining, hot forging or hot extrusion stock, both from the point of view of formability as well as energy and cost saving.

In this project, the equal channel angular extrusion/pressing (ECAE/P) process was

investigated for scale up to industrial sizes. At the start of the project, research by different 
investigators had shown that ECAE/P is a viable process for producing UFG structures in a variety of metals, and these SPD metals exhibited superplastic deformation behavior at lower temperatures and higher deformation rates than metals that had been processed by conventional means [21]. However, much of the work had been done on relatively small samples, typically around $10-\mathrm{mm}$ diameter and 50-mm long. The thrust of this project was three fold: (i) to show that the process can be scaled up to produce long samples, i.e., a continuous severe plastic deformation (CSPD) process, (ii) show the process can be scaled up to produce large cross section samples that could be used as forging stock, and (iii) to demonstrate that the potential energy and cost savings that can be realized if SPD processed stock is adopted by the forging industry

Aluminum alloy AA-6061 was chosen to demonstrate the feasibility of the approach used. The following chapters cover the state of the art of making ultra fine grained (UFG) metals by severe plastic deformation, the theoretical development and practical demonstration of a CSPD process. Also, in a parallel effort, ECAE/P was scaled up and forging studies were conducted with the UFG material produced. The later part of this report shows that many of the potential benefits of using UFG material can be realized, in particular cost and energy savings through increased material yield, and lower forging temperatures. 


\section{Chapter 2 Background}

\subsection{Literature survey}

Severe plastic deformation processes can be defined as those processes that induce very high plastic strain in a metal in order to cause grain refinement. Though such processes have been around for many decades, there has been a recent upsurge in a new class of SPD processes which generally have one characteristic feature, namely the size and shape of the work-piece remains unchanged after SPD processing. Older techniques, such as forging, extrusion or rolling, used either singly or in combination, result in a product shape substantially different from the starting billet. Extrusion, for example, can impart very large strains by reductions in area of 100:1 or greater. But the extrudate is generally longer and of smaller cross section than the starting billet. The new SPD processes, such as equal channel angular extrusion or pressing (ECAE/P), high pressure torsion (HPT), accumulative roll bonding (ARB) and multi-axial compression/forging (MAC/F) all aim to keep the starting and finishing work piece shapes the same. ECAE/P, on which the current project is based on, is discussed below, followed by some of the other processes. Among the processes discussed, some like ECAE/P, MAC/F, and HPT introduce severe plastic deformation on bulk materials, while others like ARB, RCS, and Con-shear work on sheet materials.

\subsubsection{Equal Channel Angular Extrusion or Pressing (ECAE/P)}

The equal-channel angular extrusion/pressing (ECAE/P) process was developed in Russia during the 1970s by Segal et al. [3,22] as a method for introducing large plastic strains in a metal, while maintaining the outer dimensions of the work piece substantially unchanged. In contrast, conventional mechanical processing operations, such as extrusion, rolling or forging impart substantial shape changes to achieve high accumulated plastic strains. Over the past 15 years there have been extensive investigations by many research groups all over the world on the process, and there is a large amount of published literature on this topic. As mentioned in the previous chapter, the reader is directed to the proceedings of several topical symposia or to the

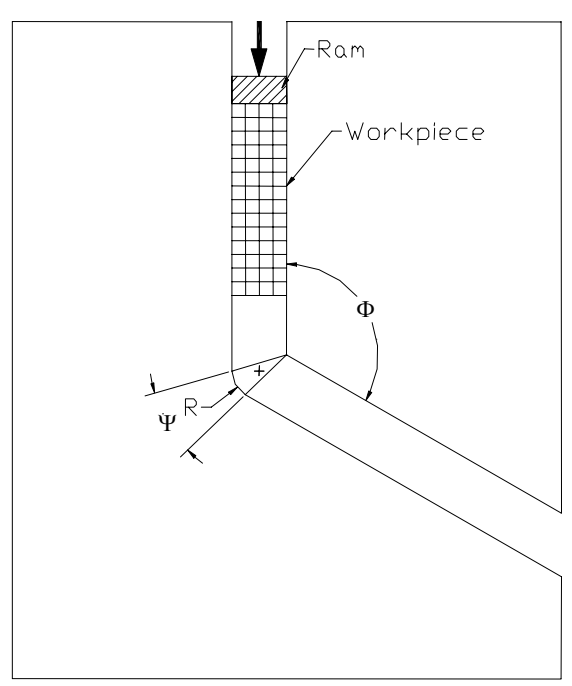
website of the world wide group working on severe plastic deformation [18].

The ECAE/P process shown schematically in Figure 2.1, pushing or extruding a work piece though two channels of equal cross-section which meet at an included angle $\Phi$. In principle, if the fillet radius $\mathrm{R}$ is zero (sharp corner) the work piece will undergo simple shear as it passes through the plane of intersection between the two channels. An approximate expression for the shear strain imposed on the deforming work piece was derived by Segal [3] for frictionless deformation. A more refined expression for the effective strain of the form

Figure 2.1: Schematic ECAE/P process 


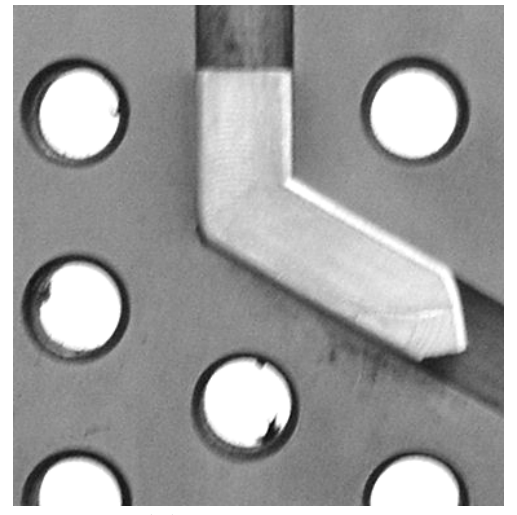

(a)

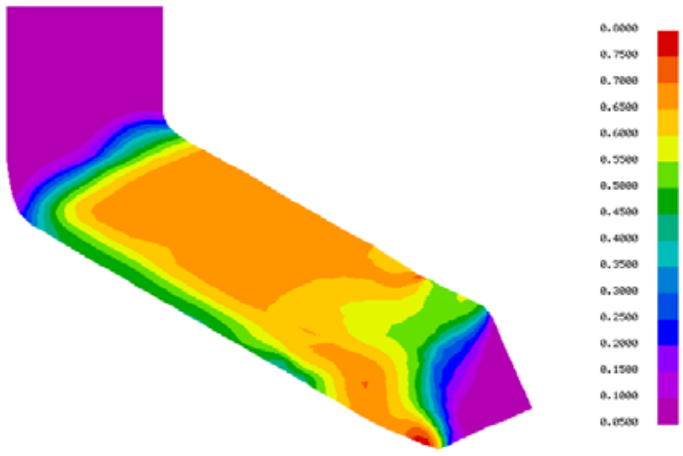

(b)

Figure 2.2: Physical and computer model of the ECAE/P process (a) ECAE/P die and partially extruded work piece, and (b) a simulation of the ECAE/P showing strain distribution in the work piece

$$
\bar{\varepsilon}=\left[\frac{2 \cot \left(\frac{\Phi}{2}+\frac{\Psi}{2}\right)+\Psi \operatorname{cosec}\left(\frac{\Phi}{2}+\frac{\Psi}{2}\right)}{\sqrt{3}}\right]
$$

that includes the angle of curvature $\Psi$ of the outside corner, was obtained by Iwahashi et al. [23]. Both these analyses assume no friction and the entire cross section of the work piece gets sheared equally as it flows through the deformation zone. Figure 2.2 shows an ECAE/P die and workpiece, and a simulation of the deformation that occurs during the process. As can be seen in the figure, the strain experienced by most of the work piece is the same, but there are regions in the front and back end of the work piece that are essentially un-deformed.

Since the cross sectional shape of the work piece does not change as a result of the deformation, the work piece can be reintroduced into the die and pressed again. Multiple passes through the die can result in a large accumulated strain, calculated by simple multiplying the result from equation 1 by the number of passes. Experimental work using plasticine by Wu and Baker [24] confirm that strains accumulated in the middle of the work piece are indeed additive.

If the cross-section of the work piece is a regular polygon, such as a square, hexagon or even
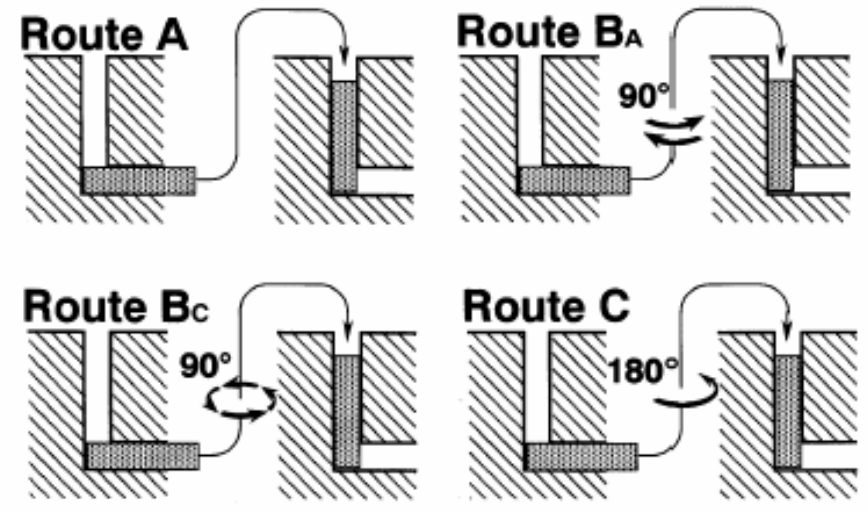

Figure 2.3: Routes for ECAE/P processing [25] 
a circle, the work piece can be rotated between passes to cause shearing on different planes. Several inter-pass rotation schemes have been proposed, such as Route A (no rotation), Route B $\left(90^{\circ}\right.$ back and forth rotation between passes), Route $\mathrm{C}\left(180^{\circ}\right.$ rotation between passes) etc. (Figure 2.3) $[25,26]$ The best route, from the point of view of uniformity of deformation has been found to be Route $\mathrm{B}_{\mathrm{C}}$, which involves rotation of the sample by $90^{\circ}$ in the same direction between passes $[27,28]$. Other work has shown that the best route from the point of view of material yield is route E [26], since this minimizes the total volume of metal with low strain at the front and back ends of the work piece.

Due to friction along the die surfaces, and the axial bending and unbending that occurs when the die corners are not sharp, strain variations may develop across the cross section [28, 29]. This conclusion is borne out by microstructural observations made by Furukawa et al. [9].

A single pass through a die with an included angle $\Phi=90^{\circ}$ introduces a strain of about 1.15 with a sharp outer corner in the die. For practical reasons the die corners cannot be sharp. But, it has been practical to make $90^{\circ}$ dies that impart a strain of about 1.0. Four passes using Route $\mathrm{B}_{\mathrm{C}}$ results in an overall strain of $\sim 4$, which is fairly uniformly distributed across the cross-section of the work piece $[28,30]$. This processing sequence has been shown to produce the most uniform grain structure over a wide range of alloys. Other studies have shown that strains greater than 6 may be needed to eliminate low angle grain boundaries to get structures consisting mainly of high angle boundaries [31]. Included angles of greater than $90^{\circ}$ introduce less strain into the work piece. Though the same total strain can now be introduced through more passes through such a die, work of Langdon et al. $[28,30]$ has shown that one may not get the level of refinement that is obtained by shear through $90^{\circ}$ dies.

The primary drawbacks of the ECAE/P process are that most material currently produced by only consists of small cross-sections and short lengths for laboratory studies, and that there is a substantial amount of undeformed material at the leading and training end of each piece. The length of the work piece is limited because very large frictional stresses can develop in the entrance channel. This imposes high stresses on the dies, which may fracture at points of stress concentration. Segal et al. [32] and Semiatin et al. [33] addressed the problem of the high frictional forces by developing a complex die in which the floor of the exit channel moved along with the work piece.

An alternative to the ECAE/P process is the equal channel angular drawing ECAD process

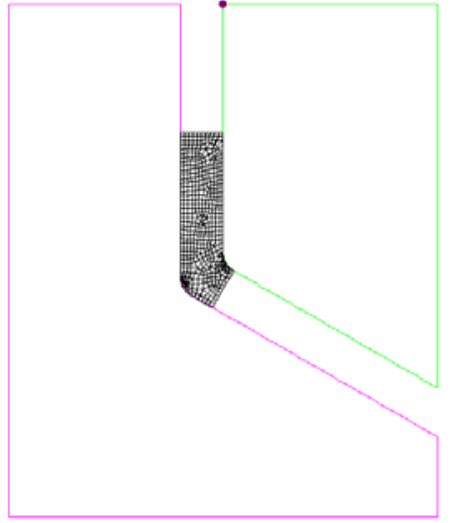

STRGE: 1 STEP: 0

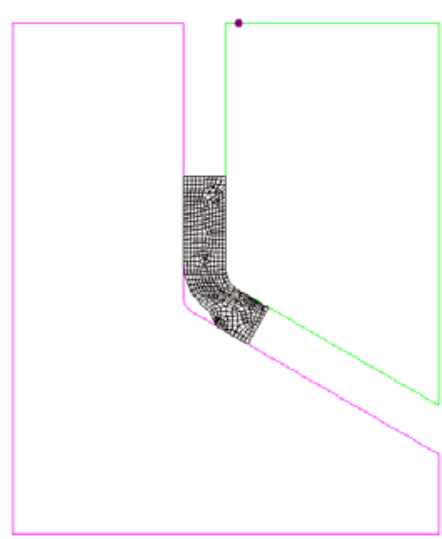

STAGE: 1 STEP: 21

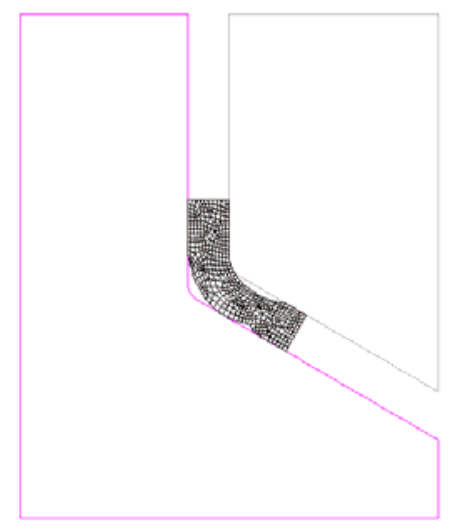

STHEE: 1 STEP: 45

Figure 2.4: Finite element simulation of the equal channel angular drawing process showing the separation of work-piece from die that can occur 
[34] which involves pulling the work piece through the die, as shown in Figure 2.4. A drawing operation would reduce the overall forming force by eliminating friction between the work piece and the entrance channel of the die. But there are several limitations to a drawing process. The first is that the stress that can be applied to draw a material cannot exceed the tensile strength of the drawn product. Under ideal conditions, i.e. no friction and no redundant work, the maximum strain is 1.0, and in most practical drawing operations strain is limited to about $0.4[35,36]$. Furthermore, since there is no reduction in the cross-sectional area of the work piece, as in a wire drawing operation, separation of the work piece from the die occurs.

\subsubsection{Other SPD Processes}

A few of the other SPD processes are reviewed below:

a) High Pressure Torsion (HPT)

Severe plastic deformation by high pressure torsion involves in the deformation of discs by pure shear between two anvils in which one anvil rotates against the other anvil holding the material as shown in Figure 2.5 [9,37]. This method is limited to small discs. The deformation induced during HPT is non uniform from the center to the outside diameter [9].

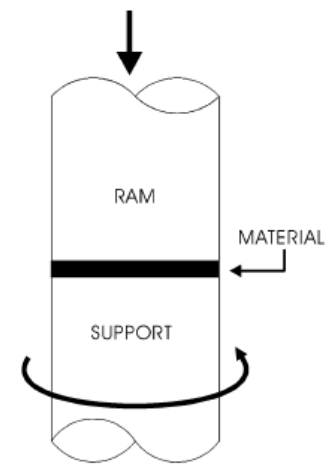

Figure 2.5: Schematic of High pressure torsion [9]

b) Multi-Axial Compressions/Forgings (MAC/F)

Multi-Axial Compressions/Forgings involves the deformation of a rectangular cross section samples through a series of compressions so that the initial dimensions of the billet are retained. The loading direction is changed through $90^{\circ}$ between

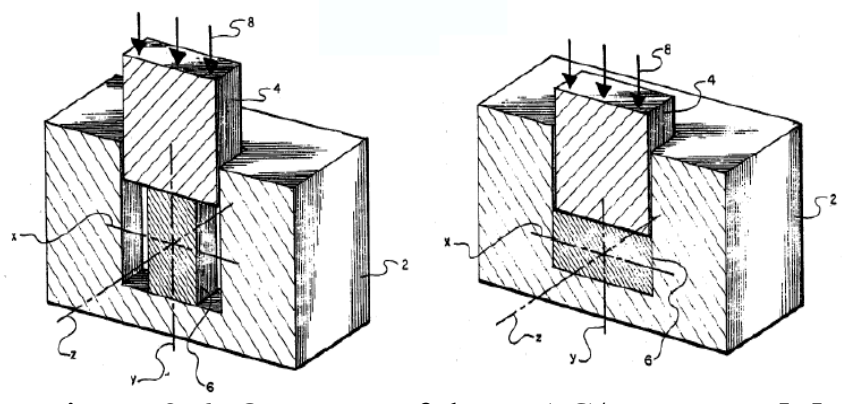

Figure 2.6: One step of the MAC/F Process [7] 
successive compressions [7,38]. A schematic of one step multiple compression/forging is shown in Figure 2.6. Multi-Axial Compression/Forgings are effective in producing fine grain structure, but are deficient due to the non-uniform strain distribution along the billet cross-section. However this non-uniformity can be eliminated by very good lubrication of the billet and through a large number of compression/forgings steps.

c) Accumulative Roll Bonding (ARB)

Accumulative Roll Bonding (ARB) involves deforming a stack of two sheets of equal thickness to $50 \%$ reduction in thickness by plane strain rolling. This amount of reduction usually causes the sheets to bond together. The rolled sheet is cut in half and stacked up to the initial thickness and rolled again to accumulate more strain. The sample dimensions are not changed during the processing, allowing the accumulation of large plastic strains [8]. A schematic of the ARB processes is shown in Figure 2.7.

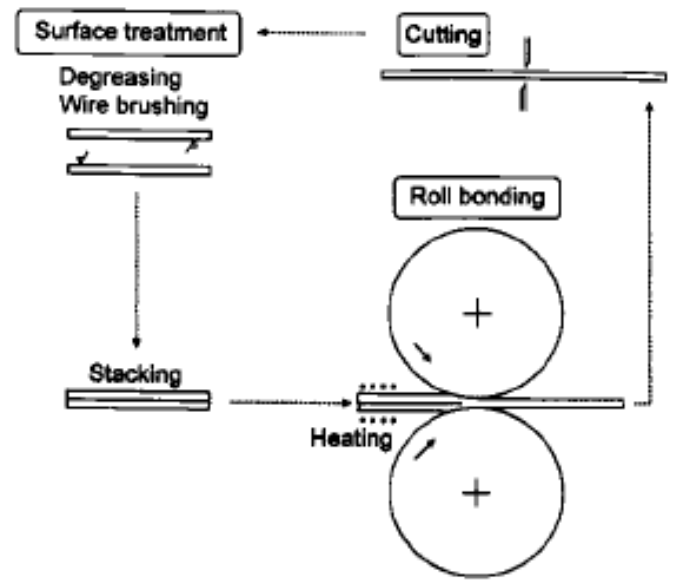

Figure 2.7: Schematic of the Accumulative Roll Bonding process [8]

d) Repetitive Corrugation and Straightening (RCS)

During the RCS process, the work piece undergoes repetitive bending and straightening, as shown in Figure 2.8. By this process, large strains are accumulated while maintaining the initial work piece shape [9]. This process can be either continuous or discontinuous (Figure 2.8.) The work piece is flattened out by flat dies in the case of discontinuous process and smooth rolls in the case of continuous process.

e) Con-shearing Process

The con-shearing process is a continuous pure shear deformation process. During the process, the sheet material is guided to an equal channel die by a large center roll, small satellite rolls, and guide shoe as shown in Figure 2.9. The material undergoes pure shear deformation as it passes through the equal channel die [39]. Since the die has equal channels, the thickness of the sheet is not changed, which allows multiple passes to accumulate more stain in the material. 
(a)

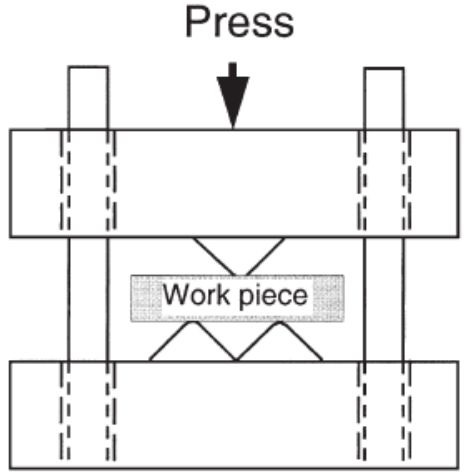

(b)

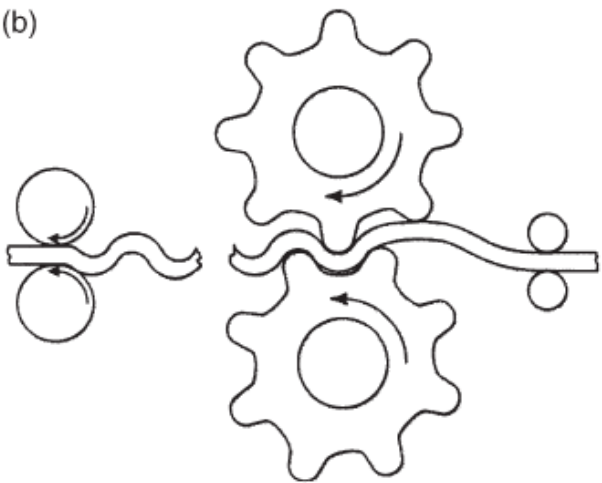

Figure 2.8: Schematic of Repetitive Corrugation and Straightening [9]: (a) Discontinuous and (b) Continuous

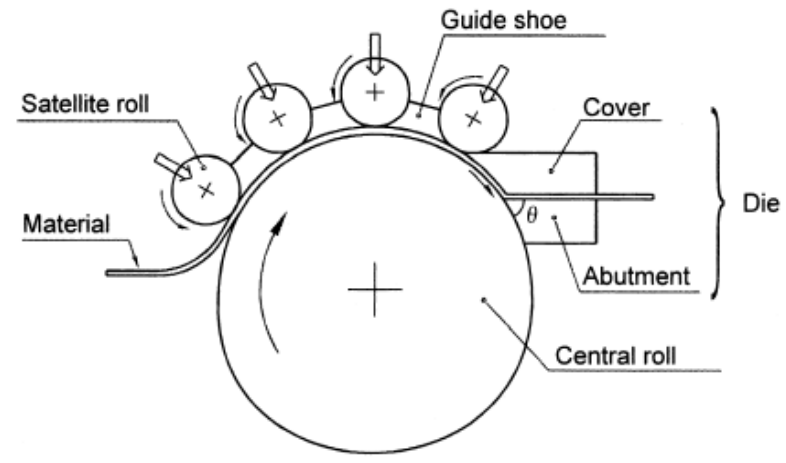

Figure 2.9: Schematic of Con-shear process [39]

\subsection{Objectives of the program}

The primary objectives of this project were

1. Scale up the ECAE/P process to produce SPD processed material of length and cross section considerably larger than currently possible

2. Demonstrate energy savings that can be achieved by the use of SPD processed stock material in forging

\subsection{Tasks}

Four main tasks were identified for this project

Task 1: $\quad$ Design and build a sub-scale CSPD machine that will process long billets by severe plastic deformation. Existing equipment at ORNL would be 
initially used in this process. Revised designs would be based on modeling and experience gained with the initial design

Task 2: $\quad$ Demonstrate that using ultra-fine grained material produced by severe plastic deformation will provide cost and energy savings during forging. This task requires scaling up the ECAE/P process to produce large size (100-mm or 4-inch cross section) billets

Task 3: $\quad$ To transfer technology to industry

Task 4: $\quad$ Provide progress reports to DOE

\subsection{The R\&D Team and Investigator Qualifications}

The R\&D team working on the project consisted of Wright State University, Oak Ridge National Laboratory, the Edison Materials Technology Center (EMTEC), a State of Ohio funded nonprofit agency, and several industrial partners. The qualifications of the principal investigators at each organization are discussed briefly below.

Wright State University (WSU), Dayton OH:

Principal Investigator: Dr. Raghavan Srinivasan

WSU was the lead institution on the project, and Dr. Raghavan Srinivasan served as the principal investigator for the project. He received his $\mathrm{PhD}$ in Materials Science and Engineering from SUNY at Stony brook, NY, and has over 20 years experience in deformation processing of materials. Through externally funded projects in excess of $\$ 4 \mathrm{M}$, he research work has included laboratory scale equipment development for various metal forming operations (ECAE/P, sheet metal forming, and elevated temperature metal deformation), finite element modeling of metal deformation and materials characterization. Prior to joining Wright State University, Dr. Srinivasan was a National Research Council Fellow at the U.S. Air Force Materials Laboratory at Wright Patterson AFB.

\section{Intercontinental Manufacturing (IMCO), Garland TX:}

Principal Investigator: Dr. Prabir Chaudhury

IMCO was the primary industrial partner on this project from 2001 through 2003. In summer 2003, IMCO became the Ordnance and Tactical Systems division of General Dynamics. GD/OTS continued as a partner in the program until Spring 2004, when they withdrew from the project. Subsequently, Dr. Chaudhury also served as an independent consultant on the project.

Prabir K. Chaudhury has B.S. and M.S. in Metallurgical Engineering. He received his $\mathrm{Ph} . \mathrm{D}$. in Engineering from University of California, Irvine. He has over 15 years of experience in thermomechanical processing of metallic materials including industrial scale process development for commercial and government programs. Dr. Chaudhury was the Chief Metallurgist at Intercontinental Manufacturing and provides technical knowledge and direction to metalworking process development, engineering, implementation, and quality assurance. His technical expertise is in the areas of cold, hot, and superplastic forming and heat treatment of metals including steel, nickel, aluminum, titanium, magnesium and other alloys. He provided leadership in thermomechanical processing of aluminum, steel, and advanced materials at the National Center for Excellence in Metalworking Technology (NCEMT) supported by the U.S. Navy Manufacturing Technology program, overseeing or managing emerging process 
development efforts worth more than $\$ 40$ Million. He also conducted funded research, development, and commercial implementation of metalworking of various materials for other government organizations such as Los Alamos National Laboratory, and many commercial companies such as Alcoa, Brush Wellman, Ladish Company, Caterpillar Inc., Ford Motor Company, and others.

Oak Ridge National Laboratory (ORNL), Oak Ridge TN: Principal Investigators: Dr. Srinath Viswanathan and Dr. Qingyou Han

Dr. Srinath Viswanathan served as the principal investigator at ORNL between 2/2001 and 1/2003. Dr. Qingyou Han served as PI between 2/2003 and the end of the project.

Dr. Qingyou Han obtained his Ph.D. degree from Oxford University in 1994. Currently he is a research scientist with Oak Ridge National Laboratory. His primary expertise is in the area of solidification and casting processing of materials. His research also covers forging, extrusion, and ultrasonic processing of materials. At Oak Ridge National Laboratory, Dr. Han is a PI/Co-PI of a number of projects including "Forging of Fine Grained Semi-Solid Aluminum Billets Created 'In-Situ' from Molten Metal," "Using Thermodynamic Simulations to Minimize Cracking Formation in Direct Chill Casting Ingots" "Next Generation of Clean Aluminum Melting Systems", "Development of Computational Tools for the Assurance of High Strength and Fatigue Resistant Aluminum Castings", and "Ultrasonic Processing of Materials." He is the author/co-author of more than 80 papers, two patents, and a number of invention disclosures.

Dr. Srinath Viswanathan received his M.S. and Ph.D. in Metallurgical Engineering from the University of Pittsburgh. He is presently a Senior Research Staff Member in the Materials Processing Group in the Metals and Ceramics Division at the Oak Ridge National Laboratory (ORNL). His research at ORNL includes the modeling and characterization of the casting, solidification, and processing of aluminum alloys and advanced materials, in particular the prediction of defects and microstructure. He was awarded an R\&D 100 award for the development of the Metal Compression Forming Process in 1997.

\section{Edison Materials Technology Center (EMTEC), Kettering OH:} Principal Investigators: Mr. Percy Gros and Mr. David W. Swenson

EMTEC is a State of Ohio funded agency Technology Center focused on solving challenges facing Ohio industries in materials and manufacturing processes. The organization's function was to facilitate the transfer of technical information generated in the project to the broader industrial base.

Mr. Percy Gros is the Director Core Technology Program manages EMTEC's Core Technology (CT) process and other materials technology projects. Mr. Gros is one of EMTEC's founding staff and works with other EMTEC senior staff in all ongoing EMTEC CT projects and prepares reports, plans, and other proposals as needed. He is a retired U.S. Air Force career officer with experience in research and development, training, and aircraft operations. Mr. Gros has over 40 years of technical experience and has been with EMTEC nineteen years. He has an M.S. degree from the Air Force Institute of Technology and over 35 years experience in project management in the Air Force and industry. Percy as managed EMTEC projects for DOE, NIST, and the state of Ohio among many other project management assignments. 
Mr. David Swenson is Vice President, Business Initiatives, for The Edison Materials Technology Center (EMTEC) has over thirty years experience in managing commercial and governmental programs with $\mathrm{P} \& \mathrm{~L}$ responsibilities in a variety of business initiatives including business start-ups and divisions of larger corporations. His career has involved full business unit management as well as senior management positions in marketing/sales, strategic planning, and manufacturing functions. Mr. Swenson has a diverse technical background covering multiple industrial materials, technologies, and processes. These include materials and technologies used in alternative energy sources such as solar cells and fuel cells as well as other unique technologies including ceramics, coatings (CVD, inorganics, and organic/polymeric), infrared materials, and controlled release systems. Mr. Swenson holds a B.S. in Chemistry from Union College, an MBA with a concentration in Finance from the University of Dayton, and is a member of the Beta Gamma Sigma honor society. In addition, he is an internationally invited speaker on technology and innovation, sits on the Advisory Board of the Dayton Entrepreneur Center, and has previously served on several other management/corporate boards. Mr. Swenson is the author of seven technical papers and two book chapters. He has been awarded several corporate excellence awards for marketing and product development and has helped two different companies in winning three new product IR100 awards in multiple technologies as a result of independent peer review that recognizes their impact in the marketplace. Mr. Swenson has extensive international business experience (Far East, India, Europe, North and South America) with previous affiliations including TFL (formerly Röhm), Rohm \& Haas (formerly Morton International), and Albany International.

\section{Queen City Forging Company (QC Forge) Cincinnati, OH: \\ Principal Investigator: Mr. Howard (Rob) Mayer}

QC Forge joined the project in 2004, a couple of months before GD/OTS withdrew from the project. Forging studies for the latter part of the project were done at QC Forge.

Mr. Howard (Rob) Mayer is a second generation owner and President of Queen City Forging Co. He has been actively participating in the Forging Industry Association (FIA), having served as a director of the organization for three years. He has also conducted specialized courses in forging design, forge tooling, furnace construction, and human resource management for FIA. Queen City Forging Co. is a small agile ISO-9000 certified business which, for over 120 years, has made forged parts out of steel, stainless steel, aluminum, brass for a variety of applications, ranging from commercial and military aerospace, to weapons systems, sewing machine and ATM components. 


\section{Chapter 3 A Continuous Severe Plastic Deformation (CSPD) Process}

The continuous severe plastic deformation (CSPD) process developed during this project is based on the equal channel angular extrusion/pressing (ECAE/P). ECAE/P is probably the most promising for production of bulk SPD processed stock material that can be used for making billets for subsequent manufacturing operations, such as forging.

\subsection{Limitations of ECAE/P}

As mentioned in the previous chapter, conventional ECAE/P involves pushing a billet through two channels that meet at an angle $\Phi$ (Figure 3.1). For an ideal rigid plastic material, once the applied force reaches a critical value, the billet material undergoes plastic deformation,

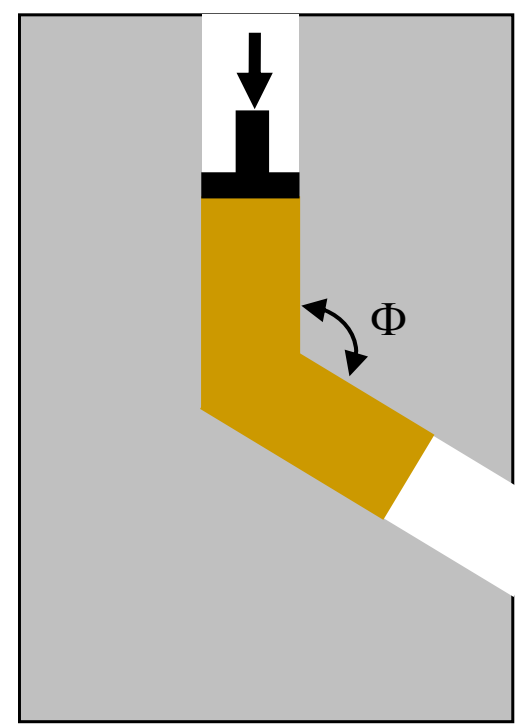

Figure 3.1: Schematic ECAE/P and the process continues without further increase in load. To produce long pieces of processed material, one simply needs to take a longer starting stock. Some experimental results using soft thermoplastic materials (plasticine or modeling clay) reported in literature to confirm this is possible, and the accumulated strain is additive [24]. However when a metal billet is used, due to elastic deformation and the Poisson effect, there is a lateral expansion of the billet in the entrance channel, and very high frictional forces develop between the work-piece and the channel walls. The force required to press a billet through the die increases very rapidly with the length of the billet. Correspondingly, there is also a large increase in stresses experienced by the die. These two factors limit the length of the billet that can be practically processed by ECAE/P. At the start of this project, the largest billet that could be processed by ECAE/P was $50-\mathrm{mm}$ square by 150 mm length $(2 \times 2 \times 6$ inch) at the U.S Air Force Research Laboratory (AFRL), and most scientific studies had been conducted on samples $10-\mathrm{mm}$ diameter or smaller. These sizes are clearly not sufficient for use as stock material for most forging applications.

The following sections discuss the development of a continuous severe plastic deformation (CSPD) process for producing long products.

\subsection{Analytical background for CSPD}

Two common metal forming processes used for producing long products are wire drawing and extrusion. Figure 3.2 shows schematics of the two processes. During wire drawing (Figure 3.2 (a)), indirect compression exerted on the wire by the dies, due to a tensile stress pulling the product, causes a reduction in the cross section of the wire. During extrusion (Figure 3.2 (b)), 


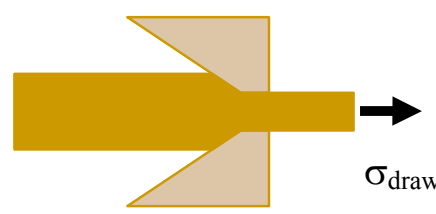

(a) Wire Drawing

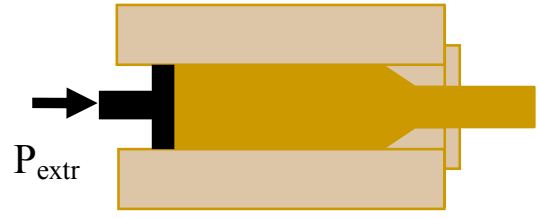

(b) Extrusion

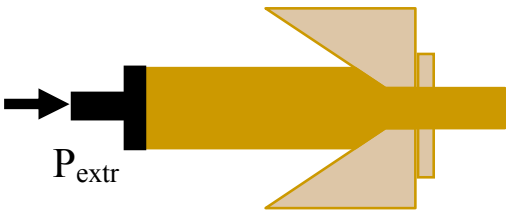

(c) Chamber-less extrusion

Figure 3.2: Schematic drawings of wire drawing and extrusion

the billet is enclosed in a chamber, and the extrusion pressure exerted by the ram causes the billet to be deformed and be pushed out of the die.

\subsubsection{Limits to Wire drawing and Extrusion}

There is a theoretical limit on the amount of reduction in cross section that can be obtained in wire drawing since the stress applied on the drawn wire cannot exceed the ultimate tensile strength. Under ideal deformation conditions, for a material whose flow stress follows power law hardening, namely, $\sigma=K \varepsilon^{n}$, the theoretical limit to the strain during wire drawing is $\varepsilon^{*}=1+n$. For a non-work-hardening material, such as a fully work-hardened material, the limiting strain is $\varepsilon^{*}=1$. If the imposed strain is greater than the critical value, the drawn product will undergo tensile failure. This is shown schematically in Figure 3.3 (a). Figure 3.3 (b) and (c) show finite element simulations of wire drawing conducted at strains of $\varepsilon=0.5$ and $\varepsilon=1.2$, which are below and above the theoretical maximum strain for a non-work hardening material. These simulations bear out the theoretical predictions.

Similarly, for a chamber-less extrusion process when the billet is not contained within a chamber, but is simply pushed through a die (Figure 3.2 (c)), if the extrusion pressure exceeds the compressive strength of the billet material, the billet will get compressed and barrel out, rather than be extruded. Again, for a non-work hardening material, the theoretical strain during chamber-less extrusion is $\varepsilon^{*}=1$. Figure 3.4 (a) shows, schematically, the upsetting of the billet of without entering the die for an imposed strain greater than 1. Figures 3.3 (b) and (c) show finite element simulation of chamber-less extrusion for strains of 0.5 and 1.2 , which are below and above, respectively, of the theoretical maximum strain.

If deformation occurred under non-ideal conditions, the maximum strain that can be achieved either by wire drawing or by chamber-less extrusion will be less than the maximum theoretical values shown above. During metal forming analysis, the effects of redundant work and friction are usually combined into an efficiency parameter $\eta<1$, and the limiting strain in each of the above cases is $\varepsilon^{*}=\eta$

\subsubsection{Combined extrusion and drawing}

If both wire drawing and chamber-less extrusion were combined, in other words, if the workpiece is pulled through the die (wire drawing) and pushed by a ram (extrusion) the total strain that can be achieved will be greater than either process, and in principle, the total strain that can be achieved without failure of the work piece can be doubled. 


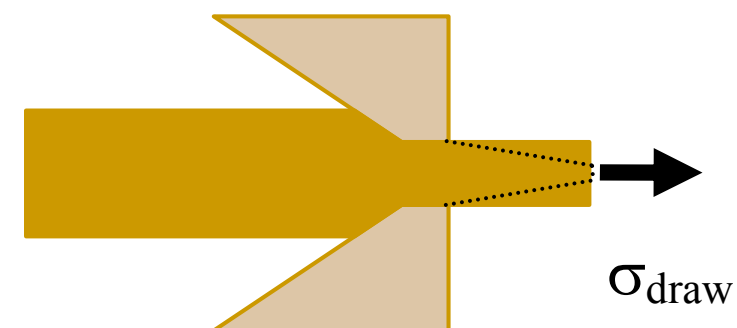

(a) Schematic tensile failure during wire drawing indicated by dashed line
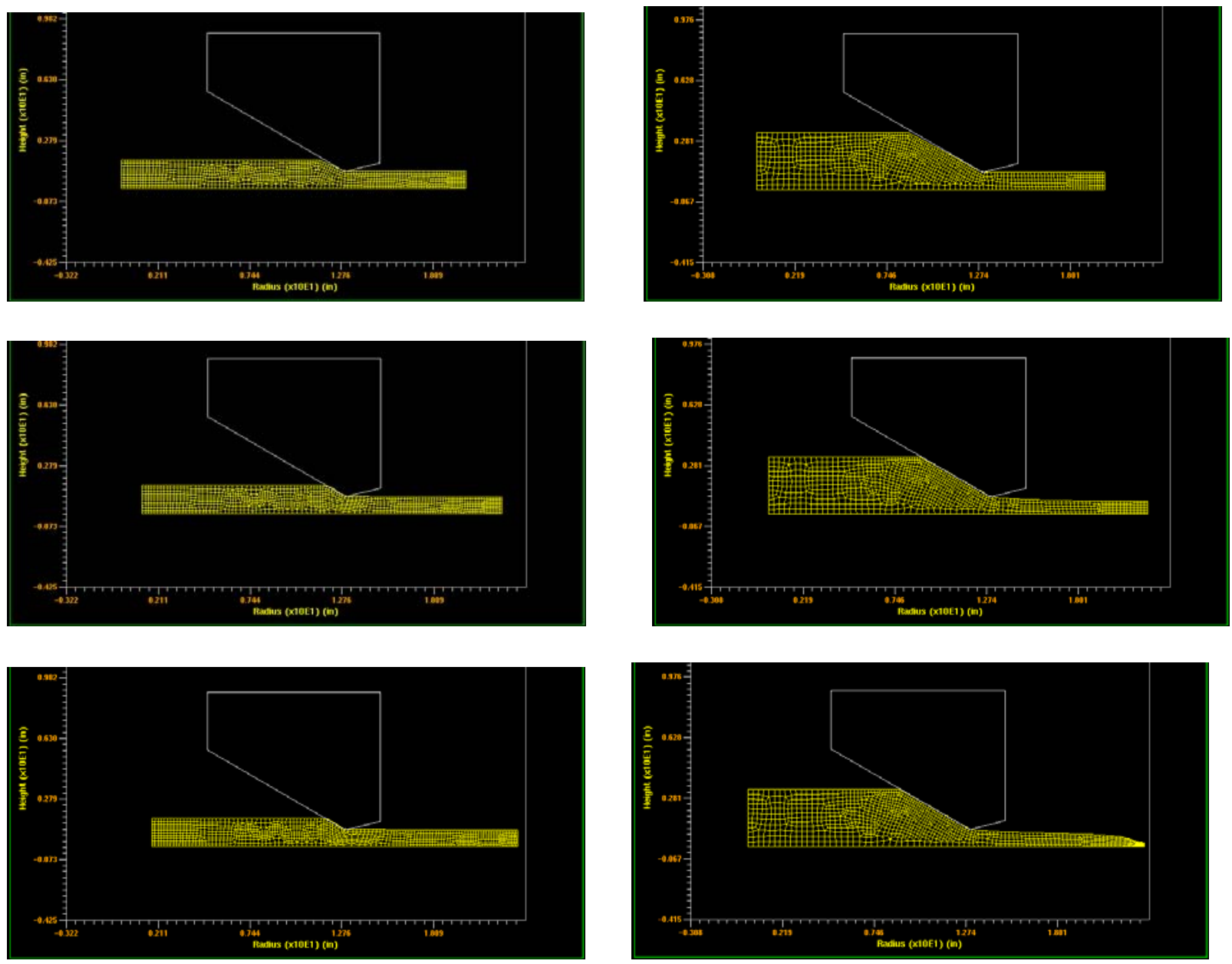

(b) Successful drawing when $\varepsilon=0.5$

(c) Tensile failure when $\varepsilon=1.2$

Figure 3.3: Schematic drawing and simulation of wire drawing. (a) Wire drawing is possible when $\varepsilon<1.0$ and (b) tensile failure occurs when $\varepsilon>1.0$. 


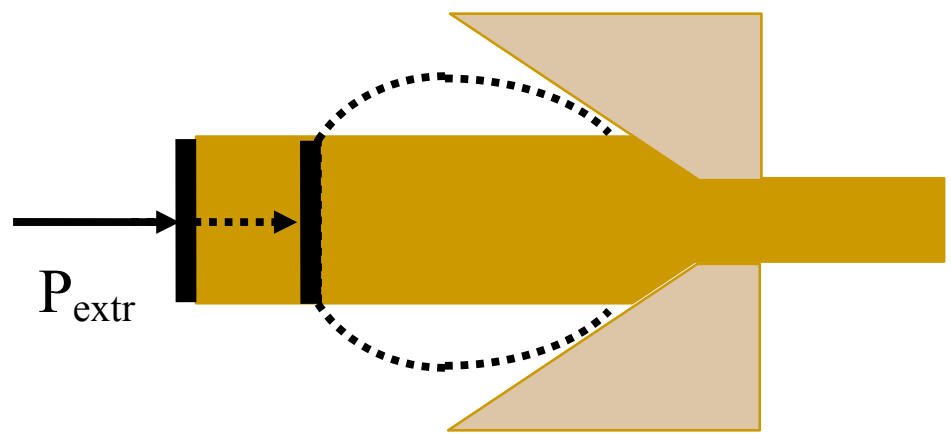

(a) Schematic bulging during chamber-less extrusion indicated by dashed line
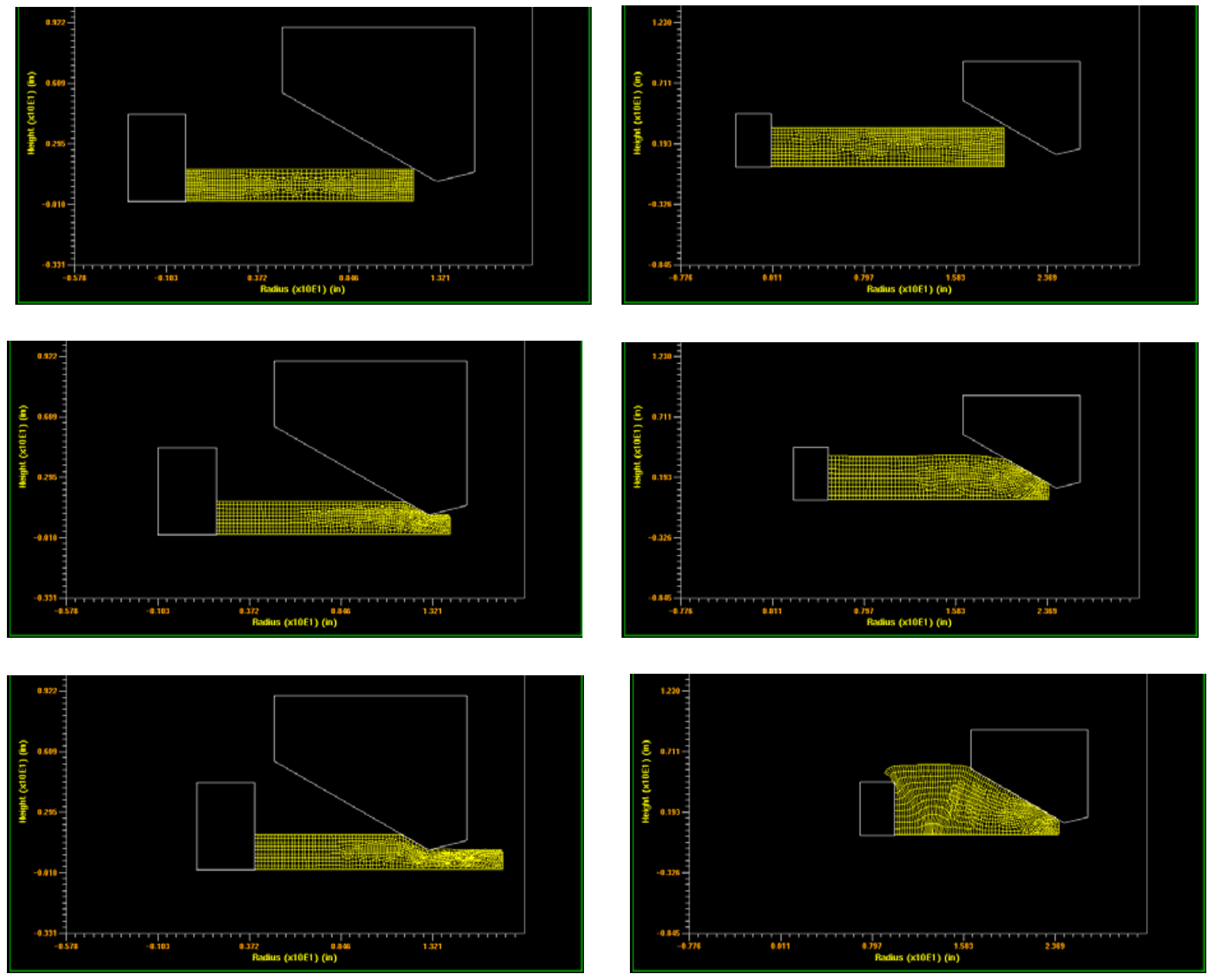

(b) Successful extrusion when $\varepsilon=0.5$

(c) Bulging when $\varepsilon=1.2$

Figure 3.4: Schematic drawing and computer simulation of chamber-less extrusion. (a) Extrusion is possible when $\varepsilon<1.0$ and (b) upsetting occurs when $\varepsilon>1.0$. During simulation, the ram, shown as a white rectangle on the left, pushes the work-piece through the die. 
Table 3.1: Theoretical strains during ECAE/P

\begin{tabular}{|c|c|}
\hline Channel Angle $\Phi$ & Theoretical Maximum Strain \\
\hline $90^{\circ}$ & 1.15 \\
\hline $120^{\circ}$ & 0.67 \\
\hline $135^{\circ}$ & 0.48 \\
\hline
\end{tabular}

Table 3.1 lists the total strain imparted on a work-piece during ECAE/P under ideal deformation conditions of no friction and no redundant work [23]. As can be seen, the strain when achieved with a $\Phi=90^{\circ}$ die is 1.15 , which a little more than half of the theoretical limit of strain $\varepsilon^{*}=2$ during combined extrusion + drawing. Under non-ideal conditions, it should be possible to perform ECAE/P with long billets, even if the efficiency is only about 0.575 for a $90^{\circ}$ die and 0.335 for a $120^{\circ}$ die.

\subsubsection{Continuous Severe Plastic Deformation (CSPD) Process}

From the above discussion, it appears that if the ECAE/P process were combined with extrusion and drawing operations, it will be possible to create a continuous severe plastic deformation process. In such a process, the length of the entrance channel can be substantially decreased, thereby reducing the frictional stress that develops between the work-piece and die. A feeding mechanism will continuously push material into the ECAE/P die, while a drawing mechanism will continuously pull the deformed product. This "push-pull" arrangement for a continuous severe plastic deformation (CSPD) is shown schematically in Figure 3.5. In the figure rollers are shown for illustrative purposes, though several other mechanisms could be used for both pushing and pulling. Furthermore, several such stages could be sequenced to cause deformation on different shear planes to achieve any of the processing routes used in standard

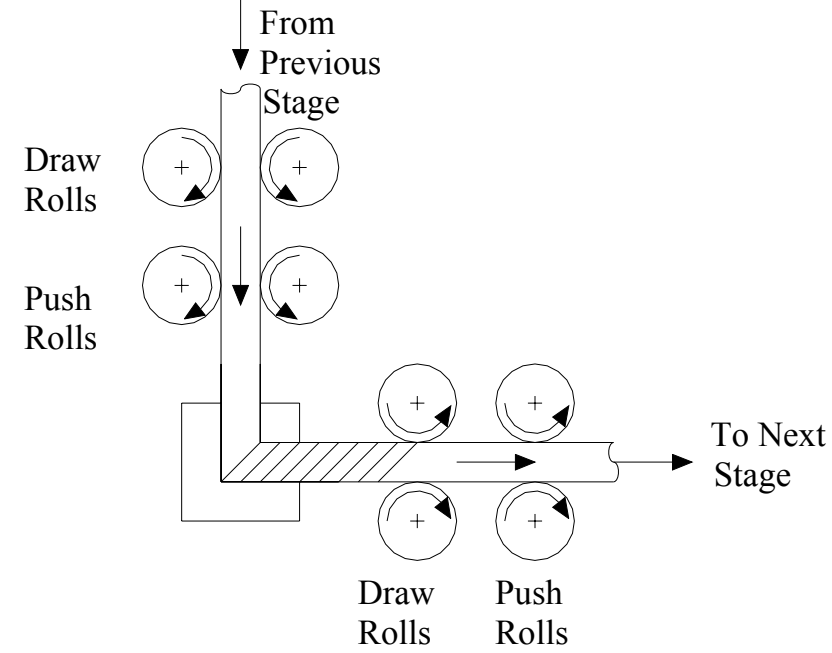

Figure 3.5: Schematic "Push-Pull" arrangement for CSPD 
ECAE/P. As shown in the figure, the ECAE/P die can be relatively short, as long as the workpiece does not buckle in the unsupported region in the "pushing" side of the die.

\subsubsection{Contact area}

The continuous "push-pull" mechanism envisioned above must provide sufficient force to move the work-piece material through the die. This force must be developed through friction between the mechanism and the work-piece without deforming the work-piece outside the die. The contact area and applied pressure between the push-pull mechanism and the work-piece can be determined as follows.

Assume the push-pull mechanism consists of a belt and roller system shown schematically in Figure 3.6. Under ideal conditions, to push a square cross section billet of width $w$ through a die that imparts a strain of 1 , the extrusion force is

$$
F=\sigma \times \text { cross }- \text { sectional area }=\sigma \times w^{2}
$$

where $\sigma$ is the flow stress of the material. If this force is to be delivered by friction over a contact length of $L$, then

$$
\begin{aligned}
F_{\text {fric }} & =\tau_{\text {fric }} \times \text { contact area } \\
& =\tau_{\text {fric }} \times w \times L=\mu \times \sigma_{n} \times w \times L
\end{aligned}
$$

In the above equation, $\tau_{\text {fric }}$ is the frictional stress, $\mu$ is the friction factor and $\sigma_{n}$ is the normal stress at the belt-work-piece interface. The normal stress that can be applied without plastic deformation occurring in the work-piece is limited by the flow stress of the material. Therefore

$$
\sigma_{n} \leq \sigma
$$

Equating $F$ and $F_{\text {fric }}$, we get

Under less than ideal conditions,

$$
\mu L=w
$$

$$
F=\frac{1}{\eta} \sigma \times w^{2}
$$

and

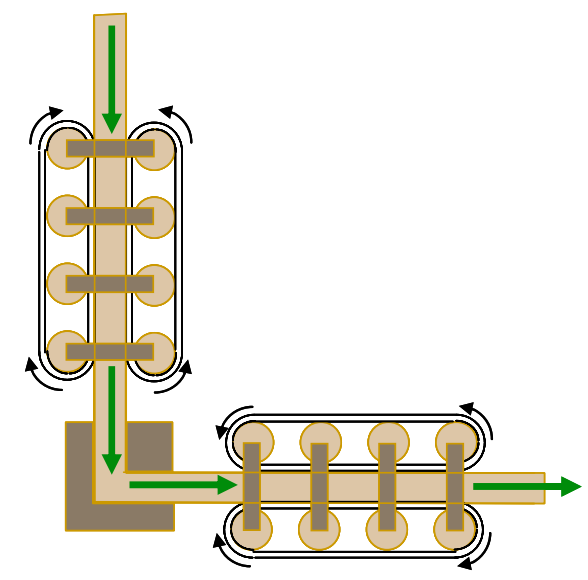

Figure 3.6: "Push-Pull" arrangement using belts and rollers 


$$
L=\frac{w}{\mu \eta}
$$

With a friction factor $=0.33$ and an efficiency parameter $\eta=0.33$, the contact length is roughly 10 times the width of the billet. If the contact length is divided between the "push" and "pull" sides, then the contact length on each side is about $5 w$. For a $12.5-\mathrm{mm}(0.5$-inch) cross section billet, the contact area is only about $60-\mathrm{mm}$ or about 2.5 -inch. This contact length can easily be provided by a rolling mill with $600-\mathrm{mm}(2-\mathrm{ft})$ diameter rolls.

\subsection{Computer simulation of CSPD concepts}

Several of the concepts developed above for a continuous severe plastic deformation process were explored using finite element modeling at Wright State University (WSU), prior to building a prototype at Oak Ridge National Laboratory (ORNL). Two concepts that showed the most potential were the guided ECAE/P and combined rolling and ECAE/P.

\subsubsection{Guided ECAE/P}

The major barrier to processing long billets is the high frictional stress that develops as the work-piece slides against the wall of the entrance channel. One possible way of decreasing this frictional stress is to have the sides of the channel move with the work piece. This concept was developed to a point by Semiatin et al [33] who designed an ECAE/P die with side walls that moved with the ram during the process. The size of the billet that can be processed by this technique is limited because the billet is contained entirely within a chamber.

The guided ECAE/P concept, shown schematically in Figure 3.7, is based on the following principles. The theoretical strain limit under ideal conditions for chamber-less extrusion is 1.0. In the presence of friction and redundant deformation the limit is lower, but still

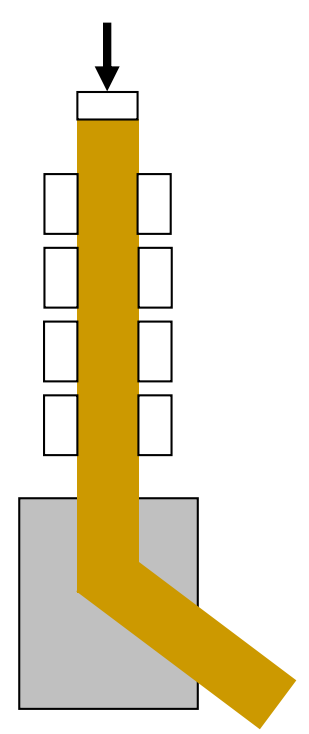

Figure 3.7: Schematic guided ECAE/P is higher than the strain imparted by a $120^{\circ}$ or $135^{\circ} \mathrm{ECAE} / \mathrm{P}$ die. In order to extrude long pieces, the incoming billet is support by a series of short guides that surround the billet, and move with the billet. The billet is unsupported in the region between the guides and the between the guide and the ECAE/P die entrance. When one of the guides gets close to the die entrance, it opens out, leaving an unsupported region of the billet. As long as the unsupported region is short enough that the billet will not buckle, a long billet can be extruded. The guides can be thought of as a segmented extrusion chamber whose primary function is to ensure the billet does not buckle. There is no relative motion between the guides and the billet. Therefore the major 


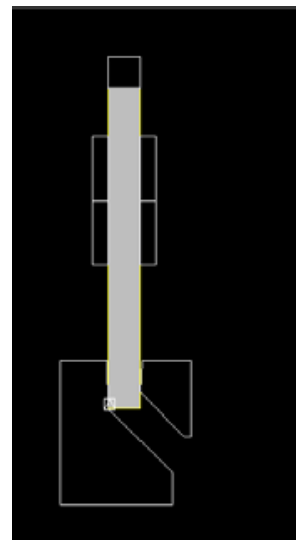

Step 0

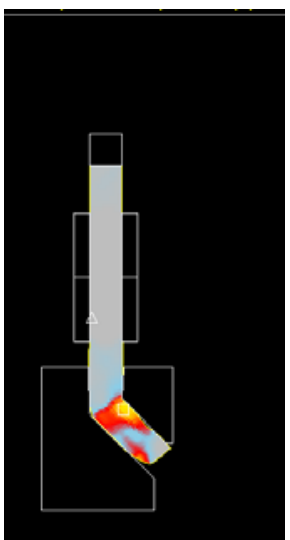

Step 7

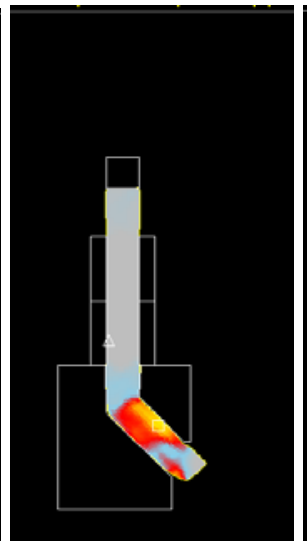

Step 13

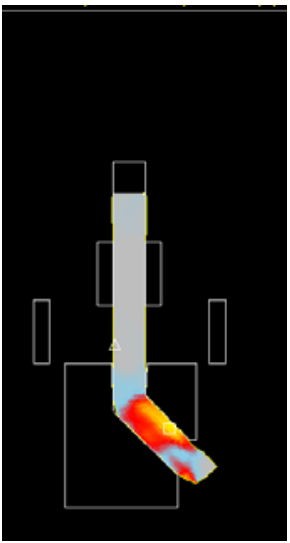

Step 14

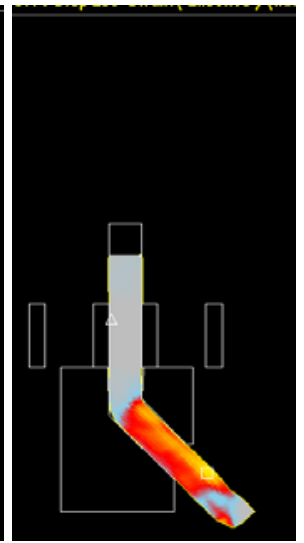

Step 27

Figure 3.8: Simulation of the guided ECAE/P for a die angle of $135^{\circ}$

contributor to high extrusion pressures is eliminated.

Figure 3.8 shows results of a computer simulation for a $135^{\circ} \mathrm{ECAE} / \mathrm{P}$ die. The billet is inserted into the die, and is pushed from the end by a ram. Two sets of guides are shown. Initially there is an unsupported length equal to 3 times the width of the billet. The moving ram at the top and the guides ensure the billet enters the die and then gets sheared as it passes through the die. At step 13 the lower guide comes into contact with the die. At this point the lower guides are moved away and the process continues until the second set of guides comes in contact with the die. This process can, in principle be carried out with very long billets and multiple sets of moving guides. This simulation was carried out in plane strain with a Coulomb friction factor $=0.1$ between the billet and the die.

Figure 3.9 shows that in the absence of the guides, the billet tends to rotate, and does not move directly downward into the die. The guides are therefore required for such a process.

Figure 3.10 shows simulations for the guided ECAE/P process with a die angle of $90^{\circ}$. Unlike the simulation results shown in Figure 3.7, the strain introduced by this die is greater than 1.0. This means that even under ideal conditions, the billet will upset at the entrance of the die. This is verified by the simulations shown in Figure 3.10. In order for the guided ECAE/P process to work, in addition to the extrusion force exerted by the ram, the product also needs to

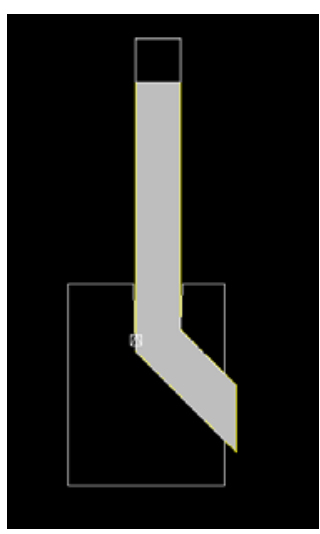

Step 0

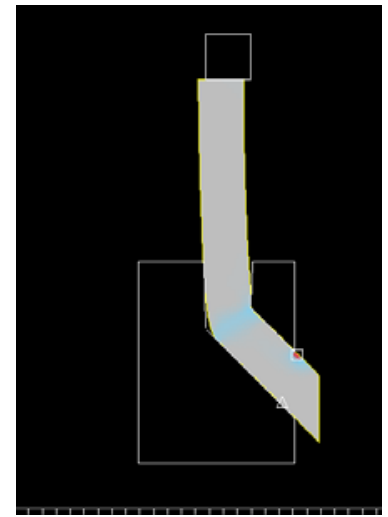

Step 8

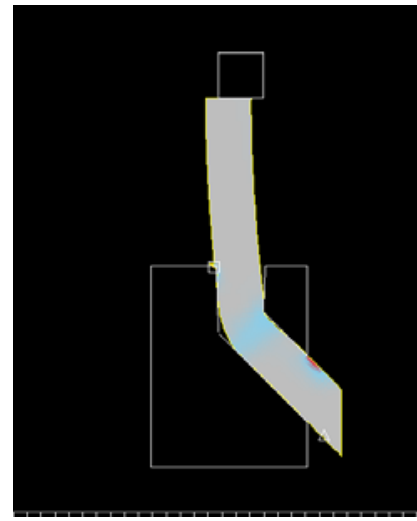

Step 15

Figure 3.9: Simulation of unsupported ECAE/P for a die angle of $135^{\circ}$ 


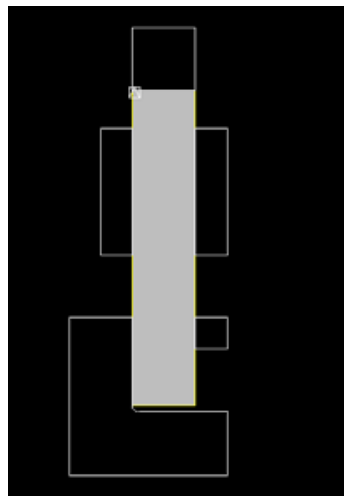

Step 0

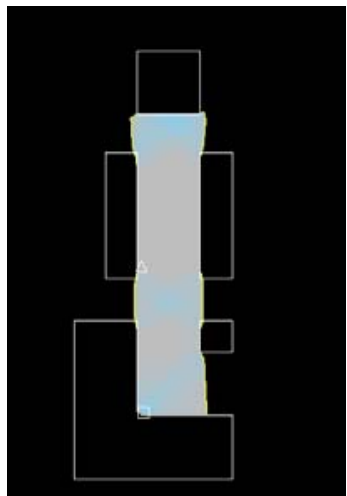

Step 3

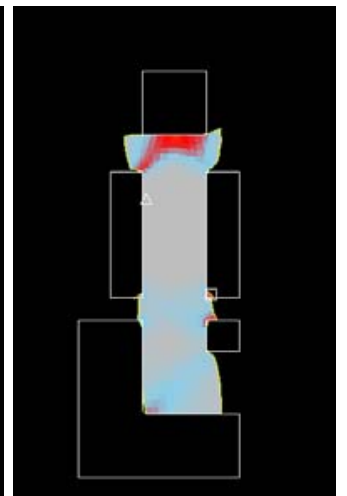

Step 7

Figure 3.10: Simulation of guided ECAE/P for a die angle of $90^{\circ}$

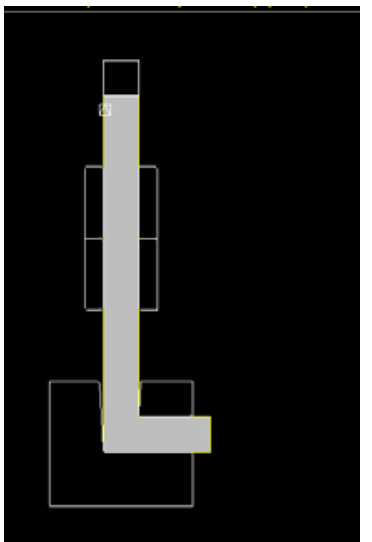

Step 0

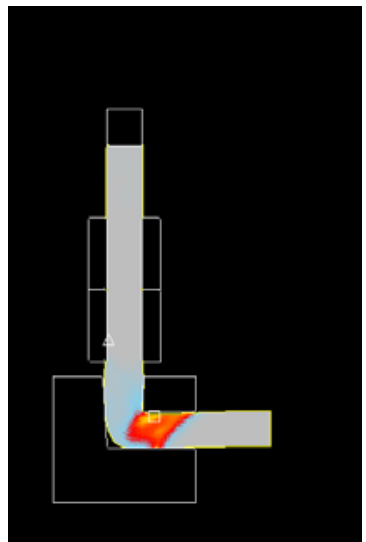

Step 80

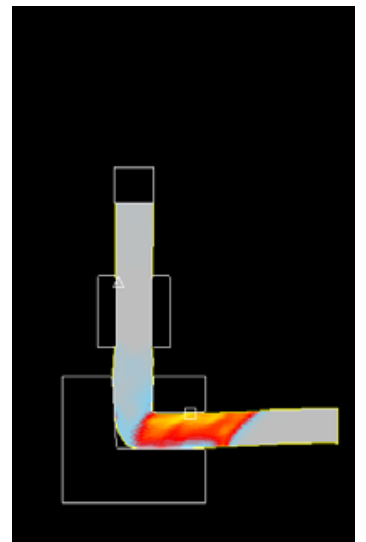

Step 160

Figure 3.11: Simulation of guided ECAE/P for a die angle of $90^{\circ}$ starting with a filled die and a "pulling" action at the front end of the work-piece.

be pulled out of the die on the exit side. Figure 3.11 shows the guided ECAE/P process, with a "pulling" action imposed on the front end of the exiting work piece. To achieve this, the die is first filled with the work-piece, and a velocity boundary condition is imposed on the exiting work-piece while also pushing with the ram. As predicted by the theoretical "push-pull" approach described in Section 3.2.3, simulation results show that this is possible.

\subsubsection{Combined Rolling and ECAE/P}

Section 3.3.2 shows simulations of ECAE/P of long billets. For these simulations, a ram provided the pushing force to deform the work piece. A survey of equipment at ORNL showed that potential components of the CSPD prototype were rolling mills and draw benches. So, the use of a rolling mill to provide the "pushing" force for a continuous ECAE/P process was investigated by computer simulation.

In Figure 3.12, the work-piece is passed between large rolls that impose a 25\% reduction in thickness. The work-piece is pushed along by the rolls though the ECAE/P die. As the workpiece exits the die, a velocity boundary condition is imposed on the front end to model the 
pulling action of a draw bench. This combination of a rolling mill to provide the pushing force and a draw bench to provide the pulling force appears to be a feasible Continuous Severe Plastic Deformation (CSPD) machine. The next section describes a physical prototype built at ORNL.
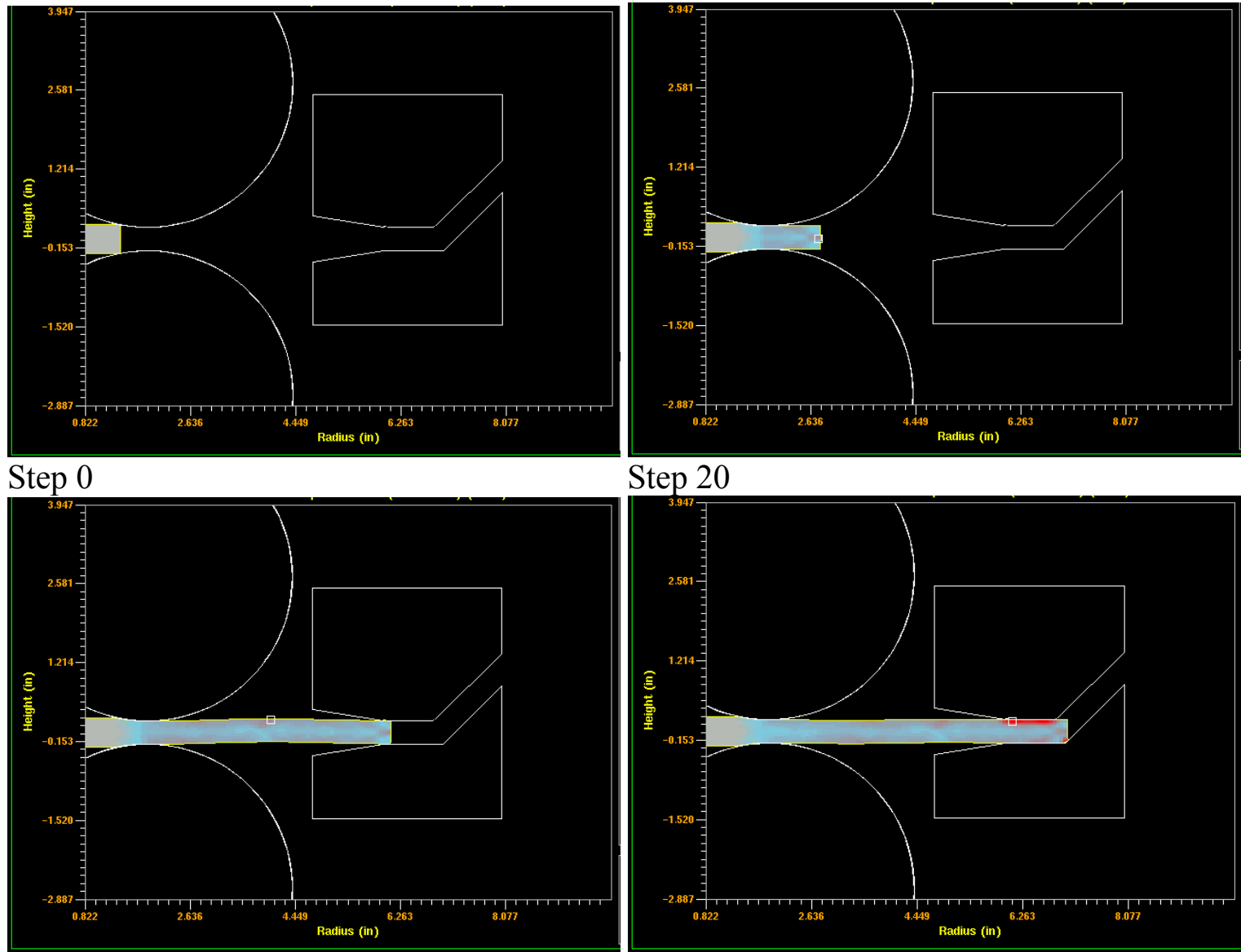

Step 20
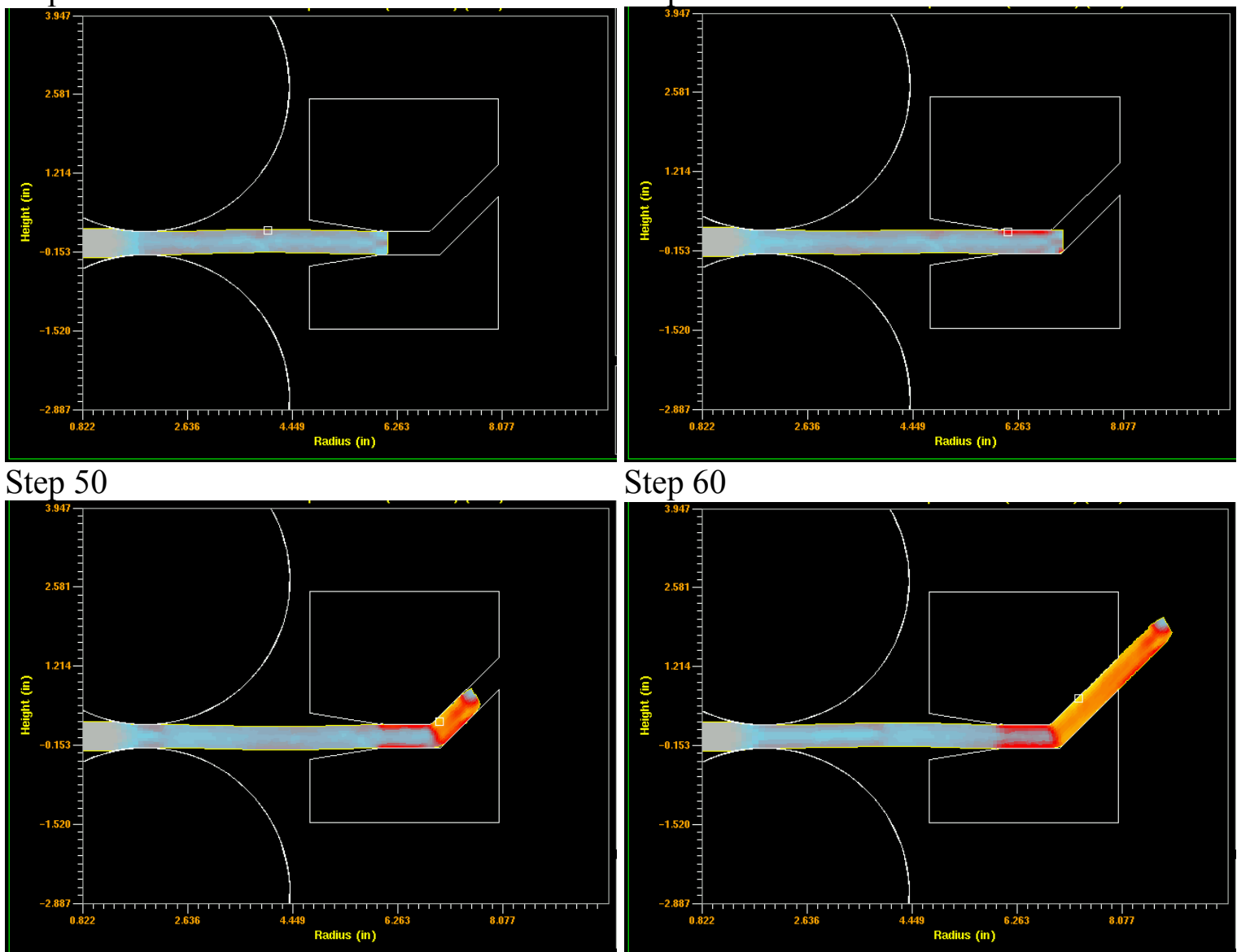

\section{Step 60}

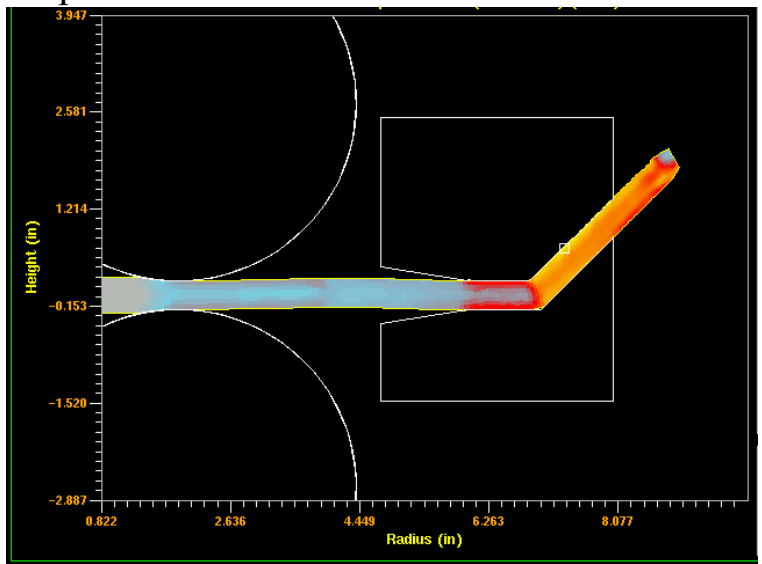

Step 70

Step 90

Figure 3.12: Simulation of rolling + ECAE/P + drawing as a model for a CSPD process 


\subsection{Prototypes of a CSPD machine}

\subsubsection{Rolling + Drawing}

For the feasibility study of the proposed severe continuous plastic deformation process, the research team examined the equipment available at ORNL and selected a rolling mill, shown

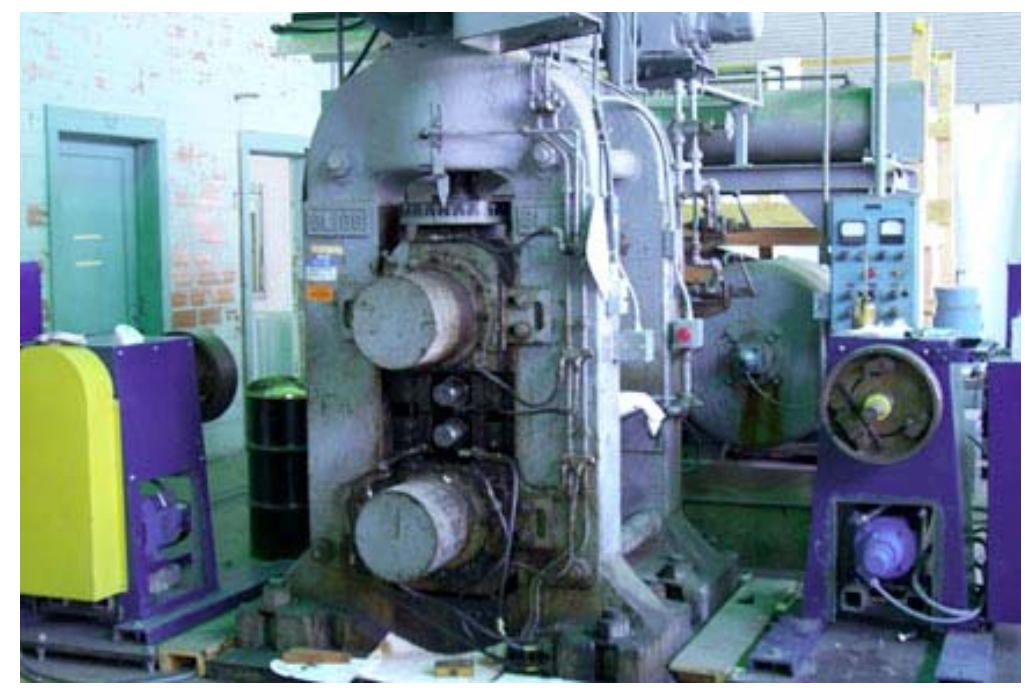

Figure 3.13: An 80 horsepower United Mill used to push metal bars during CSPD.

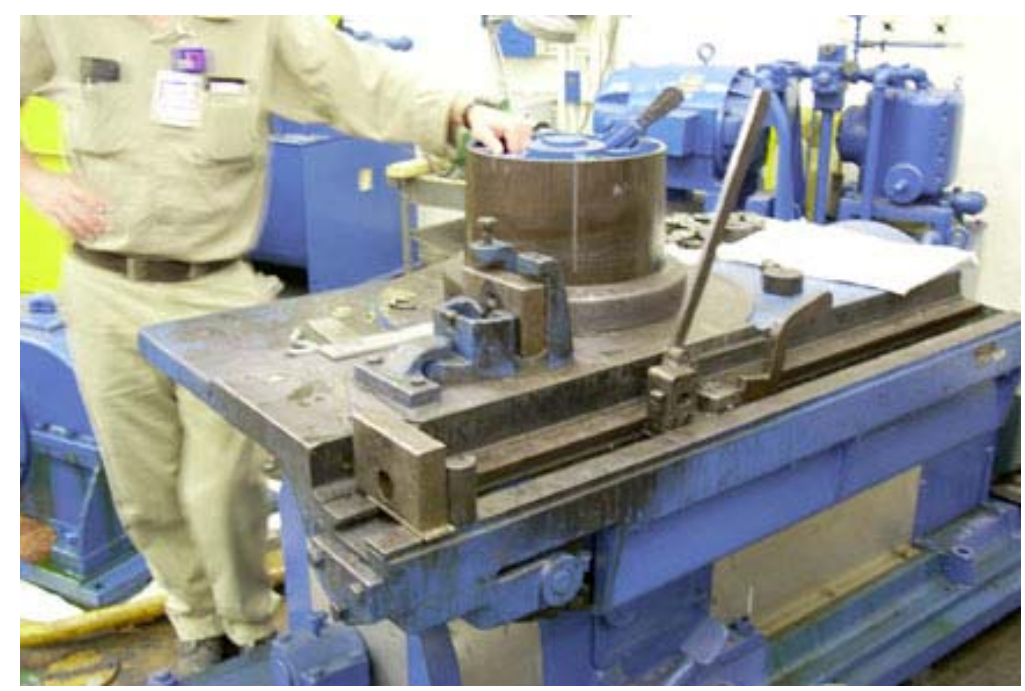

Figure 3.14: The draw bench used to pull the extruded bar during CSPD

in Figure 3.13, for pushing the aluminum bar, and a draw bench, shown in Figure 3.14, for pulling the extruded bar at the exit of the CSPD die. 
A 50,000 lb load cell was used for measuring the pushing force of the United Mill and the pulling force of the draw bench. Table 3.2 lists the forces measured using the load cell as a function of reduction during rolling operations. The pushing force of the United Mill increases with increasing reduction of the rolled materials. These results are understandable considering rolling force is higher for a large reduction of rolled material. The pushing force equals to the friction force, which is a component of the rolling force, is proportional to the rolling force. Table 3.2 also lists the measured pushing force after a $90^{\circ}$ rotation of the rolled materials. Since the materials were rolled before rotation, the materials were harder than they were rolled before. As a result, the measured force after a $90^{\circ}$ rotation was larger than that before a $90^{\circ}$ rotation.

Table 3.2: The measured pushing forces for the United mill as a function of reduction (\%)

\begin{tabular}{|c|c|c|c|c|c|c|}
\hline Reduction (\%) & 1 & 2 & 3 & 4 & 5 & 10 \\
\hline Force (lb) & 8,000 & 7,500 & 11,000 & 13,000 & 16,000 & 12,000 \\
\hline $\begin{array}{c}\text { Force (lb) after } 90^{\circ} \\
\text { rotation }\end{array}$ & 8,500 & 9,250 & 15,050 & 15,025 & & 30,050 \\
\hline
\end{tabular}

The force measured on the draw bench was $7850 \mathrm{lbs}$. Simulations carried at WSU indicated that the combination of the pushing and pulling forces are capable of processing billets with cross sections up to 1.25 -inch $(32-\mathrm{mm})$ square and channel angles from $120^{\circ}$ to $135^{\circ}$

Two equal-channel-angular extrusion dies were made: a $120^{\circ}$ die and a $135^{\circ}$ die. The internal channels were $1 / 2$ " square. Figure 3.15 shows part of the United Mill, draw bench, and a $135^{\circ}$ die. One end of the die was closely fit with the United Mill. The distance to the mill had to be as short as possible. The draw bench was located at the other end of the die. A specimen was pushed through the ECAE die using the United mill and was grabbed at the exit of the die using the draw bench.

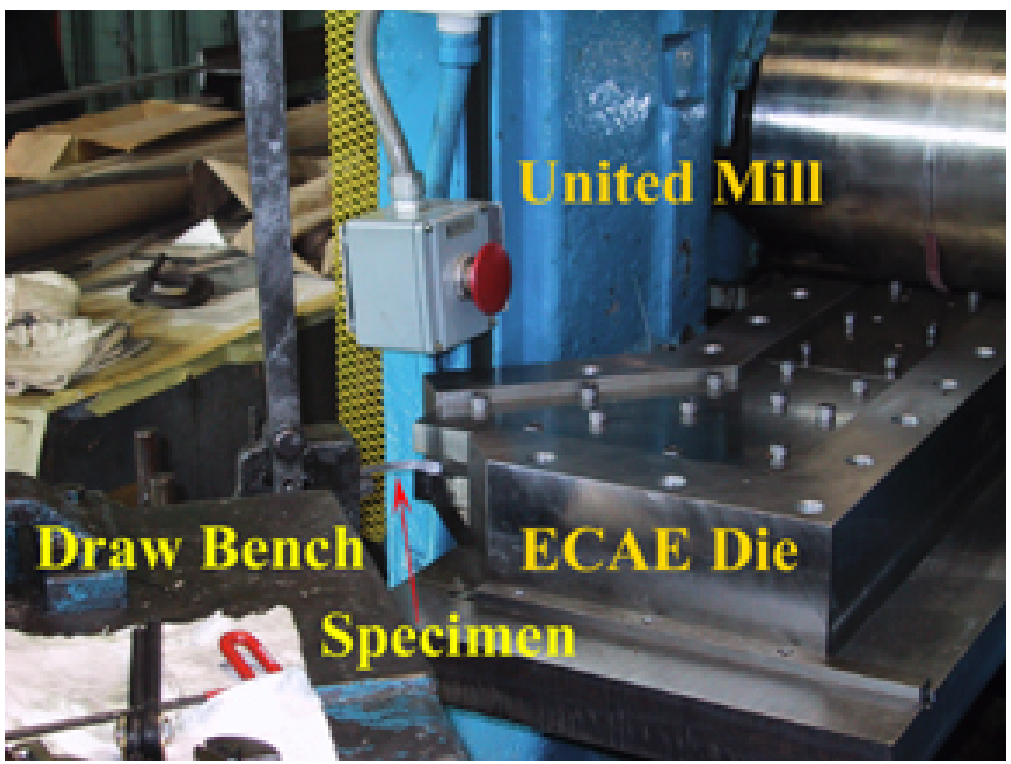

Figure 3.15: The setup of the United mill, the draw bench, and the $\mathrm{ECAE} / \mathrm{P}$ die for CSPD 

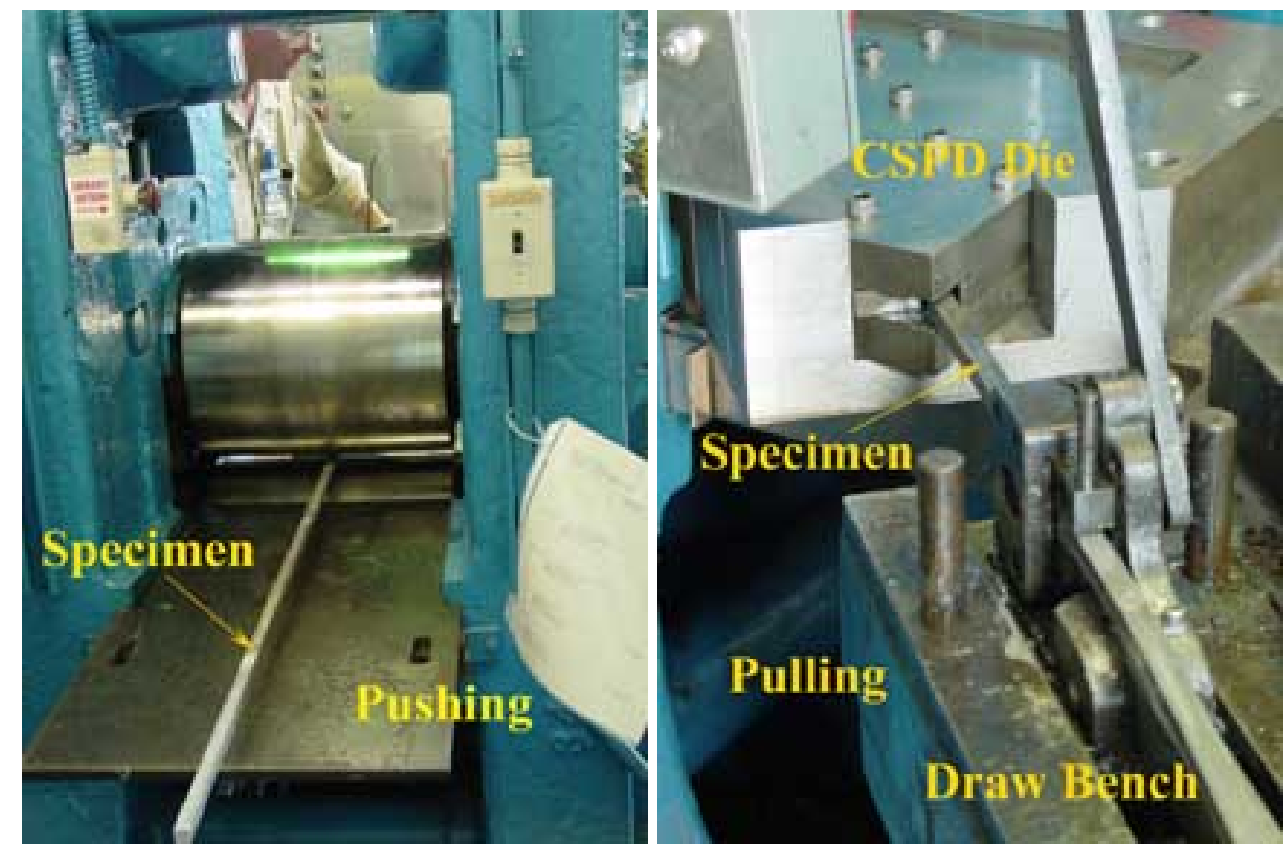

Figure 3.16: A long AA6061 specimen being pushed and pulled during CSPD. Three passes were made using the roll+draw setup

\section{(a) Testing of the Rolling + drawing CSPD Prototype}

The demonstration of the CSPD process was carried out at ORNL using the roll+draw setup. Aluminum alloy AA6061 samples (billets) 0.5 -inch $(12.5$-mm) square and 60-inches (1.5 $\mathrm{m})$ long were annealed to the $\mathrm{O}$ conditions. The first test was carried out using the $135^{\circ}$ die (true strain $\sim 0.5$ per pass). Figure 3.16 shows that the roll + draw setup is at operation. Three passes of the work-piece were successfully made. It demonstrated that CSPD is achievable.

Further testing was carried out to obtain more passes. Parameters tested included the type of lubricant, the surface finish of rolls, the heat treatment conditions of the work-piece, and the dimensions and the reduction of the work-piece as well. Under the best conditions, eight passes were successfully made. The $120^{\circ}$ die was also tested and we were able to get one pass of the work-piece.

\section{(b) Microstructure of AA 6061 after CSPD}

Microstructure of the specimens is shown in Figure 3.17. The un-extruded specimen ( 0 pass) contained larger grains at its center and smaller grains near its surface. The grain size at the center of the specimen was larger than 1-mm. Small grain formed at the surface of the specimen due to pre-rolling operations. With increasing passes, the center large grain region was reduced and the over all grain size was reduced as well. Still a few large grains existed in the center of the specimen after 3 passes. 


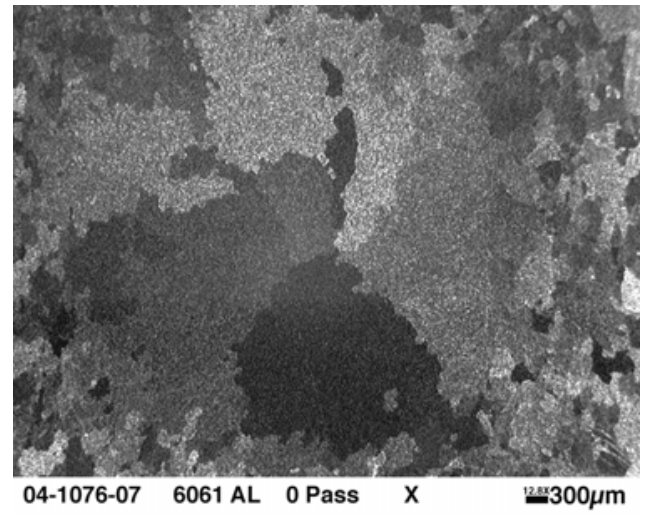

(a) 0 pass

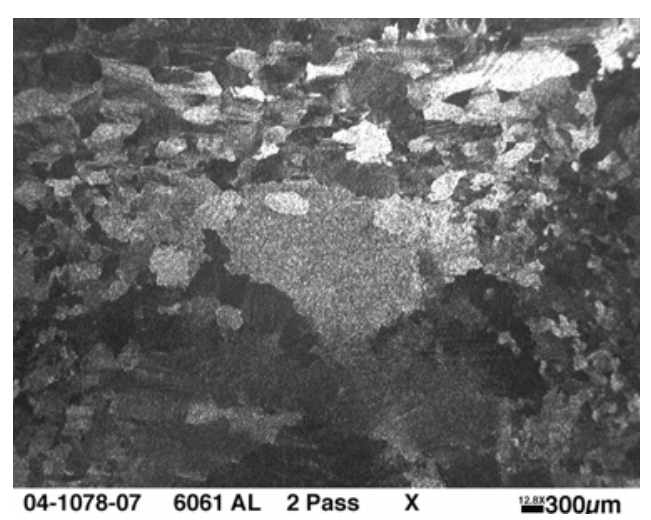

(c) 2 passes

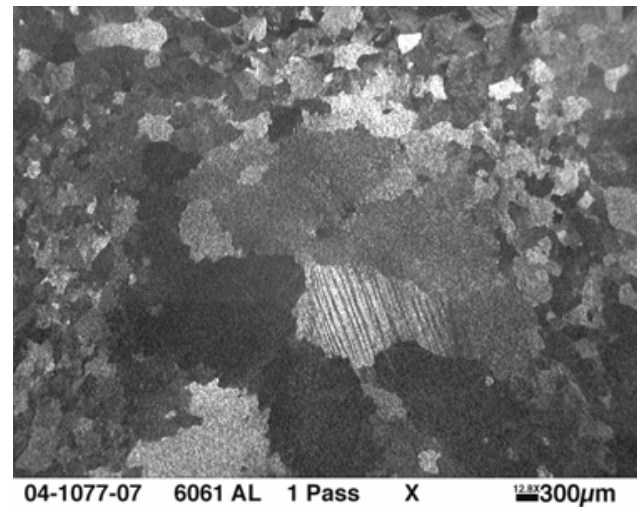

(b) 1 pass

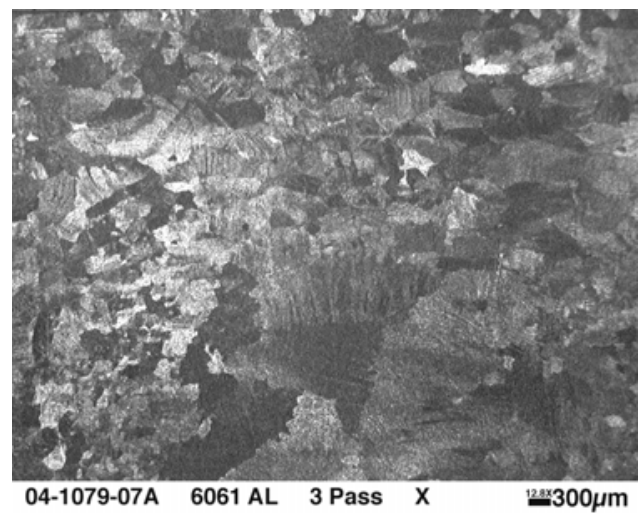

(d) 3 passes

Figure 3.17: the microstructure of AA6061 after 0 to 3 passes of CSPD

\section{(c) Factors Affecting the CSPD Using the Roll + Draw Setup}

(i) Positioning of the rolls with respect to the CSPD die: The positioning of the rolls is of vital importance for the CSPD process using the setup shown in Figure 3.16. A slight off position of the rolls with respect to the die resulted in the blemish of the surfaces of the specimen at the entrance of the CSPD die. As a result, huge resistance to the pushing of the specimen was developed at the entrance of the die. Often when the position of the rolls was not right, the specimens could not be pushed through the die. Under this situation, slippage occurred between the roll and the specimen surfaces and the pushing force became very small.

(ii) Die wear/material build up at the die surface: The grooves at the side of the inlet channel of the die walls tended to collect aluminum especially when the die side walls were blemished. This could happen when the die had been used for some time or when the specimen surfaces were blemished due to the unfavorable positioning of the rolls. During CSPD testing, a few lubricants were tried. Wax seemed to have the best results on retarding die wear and preventing material build up at the side walls of the die. Figure 3.18 illustrates the die inserts forming the side walls of the CSPD die and the blemished side surface of an aluminum 6061 bar due to the build up of materials at the groove of the die side walls. 
(iii) Synchronizing pushing and pulling: The pushing and pulling needs to be synchronized. The pushing force alone was not large enough to push the specimen through the die. Also the pushing force is limited to the contact area between the rolls and the specimen and the amount of reduction that will not lead to much increase of the specimen width. As a result, pushing using the rolls alone led to the slippage of the rolls on the specimen surface, deforming the specimen more under the rolls than in other regions. Since the specimen fitted closely to the internal dimension of the die channel, any increase in specimen dimension led to the difficulty in getting the specimen through the die. The pulling force from the draw bench alone was not large enough to pull the specimen out of the die too. Also the yield strength of the AA6061 is quite low. Too much pulling resulted in the necking of the specimen and sometimes the specimen failure. Ideally the rolling and drawing should be at same speed so that pushing and pulling could work together. It was one of the issues with this experimental setup because it was difficult to synchronize these two machines.

(iv) Continuous rolling: It is important to roll the specimen continuously without stopping. Ideally the pushing should be steady-state. In order for the pushing and pulling to act simultaneously, the specimen was designed such that it had a length of smaller cross-section at its front. The length of this smaller section was 2 " longer than the distance from the sharper corner of the CSPD channel to the point where the tip of the specimen was grabbed by the draw bench. However, the pushing using the rolls had to be stopped to allow the grabbing of the specimen tip using the draw bench. This presented a problem since the specimen at the section beneath the rolls deformed, causing increased width at that section. When this slightly larger section of the specimen went through the die, friction force increased. It was also one of the reasons for the material build up at the grooves of the side die walls shown in Figure 3.18 (a).

(v) Size effect: In order to have the maximum grain refinement during CSPD process, the die has to be totally filled. A lightly reduced size of the specimen makes the CSPD much easier but the grain refinement effect will be significantly reduced.

Based on numerous experimental trials, conditions under which multiple CSPD passes can be achieved using the ORNL rolls + draw setup have been determined. These conditions are listed below:

- Die dimensions: $0.515 \times 0.49$ in

- Specimen dimension: 0.496x0.498

- Reduction during rolling: $2 \%$ for the first pass

$1 \%$ of the smallest cross section for the second and the third passes

- Lubricant: Wax

Using these conditions, more than 100 feet of CSPD extruded aluminum 6061 bars were made. 


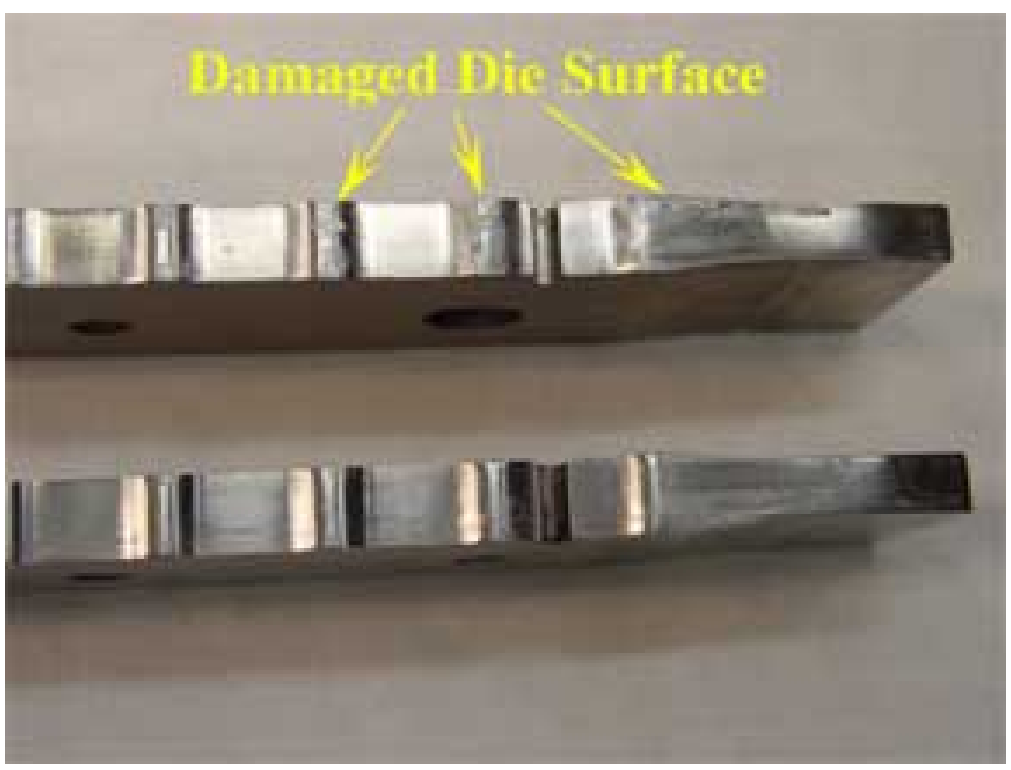

(a) The damaged surface of the inlet die channel

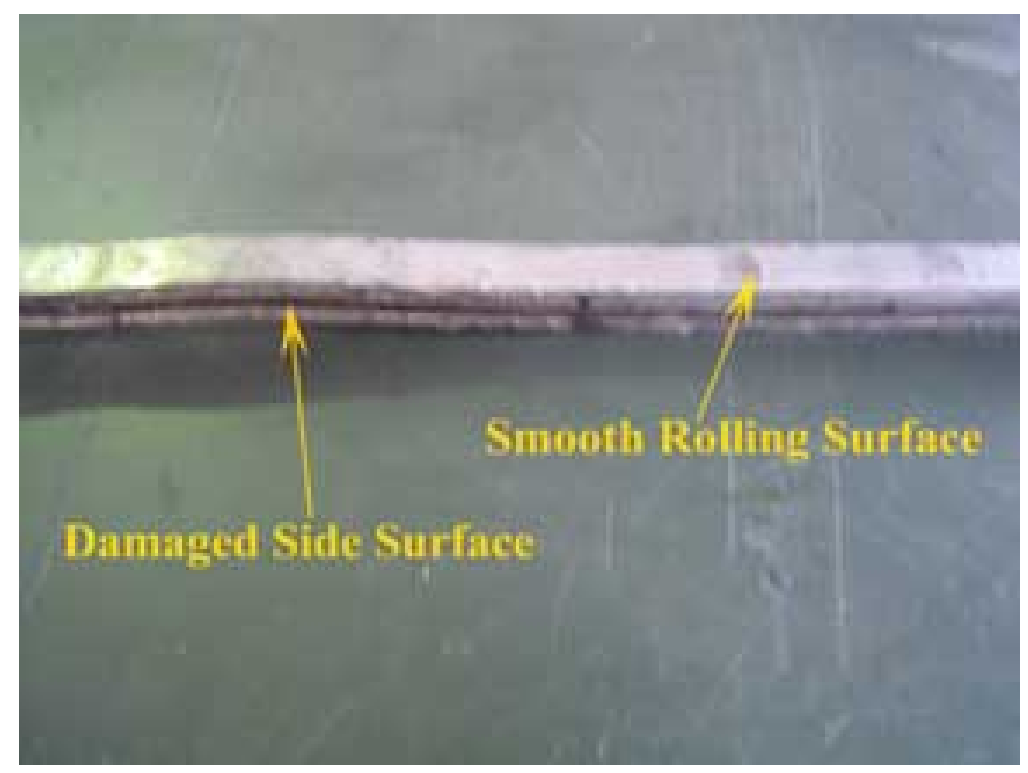

(b) The damaged Specimen

Figure 3.18: Die surface damage, material build up, and the resultant blemished specimen surface 


\subsubsection{Multiple Roller CSPD Machine}

One of the problems encountered with the roll + draw setup was the low friction coefficient between the rolls and the aluminum specimen surface. In order to increase the pushing force for the CSPD process, a large reduction of the extruded material was required. The large reduction during rolling led to increased width of the specimen and increased difficulties to push the specimen going through the CSPD die. The idea for the design of a new CSPD die was to push a 12.5 -mm (0.5-inch) cross section specimen by knurled rolls.

Two roll assemblies were built with four knurled rolls in each assembly, shown in Figure 3.19. The knurled rolls were assembled with a distance of $80-\mathrm{mm}$ (3.125-inches) between rollshaft axes. The assembly consisted of 19 -mm $(0.75$-inch) thick top and bottom plates, between these two plates the rolls were press fitted along with bearings. The two plates were also

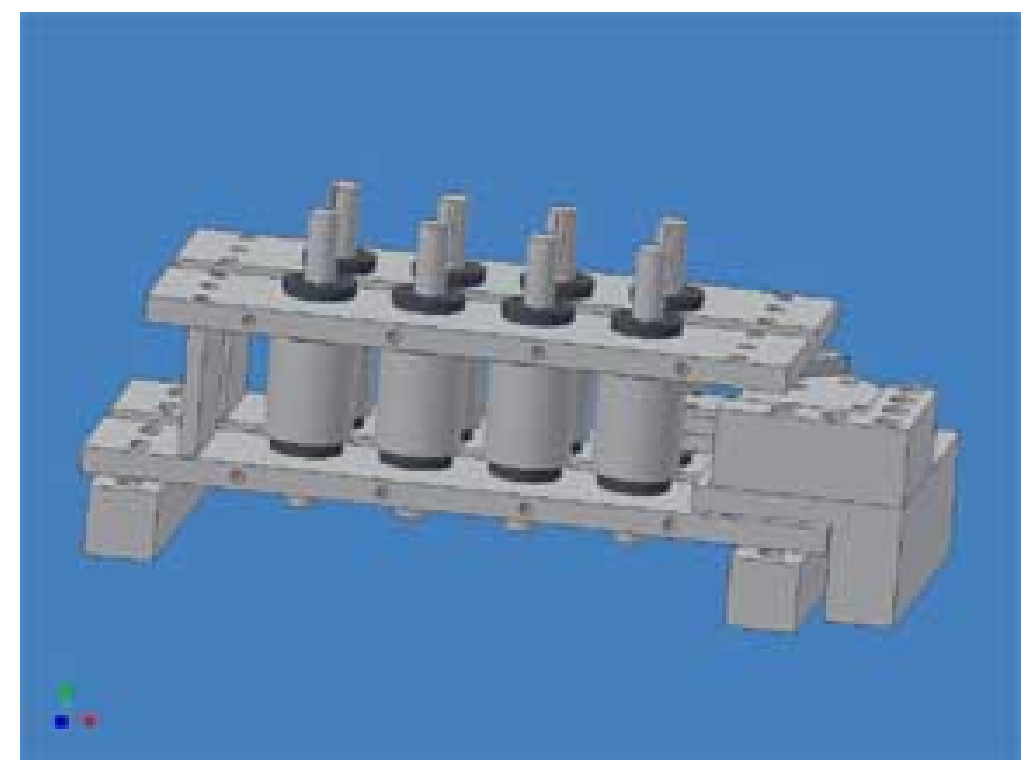

Figure 3.19: The knurled roll assemblies designed to push material during CSPD

connected with 0.5 -inch thick plate at one end. A miter gear was key-fitted on each roll-shaft above the top plate.

Figure 3.20 shows a general view of the new CSPD setup. Four rolls on each side were driven by a shaft having miter gears key fitted on to it. The two shafts transmitted power from the gear reducer shaft to the rolls by miter gears. Gear reducer had a speed reduction of 177:1 with 2,360 N-m (20,900 lb-in) output torque. Variable speed, reversible, 3 phase - 2HP motor with $1740 \mathrm{rpm}$ was used to drive the gear reducer.

The die used in the process had 2 inserts which produced 0.5 -inch square cross section channel with $135^{\circ}$ angle. Length of the inlet channel was $88-\mathrm{mm}$ (3.45-inch) of which $41-\mathrm{mm}$ (1.6-inch) was with out bumps and the rest had bumps to reduce friction effects. Outlet channel was $107-\mathrm{mm}$ (4.2-inch) of which only $32-\mathrm{mm}$ (1.25-inch) was land length and the rest of the length had 3.2-mm (0.127-inch) clearance on each side. Die was mounted very close to the rollsets with inserts sliding between the rolls. 


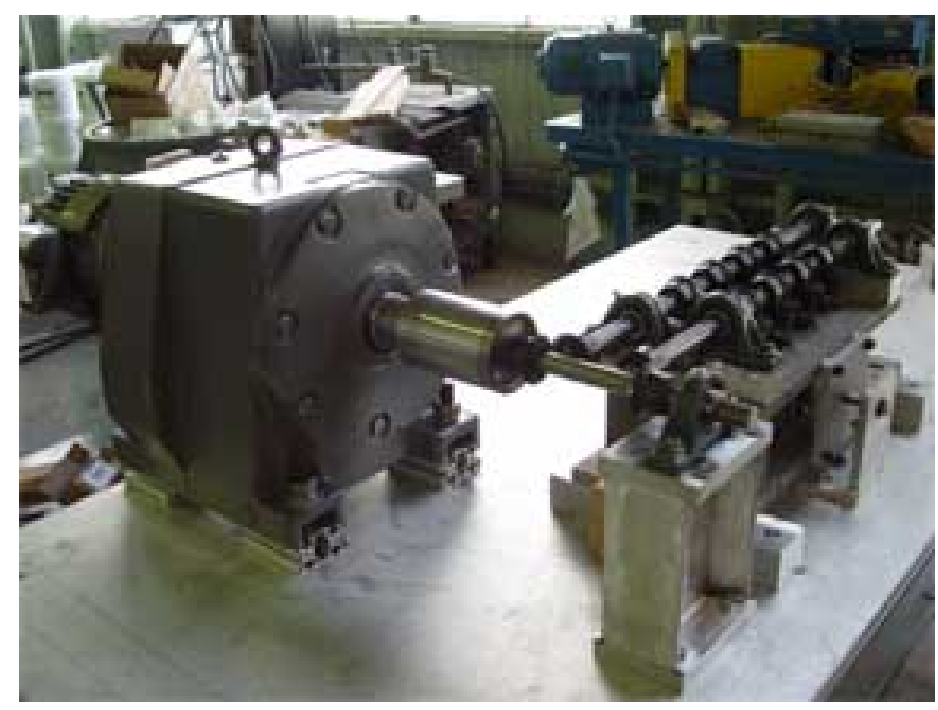

Figure 3.20: The new ORNL-CSPD set up

One set of rolls was adjustable which moves on the supporting block. The material is fed on a guide plate. Initial attempts are to push the annealed material through the lubricated $135^{\circ}$ die. A few tries were made using the new machine and several problems were encountered. The most significant of which were:

(i) The die assembly was mounted close to the rolls. During the first trial, the sample entered the die and was partly extruded. But sufficient force could not be exerted to completely extrude the work-piece which then got stuck in the die. The entire machine had to be disassembled to extract the sample. The die mounting system was redesigned to avoid this problem

(ii) Though the knurled rolls provided enough force to push the sample into the die, shafts and bearings used were under-designed. Excessive elastic displacement of the shafts caused the gears to disengage

In order to improve on this design, a commercial rolling machine manufacturer was contacted. The company initially expressed interest in becoming part of the development team for the CSPD machine, but later backed out. The prototype was then transferred to Wright State University for possible redesign. All the problems associated with this design could not be resolved within the time frame of the project.

\subsection{Patent}

During the proposal writing stage for this project, a teaming agreement was made among the three principal partners - Wright State University, Intercontinental Manufacturing, and Oak Ridge National Laboratory. A preliminary record of the invention of a CSPD machine was also made. Soon after the demonstration of concept with the Roll + Draw prototype was done at ORNL, the decision was made to file for a patent. A US patent titled "Continuous Severe Plastic Deformation (CSPD) Process," by P. Chaudhury, R. Srinivasan, and S. Viswanathan, United 
States Patent Number 6,895,795, was awarded on May 24, 2005. A copy of the patent is being submitted to DOE along with this report.

\subsection{Summary of the CSPD process development}

Analytical and computer simulation models investigated at Wright State University indicated that the equal channel angular extrusion/pressing (ECAE/P) process could be scaled up to a continuous severe plastic deformation process in which long work-pieces could be processed. The process was successfully demonstrated with a prototype built with existing metal forming equipment at ORNL. A second prototype was designed and built at ORNL. However, due to limited resources, this prototype was not fully developed. A US patent was awarded in May 2005 for the CSPD process to the principal technical participants in the team. 


\section{Chapter 4 Scaling up of ECAE/P and Forging of SPD Aluminum}

\subsection{Background}

Severe plastic deformation (SPD) has emerged as a promising technique for creating ultra fine grained (UFG) metals and alloys, with grain sizes of a micrometer or less. Several of these techniques, such as equal channel angular extrusion/pressing (ECAE/P) [40], friction stir processing (FSP) [6], and multiaxial compression (MAC) [41] can be used to produce bulk UFG material, which can potentially be used as forging stock. During SPD, the stored energy of deformation is the driving force for the refinement of the microstructure, which typically occurs in single phase metals at accumulated strains of 6 or greater $[42,43]$. However, in a two phase alloy, the presence of hard second phase particles changes the local dislocation density distribution, due to strain incompatibility between the matrix and particles. This may lead to local lattice rotations and the formation of medium to high angle grain boundaries at a lower bulk strain [44].

It has been well established that SPD results in the refinement of the microstructure to grain sizes of the order of $1-\mu \mathrm{m}$ or less [45]. Typically, materials with grain sizes of the order of $10-\mu \mathrm{m}$ or less have high strain rate sensitivity at elevated temperatures and slow strain rates $(\sim$ $\left.10^{-3} \mathrm{~s}^{-1}\right)$. Associated with the high strain rate sensitivity is superplastic behavior, which is characterized by very large tensile elongations [46]. If the grain size is reduced further, high strain rate sensitivity, and hence superplasticity, is observed at lower temperatures and higher strain rates. This high strain superplasticity (HSR SP) has been demonstrated in a variety of aluminum alloys [47,48]. Greater ductility at lower temperatures and faster deformation rates translates to several potential benefits of using SPD processed metals as stock materials for subsequent deformation processing. These benefits include lower press loads, lower forging temperatures, increased die life, increase material yield, nearer to net shape forging, and smaller press sizes; all of which have economic significance. However, there has been only a limited amount of work done in the area of scaling up of SPD processes to produce stock sizes that can be used in commercial forming processes. Work by Semiatin and coworkers [49], Valiev and coworkers [48], Horita, Langdon and coworkers [50], and many others have generally been limited to workpieces in the cross section size range of 10 to $50-\mathrm{mm}$. Furthermore, much of the published literature on the topic of severe plastic deformation has dealt with the development of SPD processes themselves, or with a scientific study of the properties of the materials that the processes can produce. (The reader is directed to the website listed in ref. 13 for a more complete listing of work on SPD.)

This chapter reports the results of the first study to verify some of the benefits of SPD processed UFG materials by scaling up the ECAE/P process to large sizes, and then using the processed material to produce industrial size forgings. 


\subsection{Scale Up of the Equal Channel Angular Extrusion/Pressing (ECAE/P) Process}

At the start of this project, the largest ECAE/P facility was at the US Air Force Research Laboratory (AFRL), Wright Patterson AFB, Ohio, where samples as large as 50-mm (2-inch) square cross section could be processed. Most of the scientific information indicating SPD can lead to improved formability was based on samples $10-\mathrm{mm}$ diameter or smaller. One of the first steps taken in this project to demonstrate practical application of SPD material was to scale up the ECAE/P process to produce larger sample sizes. This work was initiated at Intercontinental Manufacturing ${ }^{1}$ (IMCO) under the direction of Dr. Prabir Chaudhury.

ECAE/P dies for the production of $100-\mathrm{mm}$ (4-inch) cross section samples were designed and built. A segmented die concept was used. In order to avoid problems associated with a $90^{\circ}$ die, this die was fabricated with a $105^{\circ}$ angle between the two channels. Figure 4.1 (a) and (b) shows a solid model of the die, and Figure 4.1(c) shows the die mounted on a 2000-ton hydraulic press. The scale up to the larger size was primarily to provide material that could be used to make large size forgings.

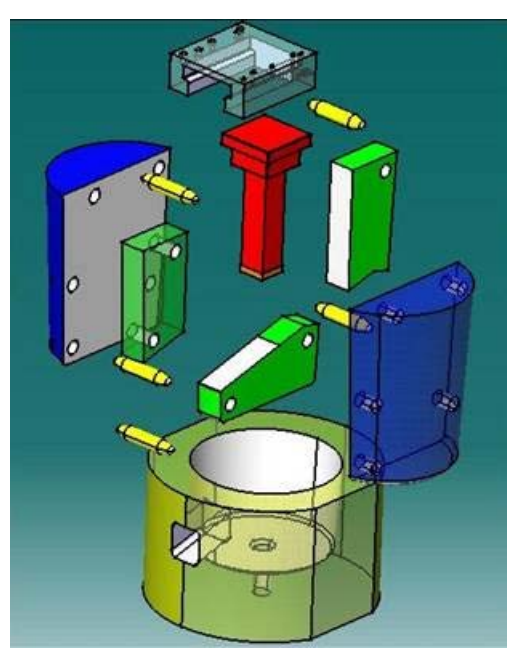

(a)

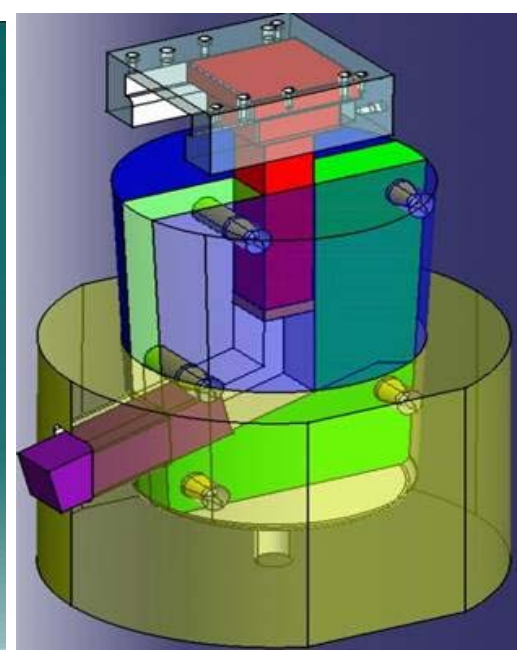

(b)

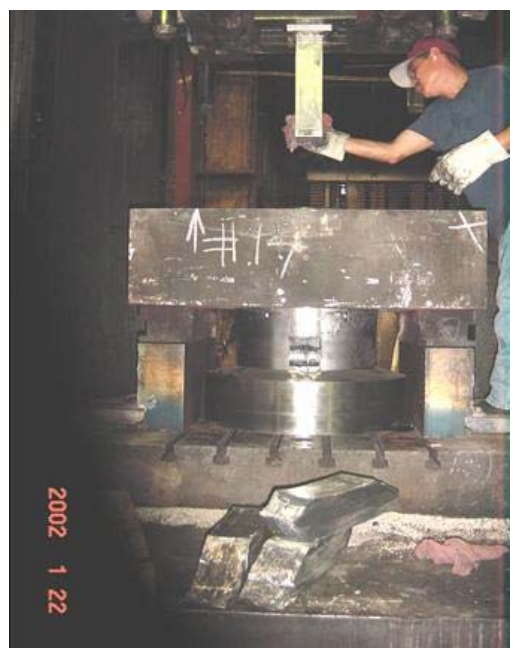

(c)

Figure 4.1: Large size ECAE/P processing dies; (a) and (b) Solid models and (c) die mounted on a forging press

\subsection{Other ECAE/P Facilities}

In addition to the large size ECAE/P dies built for the project at IMCO, two other smaller facilities were also used in this project. A $12.5-\mathrm{mm}(0.5$-inch) square cross section die was built at Wright State University for producing samples that could be used for compression testing and other small scale property evaluations. Thanks to Dr. Lee Semiatin, a 50-mm (2-inch) square cross section facility available at the US Air Force Research Laboratory (AFRL) was used to produce intermediate size samples that were also used for forging studies.

\footnotetext{
${ }^{1}$ The Intercontinental Manufacturing (IMCO) facility at Garland TX is now a part of General Dynamics - Ordnance and Tactical Systems.
} 
Table 4.1: ECAE/P processing conditions

\begin{tabular}{|l|l|l|l|}
\hline Size & Angle & Number of passes & Accumulated strain \\
\hline $12.5 \mathrm{~mm}$ square $\times 64 \mathrm{~mm}$ & $120^{\circ}$ & 6 passes $\left(\right.$ Route $\left.4 \mathrm{~B}_{\mathrm{c}}+2 \mathrm{C}\right)$ & $\sim 4$ \\
\hline $50 \mathrm{~mm}$ square $\times 150 \mathrm{~mm} *$ & $90^{\circ}$ & 3 and $4\left(\right.$ Route $\left.\mathrm{B}_{\mathrm{c}}\right)$ & $\sim 3.2$ and 4 \\
\hline $100 \mathrm{~mm}$ square $\times 380 \mathrm{~mm}$ & $105^{\circ}$ & 4 (Route $\left.\mathrm{B}_{\mathrm{c}}\right)$ & $\sim 3.5$ \\
\hline
\end{tabular}

*thanks to Dr. Lee Semiatin, US Air Force Research Laboratory, Wright-Patterson AFB, Ohio 45435 USA

\subsection{Materials}

\subsubsection{Starting Material}

Square cross section bars of commercially available AA 6061-T6 of three sizes, nominally $12.5-\mathrm{mm}, 50-\mathrm{mm}$, and $100-\mathrm{mm}$, were annealed to the $\mathrm{O}$ condition by heating to $500^{\circ} \mathrm{C}$ for 1 hour followed by slow cooling. Figure 4.2 is a typical microstructure, showing precipitates in the size range of 1 to $5-\mu \mathrm{m}$. The starting structure of aluminum matrix had grains in the size range of 100 to $800-\mu \mathrm{m}$. Samples were processed at room temperature by ECAE/P to strains between 3.2 and 4 using three ECAE/P facilities at three locations - IMCO, Wright State University and AFRL, as summarized in Table 4.1. Route $\mathrm{B}_{\mathrm{C}}\left(90^{\circ}\right.$ rotation in the same direction between passes) was mainly used at all locations.

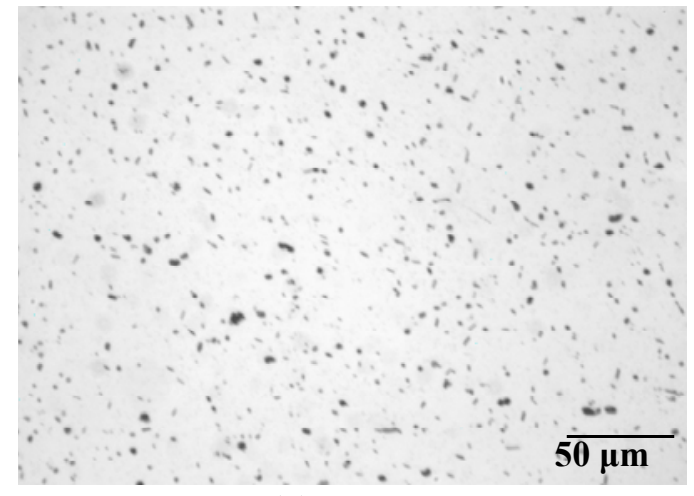

(a)

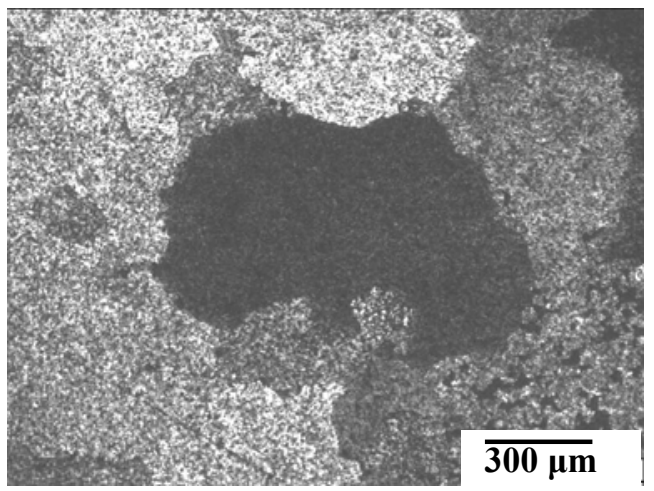

(b)

Figure 4.2: Microstructure of AA-6061-O (a) Precipitate distribution, (b) Grain size

\subsubsection{Evolution of microstructure during ECAE/P}

Figure 4.3 compares the relative sizes of the three sizes of stock materials processed. The $100-\mathrm{mm}$ cross section billet represents a scale up of 64 times on the cross section from the 12.5$\mathrm{mm}$ lab scale ECAE/P. The microstructures of the billets were examined by both optical microscopy and transmission electron microscopy. 


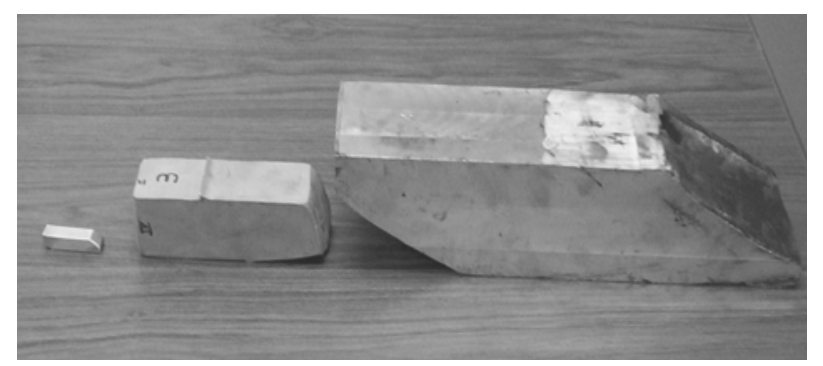

Figure 4.3: Relative sizes of the $12.5 \mathrm{~mm}, 50 \mathrm{~mm}$ and $100 \mathrm{~mm}$ cross section ECAE/P billets.

Figure 4.4 and 4.5 show the evolution of the microstructure in samples processed at the Wright State University facility. This is typical of all the material that was processed. After the first pass, the grains can be seen to have been sheared on the $\mathrm{Z}$ plane (Figure 4.4). Since the sample was rotated $90^{\circ}$ after the first pass, the microstructure after the second pass (Figure 4.5) shows the grains have sheared in both the $\mathrm{Z}$ plane (the shearing plane for the $2^{\text {nd }}$ pass) and the $\mathrm{Y}$ plane (the shearing plane for the $1^{\text {st }}$ pass). In both Figure 4.4 and 4.5 , the grains remain equiaxed on the X plane. After two passes, the microstructure is not resolvable under optical microscopy.
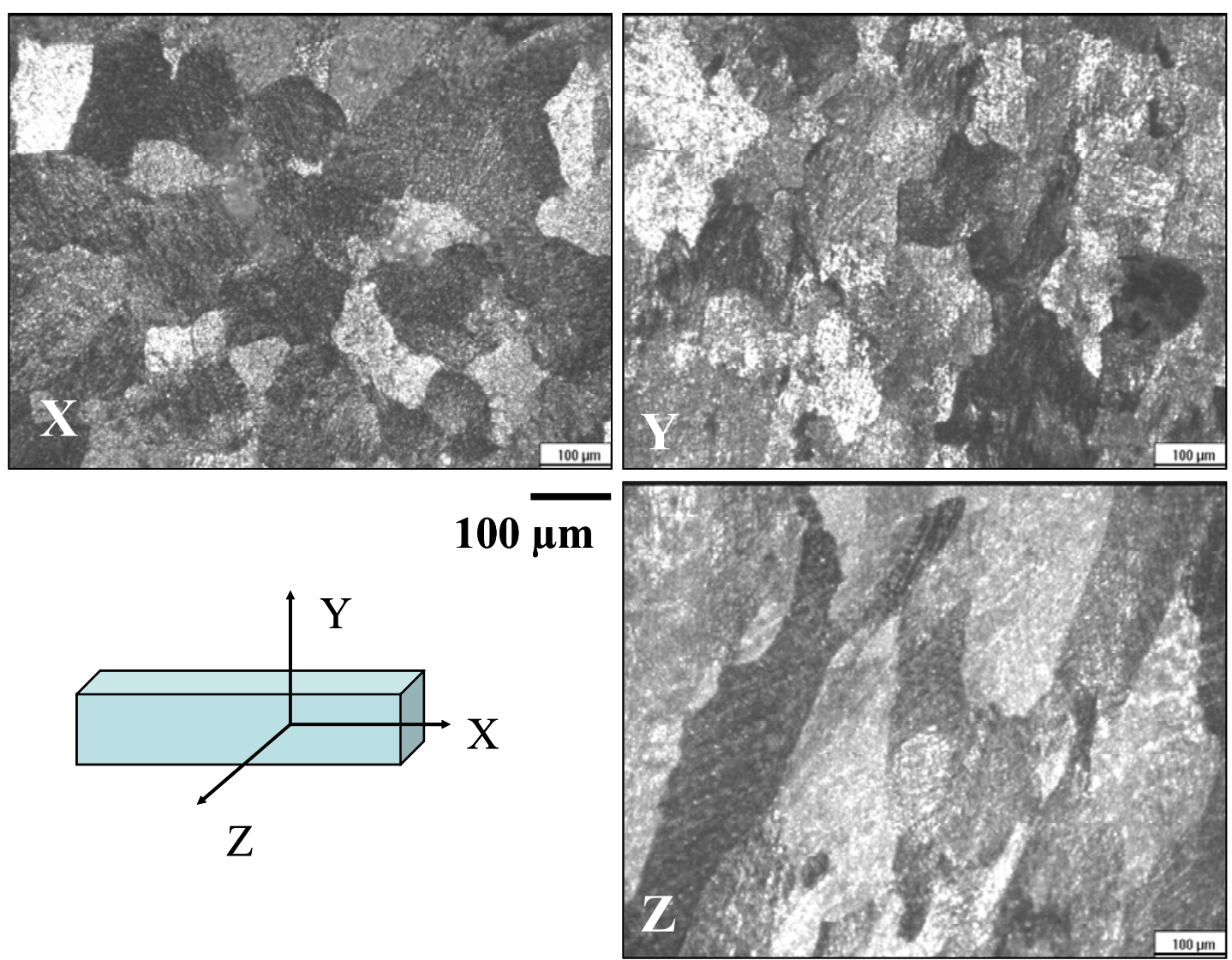

Figure 4.4: Microstructure of an AA-6061-O sample after one pass through a $120^{\circ}$ ECAE/P die 

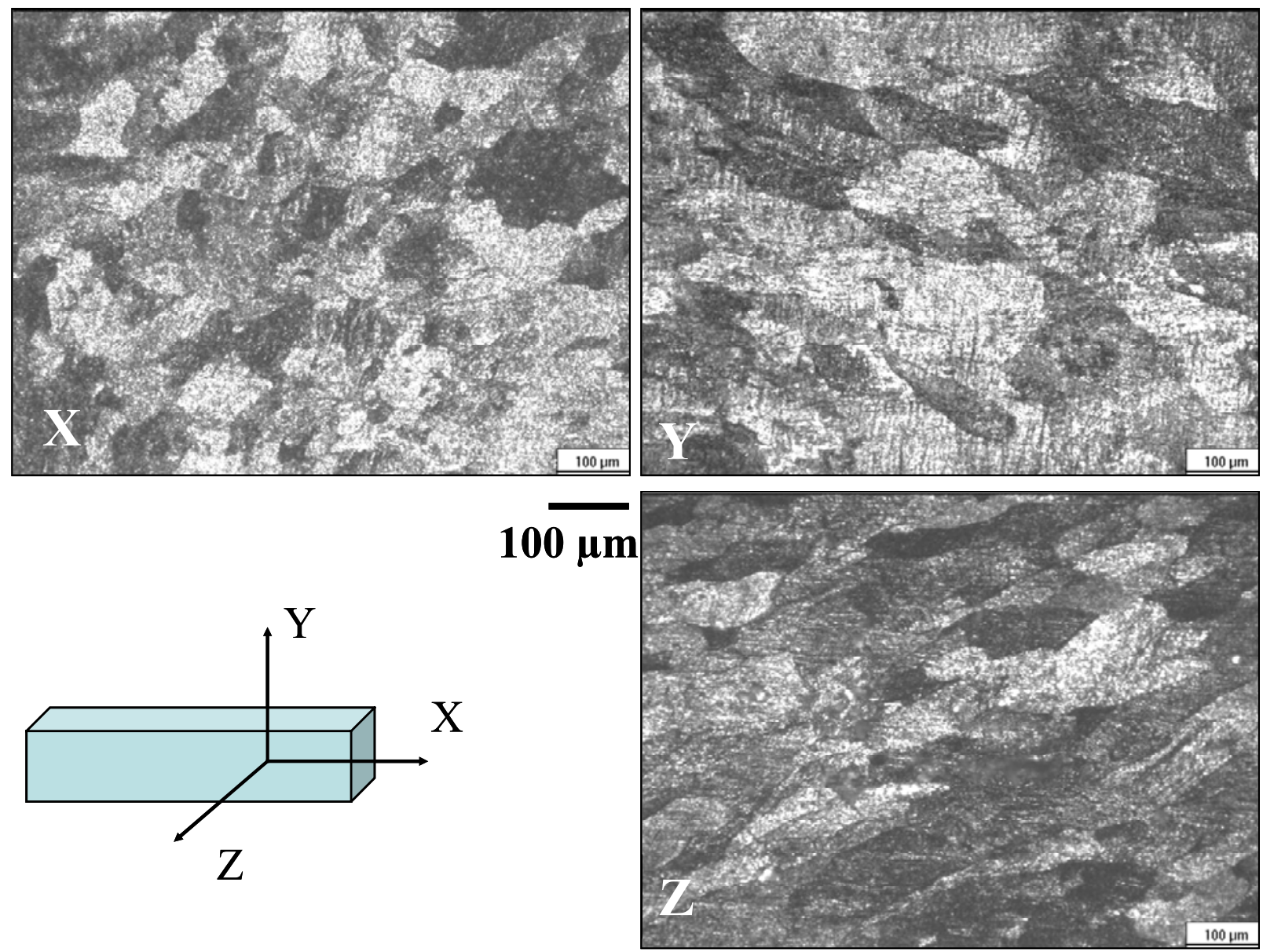

Figure 4.5: Microstructure of an AA-6061-O sample after two passes through a $120^{\circ}$ ECAE/P die

Figure 4.6 shows TEM micrographs from samples processed at all three facilities. After an accumulated strain $>3.2$, there is a considerable refinement of the microstructure. All the TEM micrographs show that the microstructure consists of grains and subgrains with both high and low angle boundaries. SAD diffraction patterns, especially for the 100-mm billet, show a spotty ring pattern indicating random orientation of the grains. A 1- $\mu$ m marker is shown on all figures.
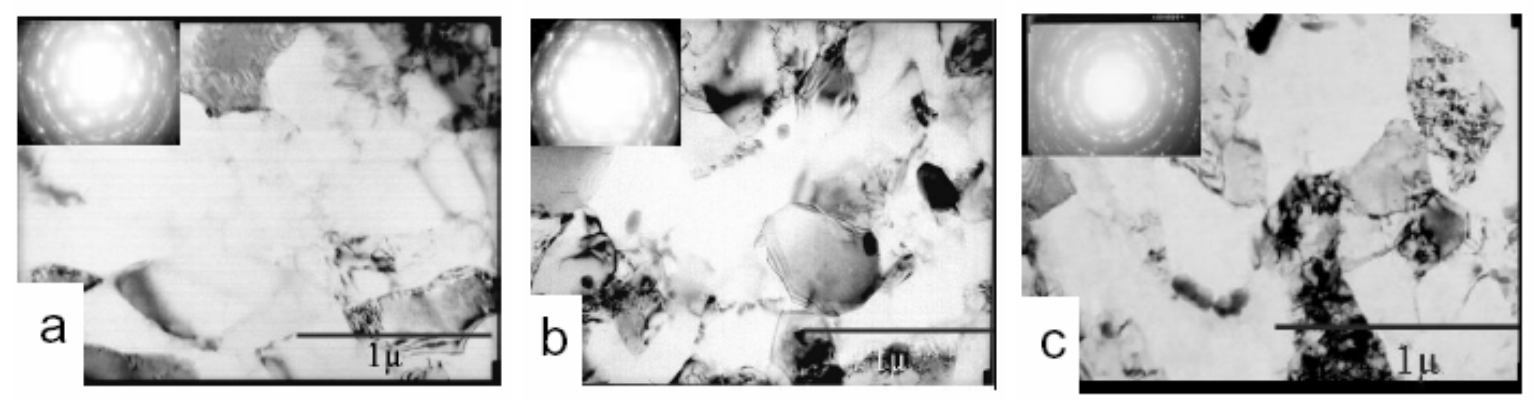

Figure 4.6: TEM of (a) $12.5 \mathrm{~mm}$, (b) $50 \mathrm{~mm}$, and (c) $100 \mathrm{~mm}$ cross section ECAE/P billets after strains of $4,3.2$, and 3.5 respectively 


\subsubsection{Mechanical Property Changes due to SPD}

The mechanical properties of the ECAE/P processed samples were evaluated using microhardness and tensile tests. For comparison, samples prepared by two other SPD processes, multi-axial compression/forging (MAC/F) and accumulative roll bonding (ARB) were also tested using these techniques [51,52]. Figures 4.7-4.10 show the results of these mechanical property evaluations.

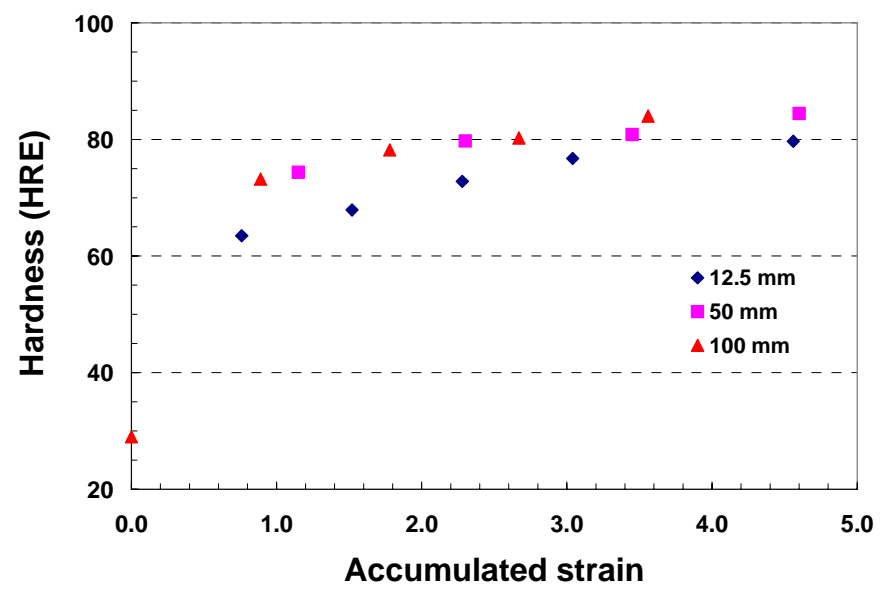

Figure 4.7: Hardness increase as a function of accumulated strain for three sizes of billets

Figure 4.7 shows the change in hardness on the cross section of the billets of different sizes with increasing number of passes. As can be seen, the change in hardness with accumulated strain follows the same trend with scale up in the billet size from 12.5-mm to 100$\mathrm{mm}$.

Figure 4.8 shows a comparison of the evolution of hardness during SPD by different techniques, including ECAE/P. It is evident from this figure that the changes in hardness are relatively independent of SPD deformation process.

Figure 4.9 shows the evolution of strength and ductility at room temperature as a function of accumulated strain by different SPD processes. Again, irrespective of the SPD technique used, there is an increase in the yield strength and a decrease in ductility with accumulated strain, a result that is expected of any cold working process.

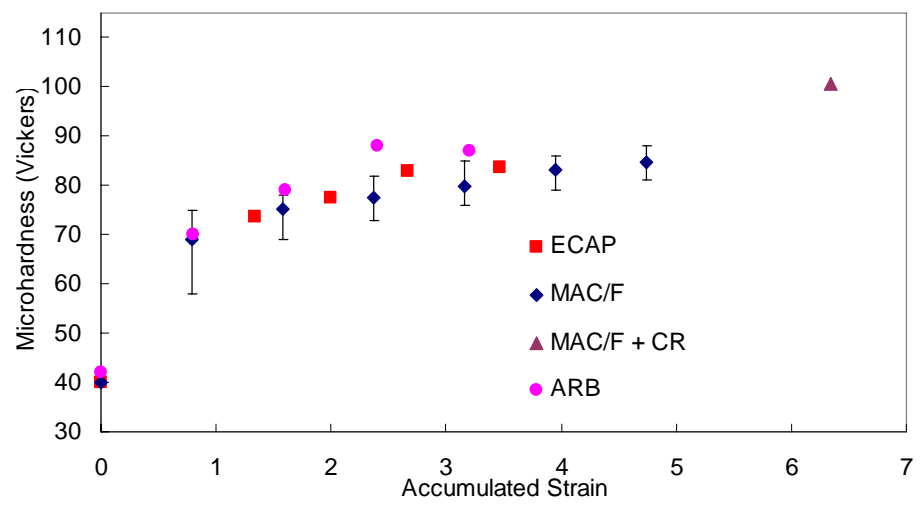

Figure 4.8: Evolution of micro-hardness as a function of accumulated strain by different SPD processing techniques 


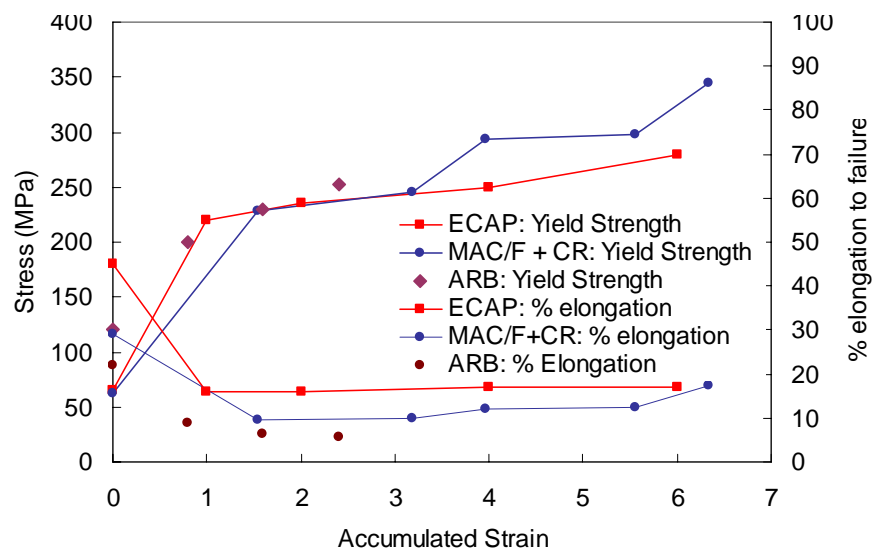

Figure 4.9: Evolution of strength and ductility as a function of accumulated strain by different SPD processing techniques

Since the objective of this phase of the project was to evaluate the hot forgeability of SPD processed material, hot tensile tests were conducted using samples of MAC/F + cold rolled material that had been deformed to a strain in the same range as that obtained by ECAE/P. Both velocity change and constant deformation rate tests were conducted on flat tensile samples at different temperatures in the range of $250^{\circ}$ to $400^{\circ} \mathrm{C}$. These results are summarized in Figure

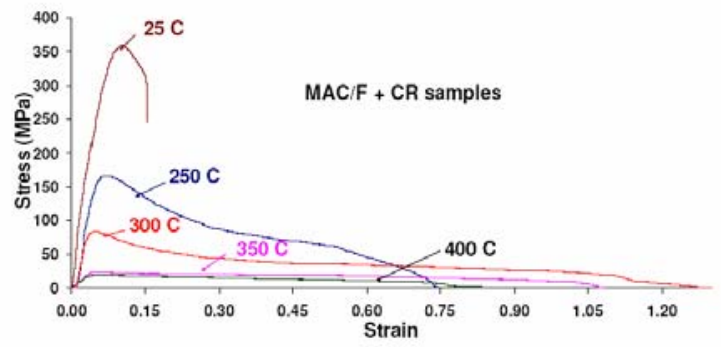

(a)

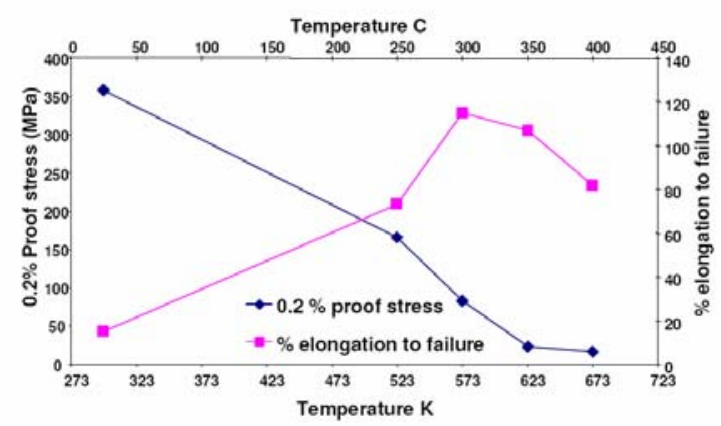

(c)

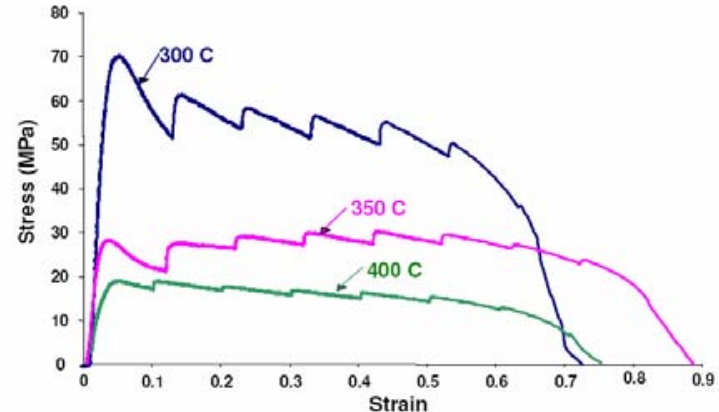

(b)

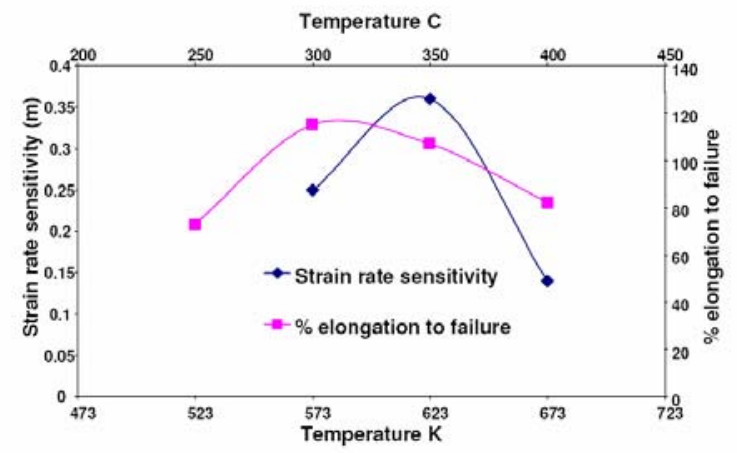

(d)

Figure 4.10: Hot deformation behavior of MAC/F+CR samples. (a) Tensile flow curves at different temperatures (b) Cross-head velocity change tests (c) Yield strength and elongation variations with temperature, and (d) Strain rate sensitivity and elongation variation with temperature 


\subsection{Details can be found in reference [52].}

The tensile flow curves show that as temperature is increased there is a continuous decrease in the yield strength of the SPD processed material. The elongation to failure, however, increases up to $300^{\circ} \mathrm{C}$, but then drops off at $350^{\circ}$ and $400^{\circ} \mathrm{C}$. The strain rate sensitivity increases as temperature is increased from $300^{\circ} \mathrm{C}$ to $350^{\circ} \mathrm{C}$, but then falls off at $400^{\circ} \mathrm{C}$. These results show that there appears to be a peak in both the strain rate sensitivity and elongation to failure in the temperature range of $300^{\circ}$ to $350^{\circ} \mathrm{C}$, indicating that the SPD processed material is most formable in this temperature regime. The forging studies discussed below bear out this prediction.

\subsection{Forging Studies}

Forging studies were conducted both at IMCO, during the first half of the project, and then at Queen City Forging Co., Cincinnati OH (QC Forge) during the latter par of the project. The studies at IMCO were done to evaluate the forgeability of SPD processed material and to estimate the energy savings that would be obtained if SPD processed material was used as stock material in secondary forming operations. Studies at QC Forge were primarily to make samples that were used for evaluating fatigue properties after forging.

\subsubsection{Forging Studies at IMCO}

Figure 4.11 shows solid models of the two forgings made with the $50-\mathrm{mm}$ cross section ECAE/P material (processed at AFRL). The cargo door latch is a relatively simple shape that can be forged in one hit. In addition to conventional forging stock and the ECAE/P material, this part was also made with a cast fine grain AA-6061 with a starting grain size of $\sim 100-\mu \mathrm{m}$. Figure

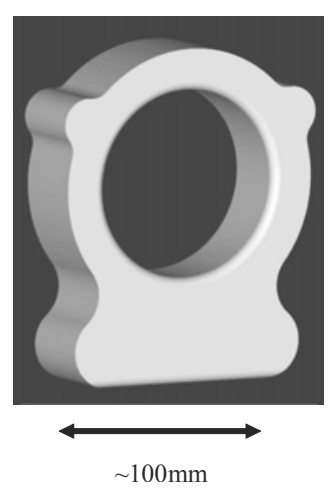

(a)

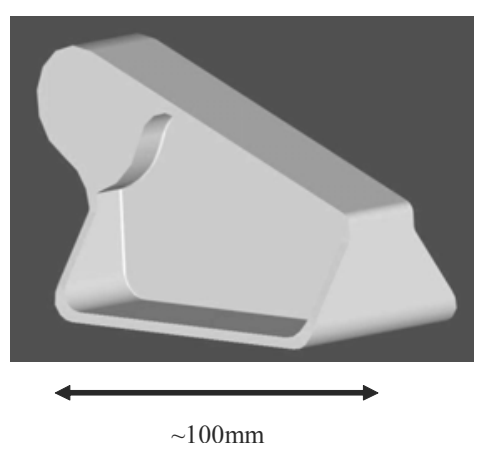

(b)

Figure 4.11: Examples of parts forged in this study (a) Cargo door latch (b) Landing gear door bracket

4.12 shows examples of forgings made with the different materials. This part was successfully forged with the ECAE/P material (Figure 4.12 (a)) starting a billet temperature of $315^{\circ} \mathrm{C}$, which is about $155^{\circ} \mathrm{C}$ lower than the conventional $470^{\circ} \mathrm{C}$ billet temperature. Since this forging was successful, the next forging was done with a smaller starting billet size equal to $85 \%$ of the size and a billet temperature $100^{\circ} \mathrm{C}$ less than conventional forging temperature. Again, the part was successfully forged with the ECAE/P material (Figure 4.12 (b)). In comparison, neither the conventional extruded stock nor the fine grain cast stock could be forged below $440^{\circ} \mathrm{C}$ (Figures 


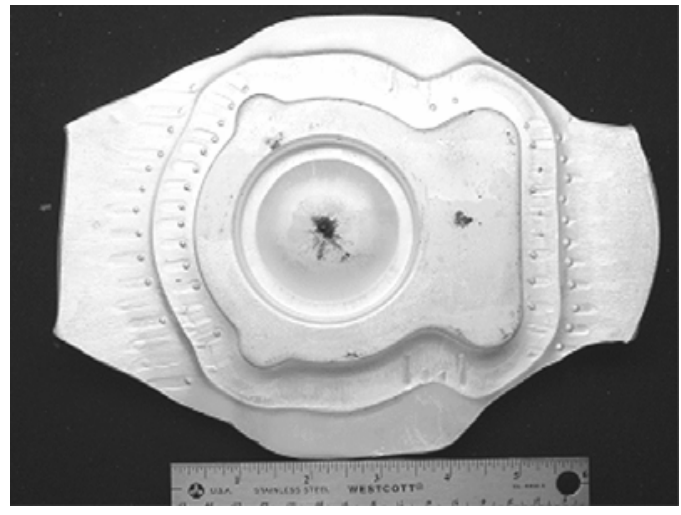

(a) $315^{\circ} \mathrm{C}, \mathrm{ECAP}, 100 \%$ stock size

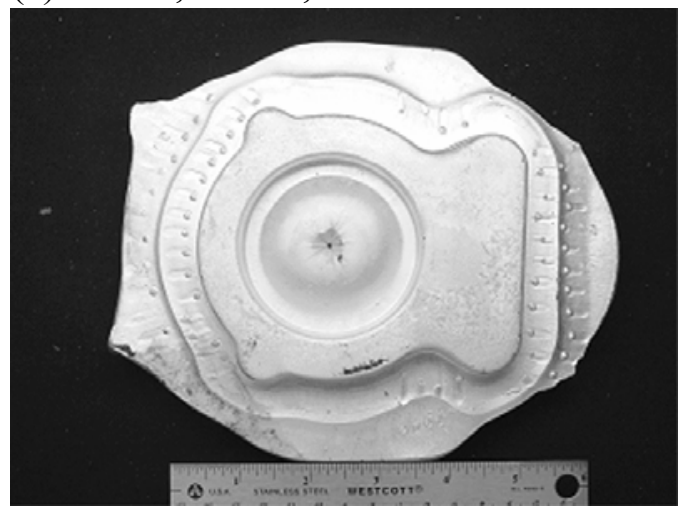

(b) $370^{\circ} \mathrm{C}$, ECAP, $85 \%$ stock size

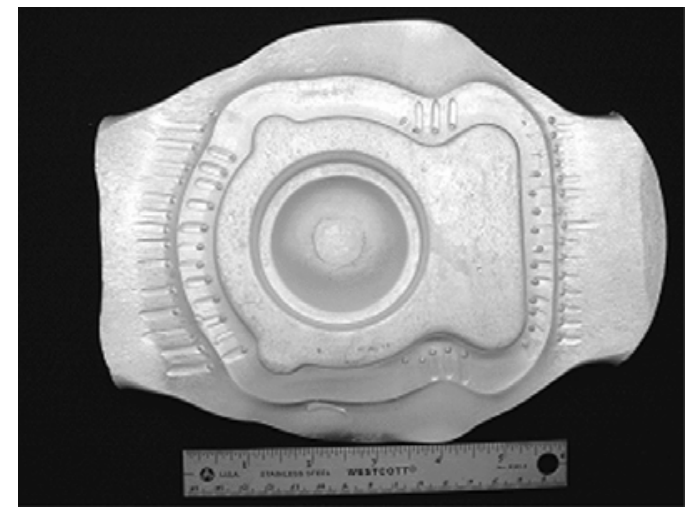

(c) $450^{\circ} \mathrm{C}$, Extruded, $100 \%$ stock size

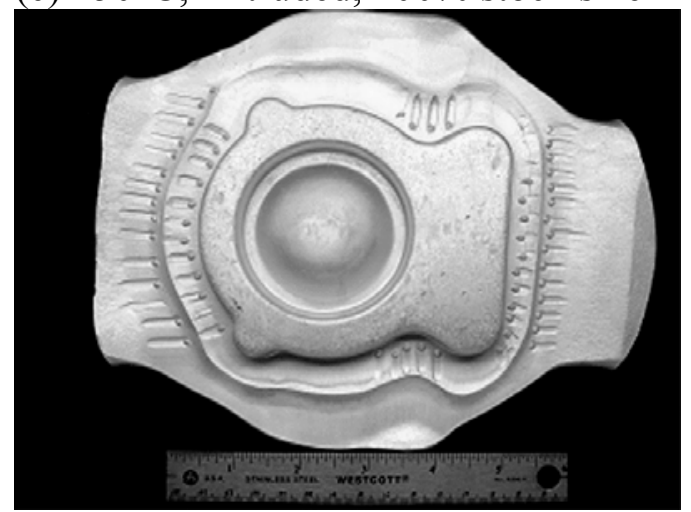

(d) $440^{\circ} \mathrm{C}$, FG Cast, $100 \%$ stock size

Figure 4.12: Forging made with different stock materials: (a) and (b) SPD processed stock, (c) conventional extruded stock, and (d) fine grain cast stock

4.12 (c) and (d)). A significant feature to note is that the parts forged from the conventional extruded stock and the fine grain cast stock showed large grains on the surface. This problem did not show up with the SPD processed stock material, probably because of the lower forging temperature.

The second study was with a slightly smaller part (Figure 4.11(b)), but one which required two hits to fill the die. After the first hit, the flash was trimmed off, and, if necessary, any defects that formed were removed by grinding. The piece was reheated before the second hit. Figure 4.13 shows parts after the first and second hit with the ECAE/P material (Figure 4.13 (a) and (b) and with conventional extruded stock (Figure 4.13 (c) and (d)). Forging with the ECAE/P material was successful at a temperature lower than that used in normal practice, whereas, with the extruded stock, a defect formed along the top edge after the first hit. Subsequently, there was incomplete die fill after the second hit.

The third part made was considerably larger than the first two, and was forged from the 100$\mathrm{mm}$ cross section ECAE/P material made using billets that had been processed in the large size ECAE/P dies discussed earlier. As shown in Figure 4.14, this part was successfully made with a smaller stock size as well as a decrease in forging temperature of $155^{\circ} \mathrm{C}$.

Two major conclusions that can be drawn from this forging study are that the use of SPD processed material as forging stock can improve the material yield and the billet temperature can 


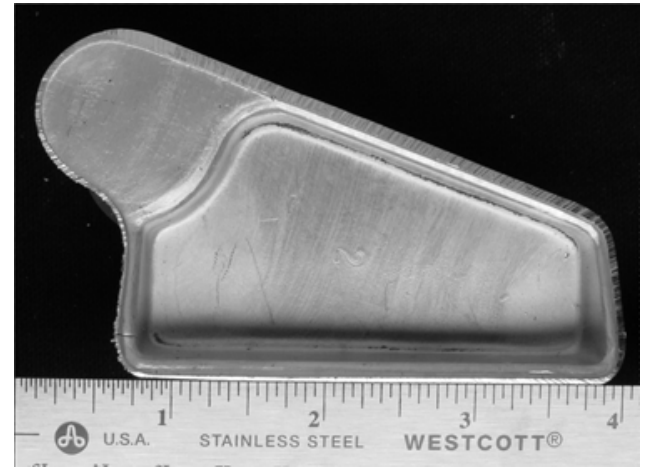

(a) ECAP, first hit

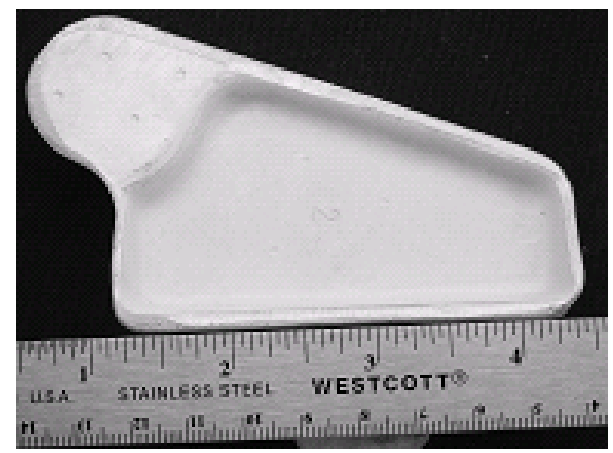

(b) ECAP, second hit

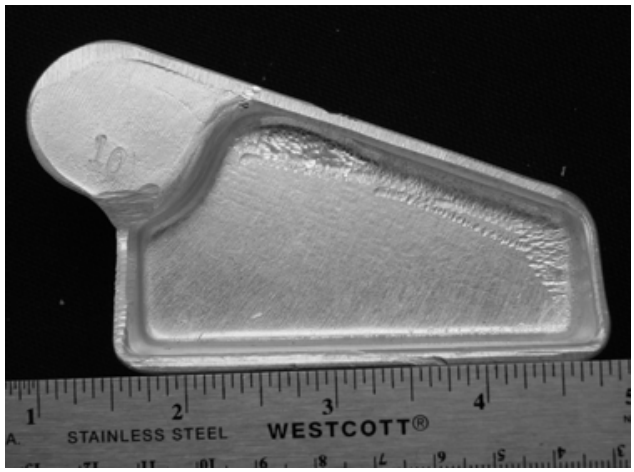

(c) Extruded, first hit

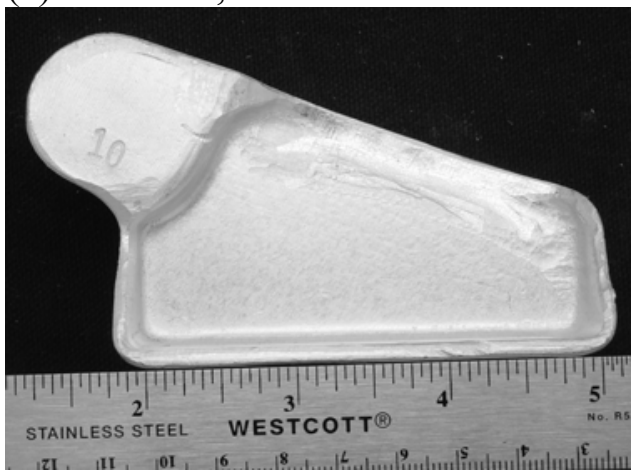

(d) Extruded, second hit

Figure 4.13: Forgings made with ECAE/P and extruded stock materials (a) and (b) ECAE/P material at $360^{\circ} \mathrm{C}$ : (c) and (d) and extruded stock at $410^{\circ} \mathrm{C}$

be substantially reduced. Both these factors play significant roles in energy savings that can be attained though the use of SPD processed stock material

\subsubsection{Heat Treatment after Forging}

Samples cut from the forgings were solutionized, quenched and aged to different times. Figure 4.15 shows the variation in hardness during aging for the three materials used in the IMCO forging studies, ECAE/P, conventional extruded and the fine grain cast. Standard aging time to reach peak hardness is 8 hours. As can be seen in the figure, all three materials attain the same hardness at the end of the standard aging time. However, the ECAE/P material reaches peak hardness in about half the time that it took for the other materials.

\subsubsection{Properties after Heat Treatment}

Table 4.2 summarizes some of the properties of the forged materials measured before and after heat treatment. In the as-forged condition, the grain size of the ECAE/P material was about $5.5-\mu \mathrm{m}$, is larger than it was before forging, but substantially less than the $25-50-\mu \mathrm{m}$ obtained with the extruded and fine grain stock materials. After solution heat treatment and aging, 


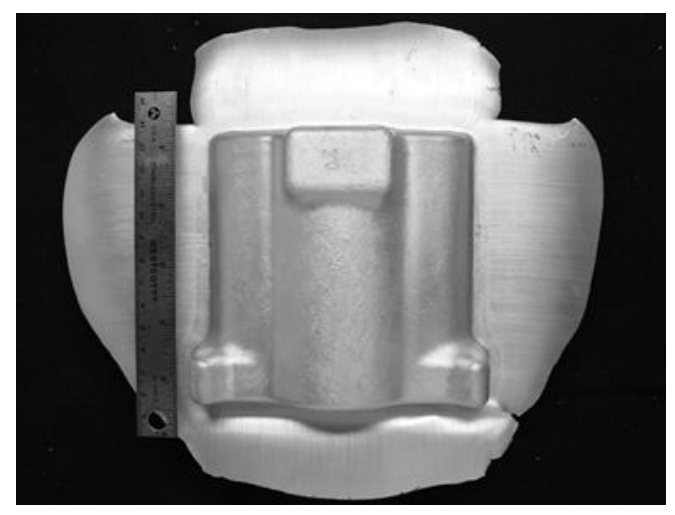

(a) ECAE/P billet temperature $=315^{\circ} \mathrm{C}$

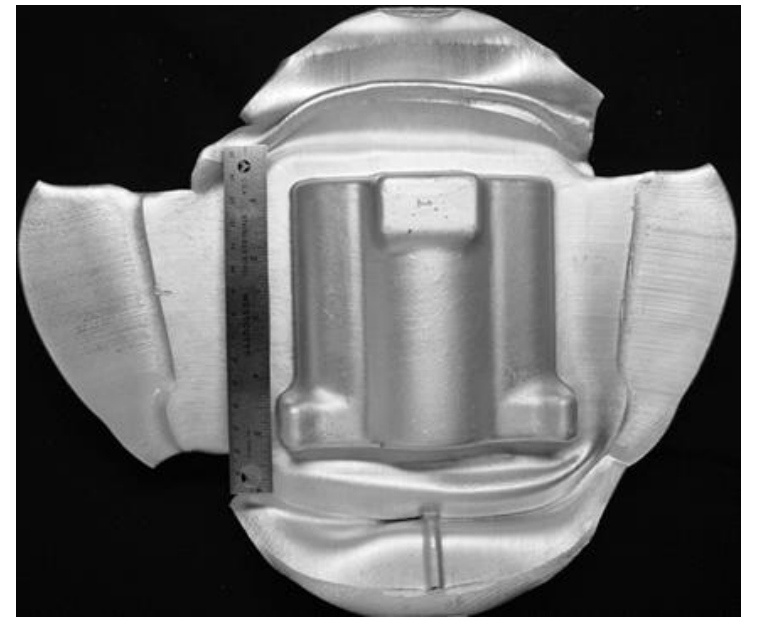

(b) Extruded stock billet temperature $=427^{\circ} \mathrm{C}$

Figure 4.14: Forging with 100mm ECAE/P stock and conventional extruded stock. ECAE/P $-90 \%$ stock size; extruded $-100 \%$ stock size. The ruler is $150-\mathrm{mm}$ long

however, the grain sizes in the conventional extruded material and ECAE/P material are virtually identical, while the grain size in the fine grain cast material is substantially greater.

The mechanical properties, namely the yield strength, ultimate tensile strength and elongation to failure, of samples taken from the forgings made from ECAE/P stock after heat treatment is essentially the same as those obtained for samples from conventional extruded stock. These properties exceed the minimum AMS specifications, also shown in Table 4.2.

An important conclusion that can be drawn from this study is that the use of SPD processed material, therefore, has not adversely affected the measured service properties. This is significant from the point of view of certification if SPD processed stock is to replace conventional extruded stock.

\subsubsection{Fatigue Property Studies}

At the October 2004 DOE annual review meeting in Chicago IL, it was suggested that, in addtion to standard mechanical properties, fatigue properties also be measured since most

Table 4.2: Properties after forging and heat treatment

\begin{tabular}{|l|c|l|c|l|l|l|l|l|}
\hline \multirow{2}{*}{ Stock Material } & \multirow{2}{*}{$\begin{array}{l}\text { Forging } \\
\text { Temp. }\end{array}$} & $\begin{array}{l}\text { As Forged } \\
\text { Hardness } \\
\text { RE }\end{array}$ & \multicolumn{2}{|l|}{$\begin{array}{l}\text { Properties after T6 } \\
\text { RTS }\end{array}$} & $\begin{array}{l}\text { YS } \\
\text { MPa }\end{array}$ & $\begin{array}{l}\% \\
\text { MPa }\end{array}$ & $\begin{array}{l}\text { After } \\
\text { Elong } \\
\text { forging }\end{array}$ & After T6 \\
\hline $50 \mathrm{~mm} 3 \mathrm{P}$ ECAP & $393^{\circ} \mathrm{C}$ & 14 & 321 & 297 & 15.8 & $5.8 \mu \mathrm{m}$ & $31 \mu \mathrm{m}$ \\
\hline $100 \mathrm{~mm} 4 \mathrm{P}$ ECAP & $315^{\circ} \mathrm{C}$ & 31 & 319 & 297 & 17.7 & & \\
\hline Extruded & $460^{\circ} \mathrm{C}$ & 31 & 305 & 283 & 16.2 & $20 \mu \mathrm{m}$ & $32 \mu \mathrm{m}$ \\
\hline Fine Grain Cast & $416^{\circ} \mathrm{C}$ & 13 & 282 & 275 & 19.7 & $50 \mu \mathrm{m}$ & $243 \mu \mathrm{m}$ \\
\hline Min. Specifications & & & 260 & 242 & 7.0 & & \\
\hline
\end{tabular}




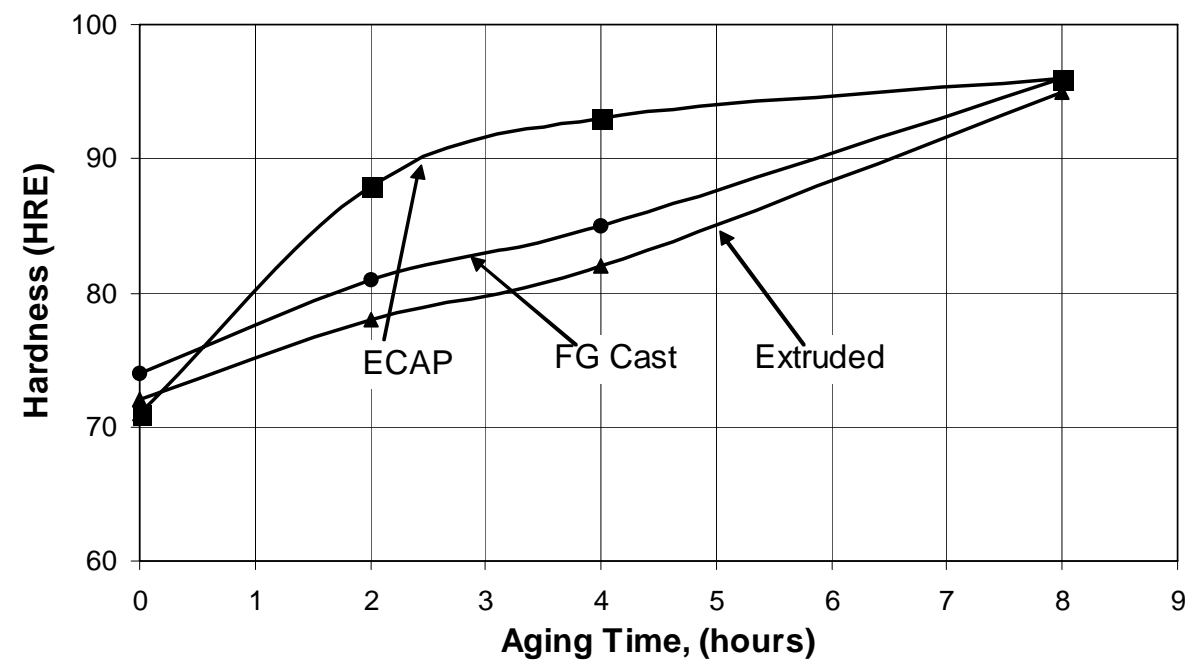

Figure 4.15: Change in hardness (Rockwell E scale) as a function of aging time

failures in service occur due to fatigue. However, by this time IMCO/GD had withdrawn from the project, and no additional large size ECAE/P billets could be processed, and all of the following work was done using the few pieces of $100-\mathrm{mm}$ and $50-\mathrm{mm}$ ECAE/P that had been processed earlier in the program. In addition, a few $12.5-\mathrm{mm}$ size pieces were also made at WSU.

\subsubsection{Fatigue Test Sample Configuration}

At the start of the fatigue study, a commercial testing facility, MetCut Research of Cincinnati was contacted for suggestions on the best specimen size for fatigue testing, considering the limited amount of ECAE/P material that was available. MetCut suggested blanks of 10.2-mm diameter and 88.9-mm length (0.40-inch dia and 3.5-inch length) be prepared

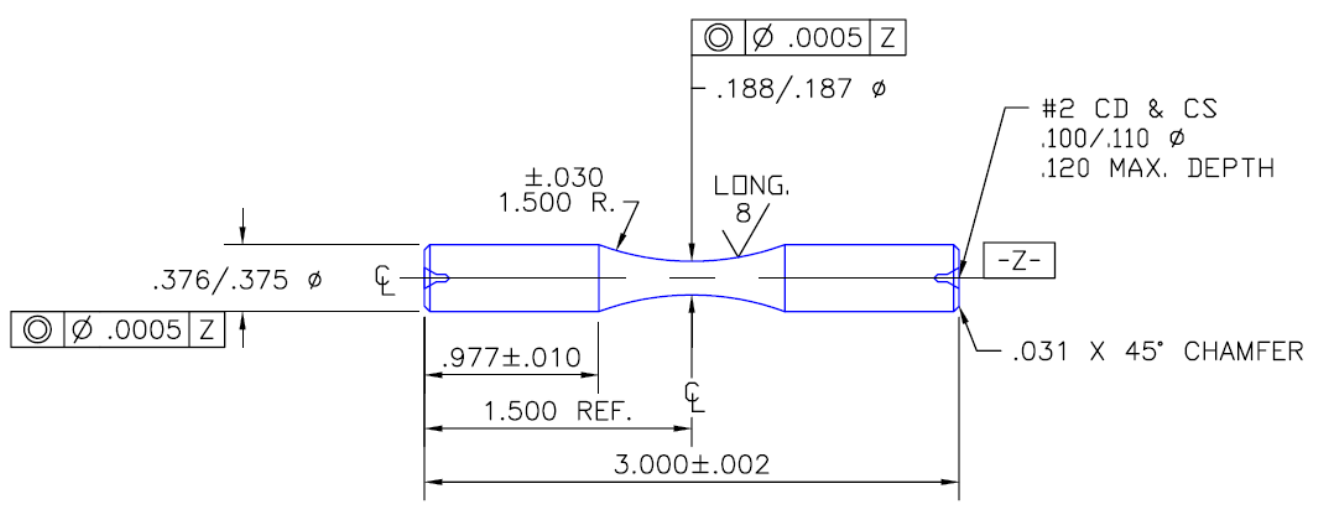

Figure 4.16: Dimensions of Krouse fatigue test sample 


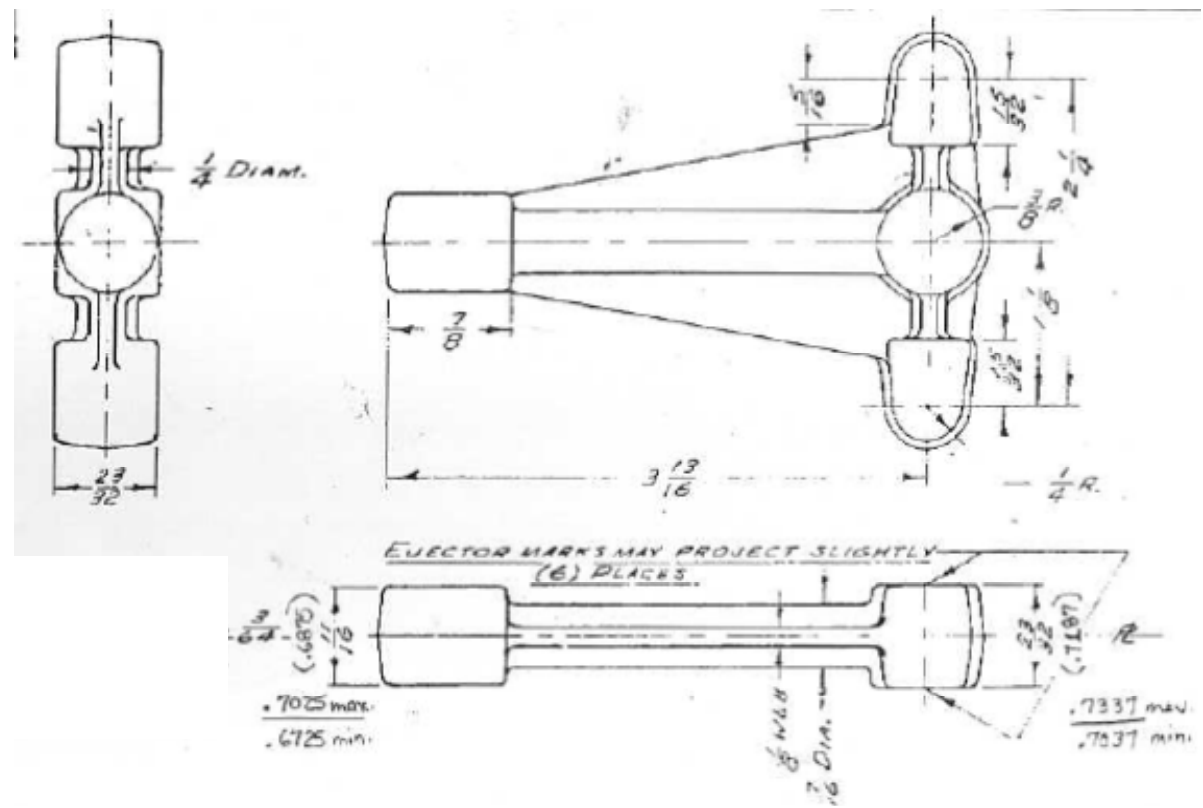

Figure 4.17: Drawing of a part used to make fatigue samples

for testing using the Krouse testing machine which used specimens of the size shown in Figure 4.16.

Consultation with Mr. Rob Mayer at QC Forge resulted in the selection of one of their existing dies "Die 400", shown in Figure 4.17 for making forgings for the fatigue studies. The central rib in the forging is large enough for making blanks for the fatigue samples. Blanks for the forging studies were sectioned from the existing ECAE/P material and heat treated to the T-6 condition. Figure 4.18 shows a solid model of the part and a trimmed forging that was used for making fatigue samples.

\subsubsection{Fatigue Testing}

Samples for Krause rotating beam fatigue tests were machined by MetCut Research and
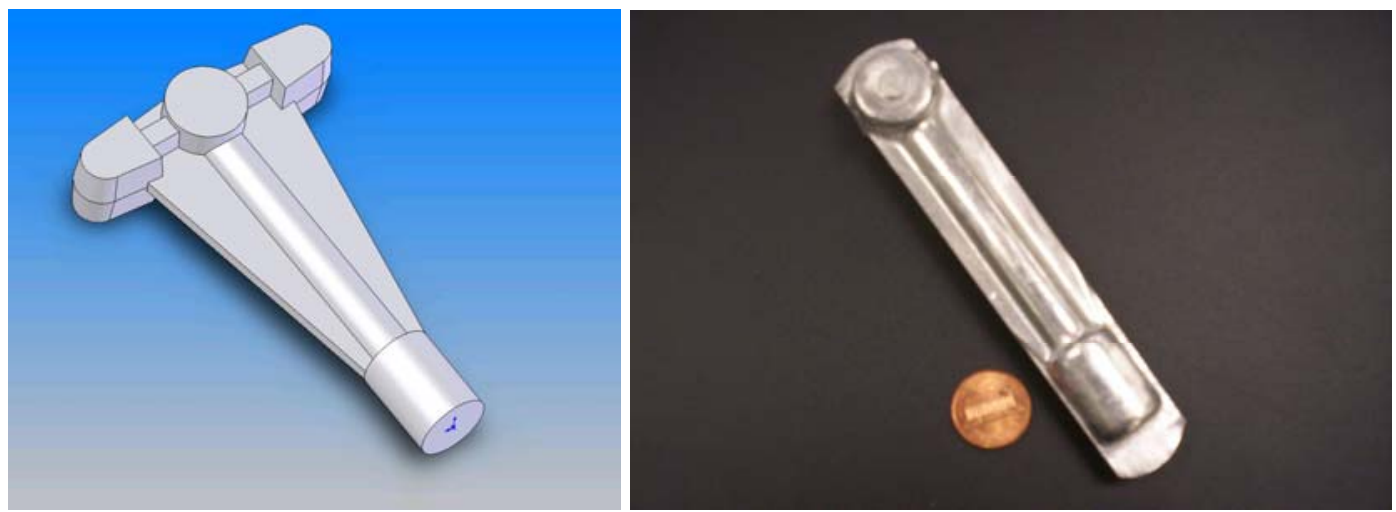

Figure 4.18: Solid model and a trimmed forging of the part used for making fatigue samples 


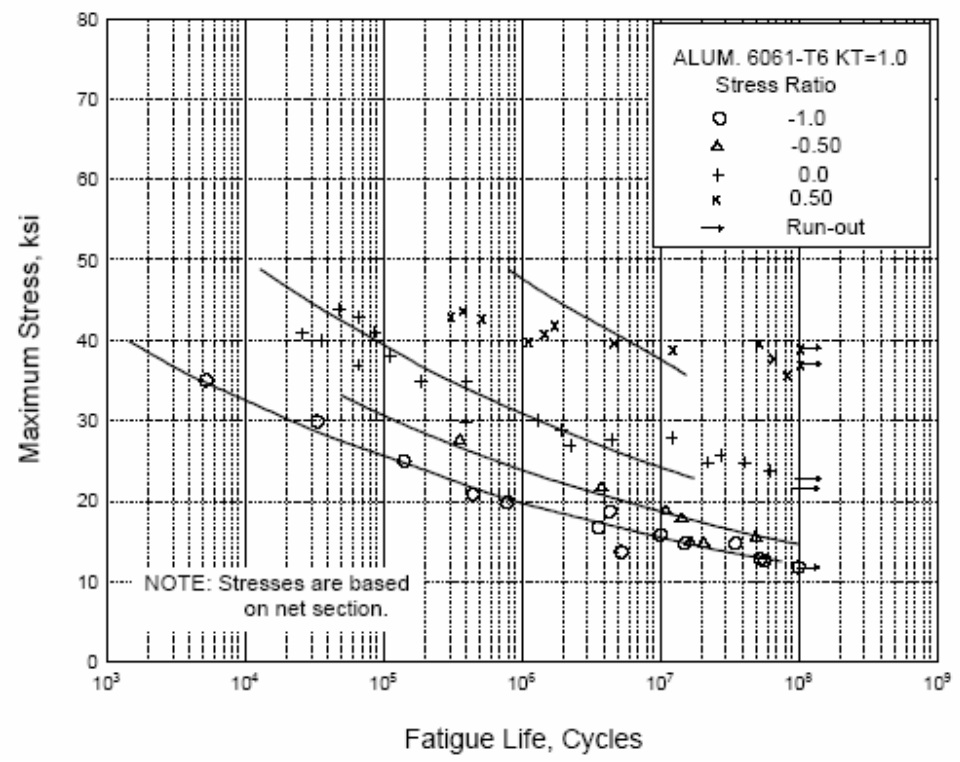

Figure 4.19: Fatigue performance specifications for AA 6061-T6 from MMPDS [53]

tested at conditions shown in Table 4.3. Figure 4.19 shows MMPDS fatigue property specification for AA-6061 [53]. The stress levels for the fatigue study were selected based on this data and the total number of samples available. Initially, three stress levels of 104, 138 and $207 \mathrm{MPa}(15,20$, and $30 \mathrm{ksi})$ were chosen. However, if a sample experienced run-out at a certain stress level (i.e. did not fail within the prescribed $10^{7}$ cycles), lower stress levels were eliminated and higher stress levels of 173 and $254 \mathrm{MPa}(25$ and $35 \mathrm{ksi})$ were added. The results from this study are summarized in Figure 4.20. The solid line indicates the MMPDS specification for AA-6061-T6 tested in fatigue with a stress ratio $\mathrm{R}=-1.0$. This is the same as the lowest line and open circles in Figure 4.19. The data generated in this project are shown as data points in Figure 4.20. Details of the fatigue test results are shown in Table 4.3. Due to a limited amount of material, only one test was conducted at each stress level. The materials tested included as-received (non-ECAE/P processed) AA 6061, as well as material that was obtained after heat treating of different ECAE/P processed and forged samples. The results show that the fatigue properties of forgings made from SPD processed stock are better than those specified by MMPDS. However, since only a limited number of tests were done for each condition, the only conclusion that can be drawn is that there has been no penalty in the fatigue properties due to the use of ECAE/P processed forging stock.

\subsection{Summary}

- The ECAE/P processes was successfully scaled up from the laboratory size by a factor of 64 to industrial cross sections of 100 -mm square.

- SPD processed billets, made using the ECAE/P process, were successfully used to make forgings of different size and complexity at lower temperature and with greater material yield than with conventionally processed billets. 


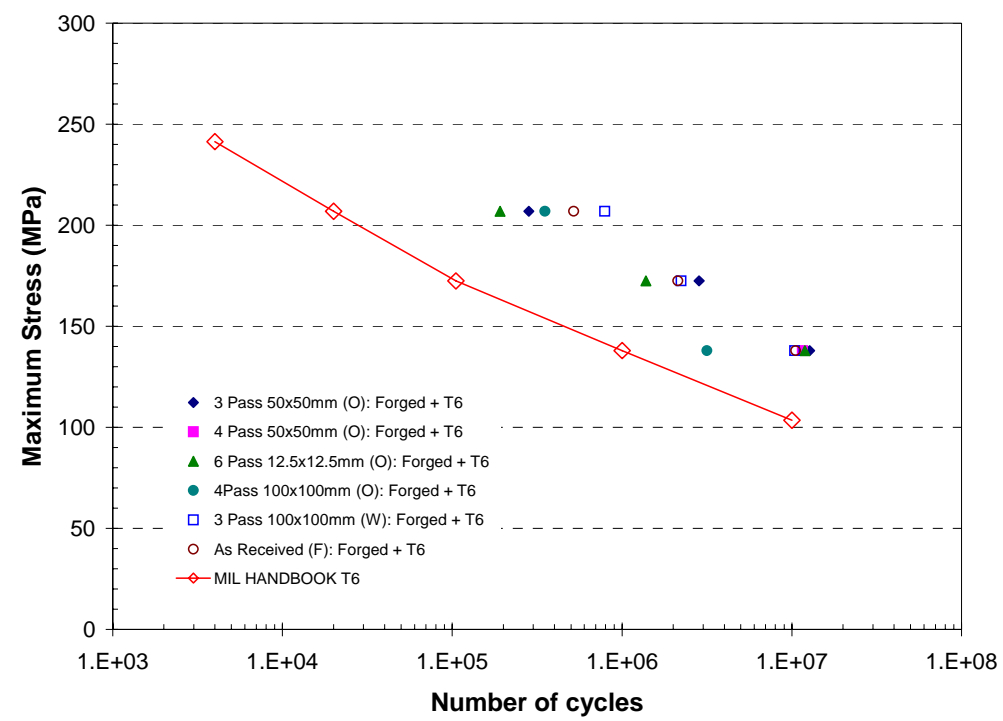

Figure 4.20: Fatigue test results

- The energy savings attainable during the forging operation can be as high as $40 \%$ of conventional energy consumption. The primary factors are the reduced furnace operating temperature and decreased amount of material sent for recycling.

- The mechanical and fatigue properties of forgings made from SPD processed stock are as good as or slightly better than those of conventional forgings. Therefore, the benefits of energy savings through the use of SPD processed stock can be attained without any penalty in the properties of the forged product. 
Table 4.3: Fatigue test results

Dynamic Ratio

$$
R=-1.0
$$

Frequency : 10,000 Max cpm

Test

Temperature :

Room Temperature

Waveform : Sinusoidal

\begin{tabular}{|c|c|c|c|c|c|c|}
\hline $\begin{array}{c}\text { Test } \\
\text { Number }\end{array}$ & Material & $\begin{array}{c}\text { Gauge } \\
\text { Dia. } \\
\text { (in) }\end{array}$ & $\begin{array}{l}\text { Cycles to } \\
\text { failure }\end{array}$ & $\begin{array}{l}\text { Stress } \\
\text { Max } \\
(\mathrm{MPa})\end{array}$ & $\begin{array}{l}\text { Frequency } \\
\quad(\mathrm{cpm})\end{array}$ & Results \\
\hline 12 & \multirow{4}{*}{ 3-Pass-AFRL } & 4.763 & 282,200 & 207.0 & 9,000 & Fracture \\
\hline 18 & & 4.745 & No data & 172.5 & 9,000 & Fracture \\
\hline 24 & & 4.775 & $2,842,000$ & 172.5 & 9,700 & Fracture \\
\hline 7 & & 4.750 & $12,724,400$ & 138.0 & 8,600 & Runout \\
\hline 8 & \multirow{2}{*}{ 4-Pass-AFRL } & 4.750 & $11,565,500$ & 138.0 & 9,000 & Runout \\
\hline 13 & & 4.750 & No data & 207.0 & 9,800 & Fracture \\
\hline 19 & \multirow{3}{*}{ 6-Pass-WSU } & 4.757 & $1,381,000$ & 172.5 & 9,000 & Fracture \\
\hline 9 & & 4.757 & $11,908,500$ & 138.0 & 8,800 & Runout \\
\hline 11 & & 4.760 & 191,000 & 207.0 & 9,000 & Fracture \\
\hline 15 & \multirow{4}{*}{ Conventional } & 4.763 & 519,400 & 207.0 & 9,300 & Fracture \\
\hline 20 & & 4.755 & No data & 172.5 & 9,000 & Fracture \\
\hline 25 & & 4.775 & $2,133,300$ & 172.5 & 9,000 & Fracture \\
\hline 3 & & 4.763 & $10,546,200$ & 138.0 & 9,100 & Fracture \\
\hline 16 & \multirow{3}{*}{ 4-Pass-IMCO } & 4.742 & 351,500 & 207.0 & 9,600 & Fracture \\
\hline 4 & & 4.737 & $3,165,100$ & 138.0 & 9,100 & Fracture \\
\hline 6 & & 4.757 & $22,511,800$ & 103.5 & 8,200 & Runout \\
\hline 17 & \multirow{3}{*}{$\begin{array}{l}\text { 3-Pass-W- } \\
\text { IMCO }\end{array}$} & 4.757 & 790,300 & 207.0 & 9,000 & Fracture \\
\hline 23 & & 4.763 & $2,231,600$ & 172.5 & 8,900 & Fracture \\
\hline 5 & & 4.763 & $10,369,100$ & 138.0 & 9,100 & Runout \\
\hline
\end{tabular}




\section{Chapter 5 Energy Savings from the use of SPD stock}

In the previous chapter, the advantages of using SPD processed billets as stock material for forging were demonstrated. These advantages translate to energy savings in the following ways:

- Lower billet temperature would lead to lower energy consumption in the billet heating furnaces

- Increased material yield would result in:

o Less scrap and therefore less energy expended in re-melting

o Smaller loss of aluminum as dross

- Improved hot forgeability would lower load and hence smaller presses and associated energy savings

- Shorter aging time would result in faster through put through the aging furnaces.

In this chapter, the methods used to estimate the energy savings that can be achieved through the use of SPD processed billets for the forging of aluminum is discussed.

\subsection{Energy Savings in Billet Heating Furnaces}

In order to determine the energy savings associated with decreased billet furnace temperature, a gas consumption study was conducted. Slugs from different size forging stock ranging from 25-mm (1-inch) to 200-mm (8-inch) in diameter were used. Each slug had a

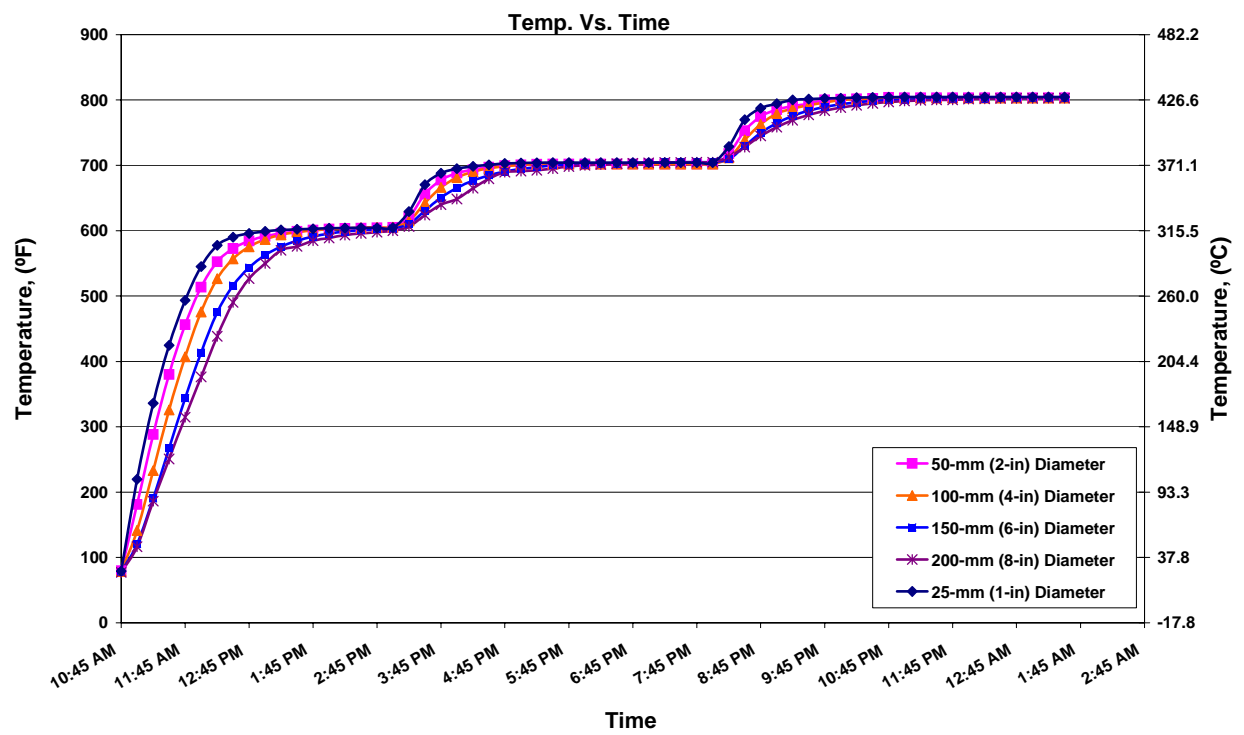

Figure 5.1: Variation of temperature with time during heat up of forging stock in a typical stock heating furnace 
thermocouple inserted at mid-length to monitor the temperature during heat up and soak time. These slugs were placed in billet heating furnaces and the temperature at the center of the slug was monitored as a function of time for heat up to different final temperatures. The temperature variation as a function of time for each size of slug is shown in Figure 5.1. As expected, the time required for larger slugs to reach the set temperature was longer.

The gas consumption during the ramp up to the operating temperature and during the steady state heating of stock was measured. Figure 5.2 shows the gas usage as a function of forging temperature for three sizes of the stock material. Larger the stock size and higher the temperature, greater is the amount of gas consumed. For each billet size, the gas consumption increases linearly with temperature.

The results of this energy consumption study are summarized in Figure 5.3. Based on the total volume of different billet stock sizes that were used in the IMCO plant, an estimated decrease in gas consumption, compared to the standard $470^{\circ} \mathrm{C}\left(880^{\circ} \mathrm{F}\right)$ operating temperature was calculated. The left most bar in the chart shown in Figure 5.3 is for a size of $135-\mathrm{mm}$ diameter billet calculated to be the weighted average size of all billet sizes used at IMCO at the time of this study. For this average size, a decrease in billet temperature from $471^{\circ} \mathrm{C}\left(880^{\circ} \mathrm{F}\right)$ to $315^{\circ} \mathrm{C}\left(600^{\circ} \mathrm{F}\right)$ would result in an energy saving of $33.7 \%$ in the billet furnaces at the plant.

\subsection{Energy Savings due to Decreased Material Usage}

The examples shown in Chapter 4 demonstrated increased material yield when forging with SPD processed material. For the cargo door latch (Figure 4.12) the starting stock size could be decreased to $85 \%$ of the conventional size. For this part, the conventional yield is about $70 \%$, indicating about $30 \%$ of the starting volume of the material is lost in the flash. When SPD stock

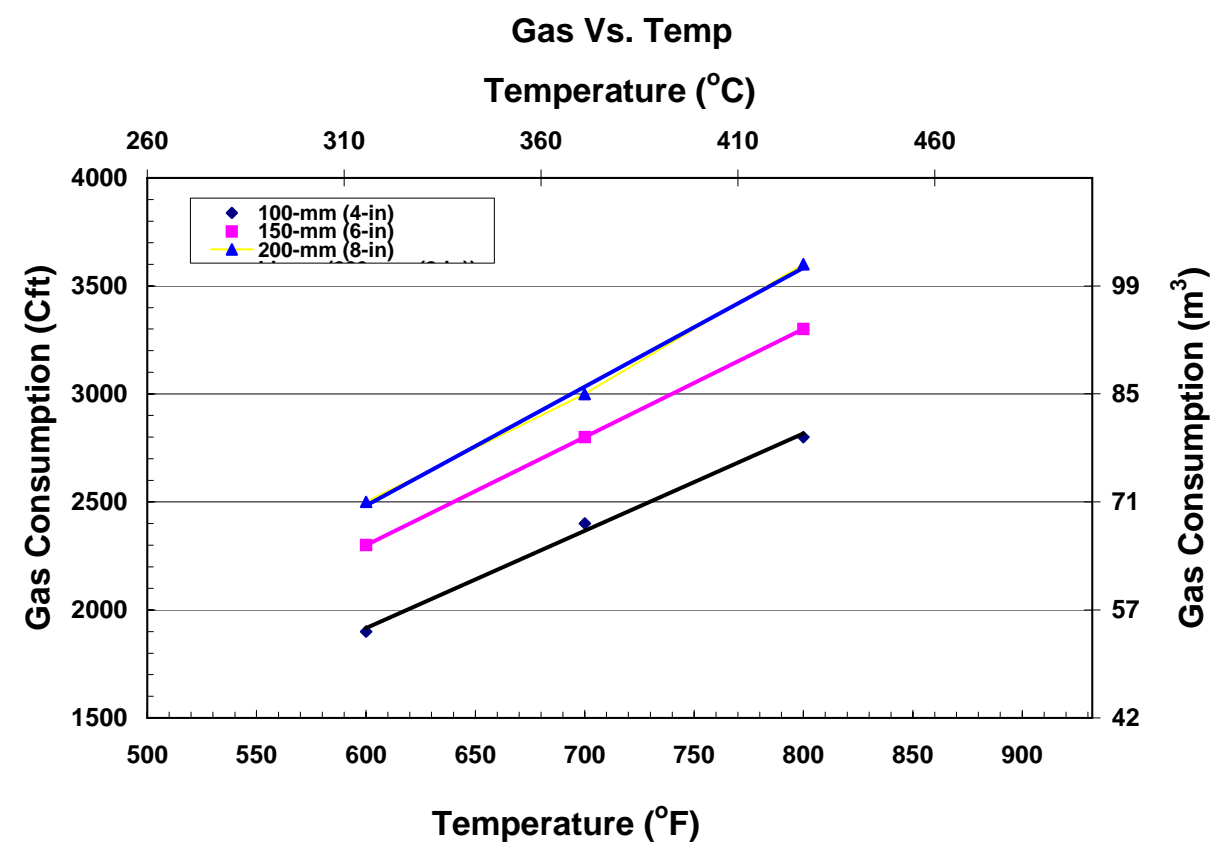

Figure 5.2: Gas consumption as a function of time to heat up for various sizes of forging stock in a typical forging stock heating furnace. 


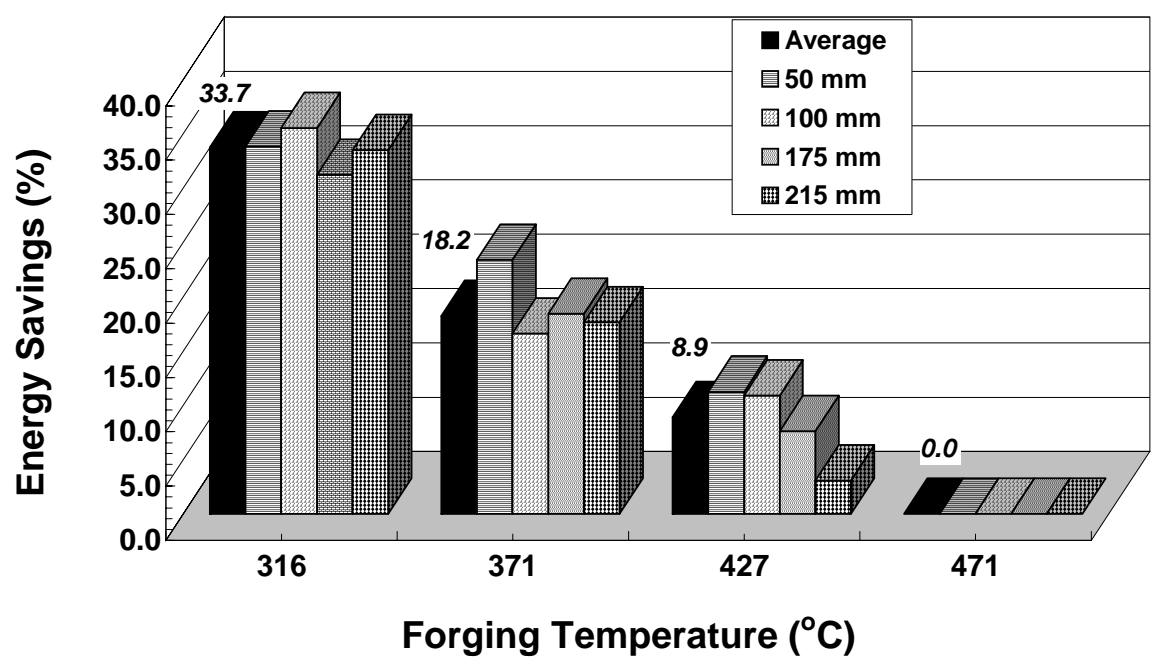

Figure 5.3: Estimated savings in furnace gas consumption for a decrease in operating temperature from $471^{\circ} \mathrm{C}$

material is used, the volume of flash would decrease by $50 \%$ from $30 \%$ to $15 \%$ of the conventional stock size. Similarly, for the part shown in Figure 4.14, the yield during conventional forging is about $80 \%$. The decrease in stock size to $90 \%$ of the conventional size by the use of SPD processed stock also represents a 50\% decrease in the amount of material lost as flash.

Aluminum is a very expensive material to extract from the ore, and recycling of trimmed material from forging production is a common practice. The trimmings are usually re-melted and cast into ingots for further processing. A decreased amount of trimmings, therefore, represents decreased energy usage during recycling. There are two sources of energy saving during the re-melting process; the first is the actual energy required to melt the metal, and the second is the energy content in metallic aluminum that is lost as dross that typically forms during melting operations.

Based on information provided by Dr. Qingyou Han, the Principal Investigator for this study at Oak Ridge National Laboratory, the energy savings that are associated with the decreased material usage is estimated as follows.

- 130 forging plants with an average production of 910,000 kg/yr (2 million lb/yr)

- Assume material yield is $70 \%$

o SPD billets reduce scrap by $50 \%$

- $\sim 4200 \mathrm{~kJ} / \mathrm{kg}(\sim 1800 \mathrm{BTU} / \mathrm{lb})$ for heating forging billet

- $\quad 5100 \mathrm{~kJ} / \mathrm{kg}(\sim 2200 \mathrm{BTU} / \mathrm{lb})$ for melting aluminum

- $4 \%$ loss as dross, with energy content of $128 \mathrm{MJ} / \mathrm{kg}(55,000 \mathrm{BTU} / \mathrm{lb})$

The projected energy materials and energy savings through the use of SPD forging stock are shown in Table 5.4. The projected energy savings for the forging operation alone is of the order of $40 \%$. 


\subsection{Other Factors Affecting Cost and Energy Consumption}

There are several other factors that will contribute to cost savings in a forging plant through the use of SPD processed stock material. The associated cost savings were not evaluated during this project.

In Figure 4.15 it was shown that a forging made from SPD processes stock reached peak hardness at about half the time that it took with conventional stock material. Benefits of the reduced aging time include increased productivity and lower furnace operating costs.

Other advantages of the use of a more formable stock material include:

(a) Lower forging loads

The force required to deform a more formable material would be less than a less formable material. The cost of press operation typically increases with the rated tonnage. Lower forming loads mean a given part can be made on smaller presses, or larger forgings can be made on a given press.

(b) Lower forging temperature

A decrease in the forging temperature would result in reduced die wear and/or the use of less expensive die materials

(c) Fewer hits

It may become possible for a given part to be made with fewer hits or with fewer intermediate steps if the material is more formable. This also will reduce die wear decrease operating costs.

Table 5.4: Projected national annual energy savings through the use of SPD stock for forging

\begin{tabular}{|c|c|c|c|c|}
\hline & \multicolumn{2}{|c|}{ Energy (J/year) } & \multicolumn{2}{c|}{ Energy (BTU/year) } \\
\hline & $\begin{array}{c}\text { Current } \\
\text { Consumption }\end{array}$ & $\begin{array}{c}\text { Projected } \\
\text { Saving }\end{array}$ & $\begin{array}{c}\text { Current } \\
\text { Consumption }\end{array}$ & $\begin{array}{c}\text { Projected } \\
\text { Saving }\end{array}$ \\
\hline Heating & $4.68 \times 10^{11}$ & $1.54 \times 10^{11}$ & $4.94 \times 10^{14}$ & $1.63 \times 10^{14}$ \\
\hline Remelting & $2.45 \times 10^{11}$ & $1.23 \times 10^{11}$ & $2.59 \times 10^{14}$ & $1.29 \times 10^{14}$ \\
\hline Dross & $2.45 \times 10^{11}$ & $1.11 \times 10^{11}$ & $2.59 \times 10^{14}$ & $1.18 \times 10^{14}$ \\
\hline Total & $9.58 \times 10^{11}$ & $3.88 \times 10^{11}$ & $1.01 \times 10^{15}$ & $4.10 \times 10^{14}$ \\
\hline \multicolumn{2}{|c|}{ Projected Saving } & \multicolumn{3}{|c}{$40.5 \%$} \\
\hline
\end{tabular}




\section{Chapter 6 Technology Transfer}

Technology transfer is the process by which knowledge or capabilities developed by one is transferred and utilized by another for a purpose to fulfill actual or potential needs. It is the hope that in the technology transfer process economic growth is attained through one or more events such as the creation of jobs, improved productivity, and/or increasing the competitiveness of the acquiring entity. To achieve successful technology transfer requires that the developing commercializable technology be an integration of three things: 1) unique intellectual property, 2) technical capability resulting in real technology achievement, and 3) meeting an unmet market need.

In the previous chapters, the potential advantages of the implementation severe plastic deformation processing into the manufacturing stream in terms of cost and energy savings during forging were demonstrated. The continuous severe plastic deformation (CSPD) technology was demonstrated on the laboratory scale using existing equipment at ORNL. A US patent was awarded for the technology in May 2005. However, during the time frame of this project, the technology could not be fully implemented due to several reasons, including team disruption (the withdrawal of IMCO), delayed funding to ORNL, and design and cost issues related to building and scale up of a stand-alone CSPD machine. Nevertheless, significant technology transfer activities were completed by all members of the team. The different activities undertaken by the team included:

- Market Assessment

- Technology Transfer Forums

- Participation in Trade Shows

- Website

- Seeking potential collaborators

- Presentation at Technical Conferences

- Publication in professional journals

- Education and training of students

- Application for intellectual property protection

These activities are discussed below.

\subsection{Market Assessment}

During 2003-2004, the Edison Materials Technology Center (EMTEC) performed a thorough market analysis of the forging and stamping industry, specifically for the automotive, aerospace, polymer dies, and agricultural equipment market. The results of the assessment are summarized below:

1) Market declining in size and in 2002 was at $\$ 27.3 \mathrm{~B}$ (a decrease of $1.5 \%$ from prior year)

a. Nonferrous forging only account for about $18 \%$ of market

b. Slowing per capital consumption of forged/stamped products

2) Fragmented but mature market

a. Approximately 3,700 entities employing around 169,000 people 
i. $>50 \%$ employ $<20$ people

ii. Only $11 \%$ employ $>100$ people

b. Growth lower than DCP for last five years

c. California, Illinois, Ohio, Michigan Pennsylvania have largest number of establishments

3) Level of exports steady but slow (ca. \$245M in 2002); Level of imports low (\$191M) but increasing $(8.5 \%)$

4) Major market segments

a. Automotive 30\%; Aerospace 20\%; Agricultural 20\%; Other 30\%

b. Low level of concentration - top four firms account for $8 \%$ of industry revenue

c. Low barriers to entry except for high cost capital equipment

i. Capital to labor ration is medium to high

ii. Investments are in capital rather than labor

d. Regulation of industry is light

5) Structural changes in automotive industry have and major impact on economic performance of industry

6) Computer aided technologies have begun but industry continues to be labor intensive a. Rate of change in industry is moderate to low

7) Investments emphasize production cost reduction or production flexibility

a. Key benefits of change would be increased capacity, lower break-even levels, decreased cycle times, reduction of defect levels

8) Key is manufacturer involvement with their customer at design and prototype stage

9) Restricted distribution channels

a. Long term contracts in place

b. Greater price/product pressures

c. New part designs are requiring less forgings and stamping

10) Consolidation is expected in market with smaller firms acquired or closed

11) New technology adopted only to remain competitive

\subsection{Technology Transfer Forums}

EMTEC is a consortium of industry, academia and government laboratories, with over 160 members. The consortium meets regularly to exchange technical information and to review projects involving EMTEC as a participant, either as a funding source or as a participant. During the duration of the DOE sponsored project, EMTEC conducted six (6) of these formal technology transfer forums and multiple additional smaller presentations of the current status of the CSPD technology. Specifically EMTEC conducted these forums where the CSPD technology was presented on 11/14/01, 08/20/02, 11/02/02, 11/06/02, 04/22/04, and 10/28/04. During these forums 76 companies were given a CSPD technology review. Several of those in attendance were provided additional information through one-on-one follow-up visits. 
Table 6.1: Trade show listing where CSPD Technology was presented

\begin{tabular}{l|l} 
TRADE SHOW & DATE \\
\hline SAMPE & \\
\hline NADCA - Cincinnati & October, 2001 \\
\hline ASM/TMS Materials Week - Indianapolis & November, 2001 \\
\hline Dayton Industrial Exposition - Dayton & November, 2001 \\
\hline ASM/TMS Materials Week - Columbus & October, 2002 \\
\hline Dayton Industrial Exposition - Dayton & October, 2002 \\
\hline ASM/TMS Materials Week - Pittsburgh & October, 2003 \\
\hline ASM?TMS Materials Week - Columbus & October, 2003 \\
\hline Dayton Industrial Show - Dayton & October, 2005
\end{tabular}

\subsection{Trade Show Participation}

Trade shows are a traditional and often effective way to communicate new technology opportunities to the trade show attendees. This, when combined with technical paper presentations, impart an even better communication vehicle. In this project EMTEC was committed to exhibit the CSPD technology at major trade shows. While EMTEC was not involved in the technical paper presentations, EMTEC did exhibit the CSPD technology at nine (9) different trade shows during the course of the project. Table 6.1I provides a summary of these events:

\subsection{Website}

In order to improve intra-team communication and to make available to the public nonproprietary information, two domain names (cspd.biz and cspd.info) were registered. EMTEC developed and maintained the websites. The site was originally created using Microsoft FrontPage98 but is now maintained using Dreamweaver MX2004. While the site allowed interested parties to view some information, proprietary information was password protected and accessible only to the team members.

\subsection{Seeking potential collaborators}

Throughout the project, all team members sought out potential collaborators. Of the several hundred individuals and companies present at various meetings and technical presentations, abut 15 were contacted for further discussions, and non-disclosure agreements were signed with six companies for detailed technical discussions. Representatives from these companies were invited to attend quarterly team meetings. Queen City Forging Co., an EMTEC member and a participant in other DOE sponsored programs and with active collaborations with ORNL, joined the team at a critical stage when IMCO/General Dynamics OTS withdrew from the program. 
QC Forge brought into the team aluminum forging experience that was critical for making the parts that were needed for fatigue testing.

\subsection{Presentations at technical conferences}

Over the course of the project, presentations covering non-proprietary information were made at different technical conferences. The list below shows the conferences and the titles of the presentations:

- "Microstructure Evolution In AA 6061 Subject To Severe Plastic Deformation," ASMTMS Materials Week, October 7-10, 2002, Columbus, Ohio (Y. Bhambri, S. Indrakanti, B. Cherukuri, R. Srinivasan)

- "Deformation Behavior of AA 6061 Subject to Severe Plastic Deformation," ASM-TMS Materials Week, October 7-10, 2002, Columbus, Ohio (S. Indrakanti, Y. Bhambri, B. Cherukuri, R. Srinivasan)

- "Material and Energy Savings in Forging with Stock Produced by Severe Plastic Deformation (SPD)," 24th Forging Industry Technical Conference, October 14-16, 2002 in Cleveland, Ohio (P. Chaudhury, R. Srinivasan)

- "Forging Studies with Severe Plastic Deformation Processed Aluminum Alloy 6061," presented at Thermec-2003, Madrid, Spain July 6-11, 2003 (R. Srinivasan, P. Chaudhury)

- "Microstructural Evolution of AA-6061 subjected to Severe Plastic Deformation," TMS Annual Meeting, March 14-18, 2004 Charlotte, NC (Y. Bhambri, S. Indrakanti, B. Cherukuri, P. Chaudhury, Q. Han, R. Srinivasan)

- "Forging Studies with SPD Processed Aluminum 6061," Indian Institute of Metals Chennai Chapter, Indian Institute of Technology Madras, June 2004 (R. Srinivasan)

- "Heat Treatment of Aluminum Alloy 6061 Processed by Severe Plastic Deformation," ASM Materials Week, Oct. 17-20, 2004, Columbus OH (P. Chaudhury, B. Cherukuri, R. Srinivasan)

- "Forging Studies With Severe Plastic Deformation (SPD) Processed AA 6061," ASM Materials Week, Oct. 17-20, 2004, Columbus OH (P. Chaudhury, B. Cherukuri, R. Srinivasan)

- "Scaling up of equal channel angular pressing (ECAP) and its effect on mechanical properties, microstructure, and hot workability of AA 6061," TMS Annual Meeting, San Francisco CA, February 2005 (P. Chaudhury, R. Srinivasan)

- "A comparison of the properties of SPD processed AA-6061 by equal channel angular pressing (ECAP), multi-axial compressions/forgings $(\mathrm{MAC} / \mathrm{F})$ and accumulative roll bonding (ARB)," San Francisco CA, February 2005 (Poster) (B. Cherukuri, T. Nedkova, R. Srinivasan)

- "Scaling up of Equal Channel Angular Pressing (ECAP) for the Production of Forging Stock," NanoSPD3 - Third International Conference on Nanomaterials by Severe Plastic Deformation, Fukuoka, Japan, September 2005 (Invited) (R. Srinivasan, P. Chaudhury, B. Cherukuri)

- "Acceleration of Precipitation Process in AA6061 after Severe Plastic Deformation (SPD)," Materials Science \& Technology (MS\&T) 2005 conference at Pittsburgh PA, September 2005 (P. Chaudhury, B. Cherukuri, R. Srinivasan) 
- "Deformation Processing Research at Wright State University," Indian Institute of Metals, Kalpakkam Chapter, Indira Gandhi Center for Atomic Research (IGCAR), Kalpakkam, July 2005, (R. Srinivasan)

- "Scaling up of Equal Channel Angular Pressing (ECAP) for the Production of Forging Stock," NanoSPD3 - Third International Conference on Nanomaterials by Severe Plastic Deformation, Fukuoka, Japan, September 2005, (R. Srinivasan)

- "Severe Plastic Deformation (SPD) Processing of Aluminum," DOE/Ohio Technology Showcase Focusing on Energy Efficient Manufacturing Technologies and Energy Management Best Practices, Cleveland, OH, September 2005, (P. Chaudhury, B. Cherukuri, R. Srinivasan)

\subsection{Publications in peer reviewed journals}

In addition to presentation at conferences, significant accomplishments of the program were also published as peer reviewed journals articles, as indicated in the following list:

- B. Cherukuri and R. Srinivasan, "Properties of AA6061 Processed By Multi-Axial Compressions/Forging (MAC/F)," accepted by Materials and Manufacturing Processes, April 2005

- R. Srinivasan, B. Cherukuri, and P.K. Chaudhury, "Scaling up of Equal Channel Angular Pressing (ECAP) for the Production of Forging Stock," Materials Science Forum, Vol. 503-504, pp 371-378, 2006

- P. K. Chaudhury, B. Cherukuri, and R. Srinivasan, "Scaling up of equal channel angular pressing (ECAP) and its effect on mechanical properties, microstructure, and hot workability of AA 6061," Materials Science and Engineering A, Vol 410-411, pp 316-318, 2005

- B. Cherukuri, T. Nedkova and R. Srinivasan, "A comparison of the properties of SPD processed AA-6061 by equal channel angular pressing (ECAP), multi-axial compressions/forgings (MAC/F) and accumulative roll bonding (ARB)," Materials Science and Engineering A, Vol 410-411, pp 394-397, 2005

- R. Srinivasan and P. Chaudhury "Forging Studies with Severe Plastic Deformation Processed Aluminum Alloy 6061," Materials Science Forum, Vol. 426-432, pp. 267-272, 2003

- R. Srinivasan, "Computer Simulation of the Equal Channel Angular Extrusion (ECAE) Process," Scripta Materialia, Vol. 44, pp. 91-96, 2001.

\subsection{Education and Training of Students}

One of the primary paths to transfer of technology out of a university is the education of students. Several graduate and undergraduate students conducted research associated with this project. The topics which were related to various aspects of severe plastic deformation, were published as master's theses and senior design reports, as listed below: 
- S. Indrakanti, "Flow Behavior of AA 6061 processed by Equal Channel Angular Pressing (ECAP), MS thesis December 2003

- Y. Bhambri, "Microstructural Evolution of AA6061 Subjected to Severe Plastic Deformation," MS thesis, December 2003

- B. Cherukuri, "Multi Axial Compression/Forging (MAC/F) of AA 6061," MS thesis, August 2004

- T. Nedkova, "Processing of AA 6061 by Accumulative Roll Bonding (ARB)," MS Thesis (expected August 2006)

- J. McCloskey, C. Logan, K. McCormick, and R. Smith, "Development of Equal channel Angular Drawing Equipment," Senior design report March 2002

- N. Xavier and P. Brown, "Refining of the Equal Channel Angular Extrusion Die," Senior design report, March 2003

These students have since graduated and are either pursuing advanced degrees or are employed in industry. Employers include Capstone Engineering, Houston TX, Kaiser Aluminum, Seattle WA and Aerotec USA, Bessemer AL.

\subsection{Intellectual Property Protection}

The concept of continuous severe plastic deformation was conceived an initial description was written between March and May 2000. These events took place prior to the submission of a proposal to DOE. The initial patent disclosure was recorded at Wright State University on 6/16/2000. The patent application was then filed on June 26, 2002. The patent was allowed and published as "Continuous Severe Plastic Deformation (CSPD) Process," by P. Chaudhury, R. Srinivasan, and S. Viswanathan, United States Patent Number 6,895,795, May 24, 2005. A copy of the patent is being submitted to DOE along with this report. 


\section{References}

[1] R. Z. Valiev, et al., "Producing Bulk Ultrafine-Grained Materials by Severe Plastic Deformation" JOM, pp 33-39, (2006)

[2] M. Morehead, Y. Huang, American Society of Mechanical Engineers,-Manufacturing Engineering Division, v 16-2, p 1167-1176, (2005)

[3] V. M. Segal, USSR Patent No. 575892, (1977)

[4] H. S. Kim, Journal of Materials Processing Technology, 113, p 617-621, (2001)

[5] Y. Beygelzimer, V. Varyukhin, D. Orlov, B. Efros, V. Stolyarov, H. Salimgareyev, Ultrafine Grained Materials II; Edited by Y.T. Zhu, T.G. Langdon, R.S. Mishra, S.L. Semiatin,

M.J. Saran, and T.C. Lowe. TMS, Warrendale PA, p43, (2002.)

[6] W.M. Thomas, N.D. Edward, J.C. Needham, M.G. Murch, P. Temple-Smith, Dawes, and J. Christopher, "Friction Stir Welding," GB Patent Application 9125978.8, Dec. 1991, US Patent 5460317, Oct. 1995

[7] A. K. Ghosh, U.S.Patent- 4,721,537, January 26, (1988)

[8] N. Tsuji, Y. Saito, H. Utsunomiya, S. Tanigawa, Scripta Materialia, v 40-7, p 795-800, (1999)

[9] J. Y. Huang, Y. T. Zhu, H. Jiang, T. C. Lowe; Acta Materialia, 49, p 1497-1505, (2001)

[10] Investigations and Applications of Severe Plastic Deformation, edited by T. C. Lowe and R. Z. Valiev, Kluwer Academia Pub., Dordrecht, (2000)

[11] Nanomaterials by Severe Plastic Deformation, edited by M. J. Zehetbauer and R. Z. Valiev, Wiley-VCH, Weinheim, Germany, (2004)

[12] The Langdon Symposium: Flow and Forming of Crystalline Materials, edited by Y. T. Zhu, P. B. Berbon, A. H. Chokshi, Z. Horita, S.V. Raj, and K. Xia. Elsevier, (2005)

[13] www.nanospd.org

[14] "Ultrafine Grained Materials," Proceedings of a symposium at the 2000 TMS Annual Meeting, Nashville TN, Ed. R.S. Mishra et al., TMS, Warrendale, Pennsylvania, 2000

[15] "Ultrafine Grained Materials-II," Proceedings of a symposium at the 2002 TMS Annual Meeting, Seattle WA, Ed. Y.T. Zhu et al., TMS, Warrendale, Pennsylvania, 2002

[16] "Ultrafine Grained Materials-III," Proceedings of a symposium at the 2004 TMS Annual Meeting, Charlotte NC, Ed. Y.T. Zhu et al., TMS, Warrendale, Pennsylvania, 2004

[17] Ultrafine Grained Materials IV, edited by Y. T. Zhu, T. G. Langdon, Z. Horita, M. J. Zehetbauer, S. L. Semiatin, and T.C. Lowe. The Minerals, Metals and Materials Society, Warrendale, PA, (2006)

[18] http://www.nanospd.org/

[19] E. O. Hall, Proc. Phys. Soc. London, Vol. 643, p 747, (1951)

[20] N. J. Petch, J. Iron Steel Inst. London, Vol. 183, p 25, (1953 )

[21] S. Komura, Z. Horita, M. Furukawa, M. Nemoto, T.G. Langdon, Metall. Mater. Trans. A 32, 707-16 (2001)

[22] V. M. Segal, V. I. Reznikov, A. E. Drobyshevskiy, and V. I. Kopylov, Russ. Metall, 1, p99 (1981)

[23] Y. Iwahashi, J. Wang, Z. Horita, M. Nemoto and T. G. Langdon, Scripta Materialia, 35, p143 (1996)

[24] Y. Wu and I. Baker, Scripta Materialia, 37, p437 (1997)

[25] K. Nakashima, Z. Horita, M. Nemoto, T. G. Langdon; Materials Science and Engineering A 281, pp 82-87, (2000) 
[26] R. E. Barber, T. Dudo, P. B. Yasskin, and K. T. Hartwig, "Processing yield for ECAE processing," Scripta Mat., vol. 51, pp. 373-377, (2004)

[27] A. A. Salem, Z. Horita, T. G. Langdon, T. R. McNelley, S. R. Kalidindi, and S. L. Semiatin, "Strain-Path Effects on the Evolution of Microstructure and Texture during the Severe-Plastic Deformation of Aluminum", Met. Mat. Trans. A, (in press), (2006)

[28] M. Furukawa, Z. Horita, M. Nemoto, and T. G. Langdon, Ultrafine Grained Materials, edited by R. S. Mishra et. al, The Minerals, Metals \& Materials Society, Warrendale Pennsylvania, p125 (2000)

[29] R. Srinivasan, "Computer Simulation of the Equal Channel Angular Extrusion (ECAE) Process," Scripta Materialia, Vol. 44, pp. 91-96, (2001)

[30] T. G. Langdon, et al., Journal of Metals, pp. 30-33, (2000)

[31] R. Z. Valiev et al., Progress in Materials Science, 45, pp. 103-189, (2000)

[32] V. Segal, et al. US Patent No. 5,400,633, (1995)

[33] S. L. Semiatin, D. P. DeLo US Patent No. 5,904,062 (1999)

[34] U. Chakkingal, A. B. Suriadi, and P. F. Thomson, Scripta Materialia, 39, pp 677-684, (1998)

[35] Metal Forming: Mechanics and Metallurgy, W. F. Hosford and R. M. Caddell, $2^{\text {nd }}$ Edition, PTR Prentice Hall, (1993)

[36] Mechanical Metallurgy, by G.E. Dieter, $3^{\text {rd }}$ Edition, McGraw-Hill, (1986)

[37] H. S. Kim, Journal of Materials Processing Technology, 113, pp 617-621, (2001)

[38] B. Cherukuri, "Multi Axial Compression/Forging of AA6061," MS Thesis, Wright State University, Dayton OH, (2004)

[39] Y. Saito, H. Utsunomiya, H. Suzuki, T. Sakai, Scripta Materialia, 42, pp 1139-1144, (2000)

[40] V. Segal, "Materials Processing by Simple Shear," Materials Science and Engineering, Vol. A197, p 157-164, 1995

[41] W. Chen, D. Ferguson, and H. Ferguson, "Multi-axis Deformation Methods to Achieve Extremely Large Strain and Ultrafine Grains," in Ultrafine Grained Materials, Ed. by R.S. Mishra et al., TMS, Warrendale, Pennsylvania, pp 235-245, 2000

[42] J.S. Hayes, R. Keyte, and P.B. Prangnell, "Effect of Grain Size on the behavior of a Submicron Grained Al-3-wt\%Mg Alloy Produced by Severe Deformation," Materials Science and Technology, pp. 1259-1263, 2000

[43] P.L. Sun, P.W. Kao, and C.P. Chang, "Characteristics of submicron grained structure formed in aluminum by equal channel angular extrusion," Materials Science and Engineering, Vol. A283, pp 82-85, 2000

[44] P. Apps and P.B. Prangnell, "Grain refinement Mechanisms operating during severe plastic deformation of aluminium alloys containing second phase particles," Ultrafine Grained Materials-III, Ed. Y.T. Zhu et al., TMS, Warrendale, Pennsylvania, pp 131-136, 2004

[45] N.A. Akhamadeev, N.P. Kobelev, R.R. Mulyukov, Ya.M. Soifer, R.Z. Valiev, Acta Metall. Mater, Vol. 41, pp 1041, 1993

[46] J.W. Edington, K.N. Melton, and C.P. Cutler, Progress in Materials Science, Vol 21, pp 63170,1976

[47] Z. Horita, T. Fujinami, M. Nemoto and T.G Langdon, "Equal channel angular pressing of commercial aluminum alloys: grain refinement, thermal stability and tensile properties," Metall. Mater. Trans A. Vol 31A, pp 691-701, 2000 
[48] S. Lee, P.B Berbon, Z. Horita, T. Fujinami, M. Nemoto, N.K. Tsenev, R.Z. Valiev and T.G Langdon, "Developing superplastic properties in an aluminum alloy through severe plastic deformation," Mater. Sci. Eng, Vol A272, pp 63-72, 1999

[49] D.P. DeLo and S.L. Semiatin, "Hot Working of Ti-6Al-4V via Equal Channel Angular Extrusion," Metall. Matls. Trans. A, Vol. 30A, pp 2473-2481, 1999

[50] Z. Horita, T. Fujinami, and T.G. Langdon, "The potential for scaling ECAP: effect of sample size on grain refinement and mechanical properties," Mater. Sci. Eng. Vol A318, 34-41, 2001

[51] B. Cherukuri, T. Nedkova and R. Srinivasan, Materials Science and Engineering A, Vol 410-411, pp 394-397, 2005

[52] B. Cherukuri and R. Srinivasan, "Properties of AA6061 Processed By Multi-Axial Compressions/Forging (MAC/F)," accepted by Materials and Manufacturing Processes, 2005 [53]R. C. Rice, J. L. Jackson, J. Bakuckas, and S. Thompson; Metallic Materials Properties Development and Standardization (MMPDS), Office of Aviation Research, Washington DC, p.3-289, 2003 